\title{
DR. 2290
}

SAND78-2306

Unlinited Rolease UC-21

\section{HASTER}

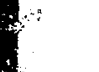

Laser Development for Laser Fusion Applications Research Progress Report April 1978 - September 1978

Directorato of Physical Research 4200

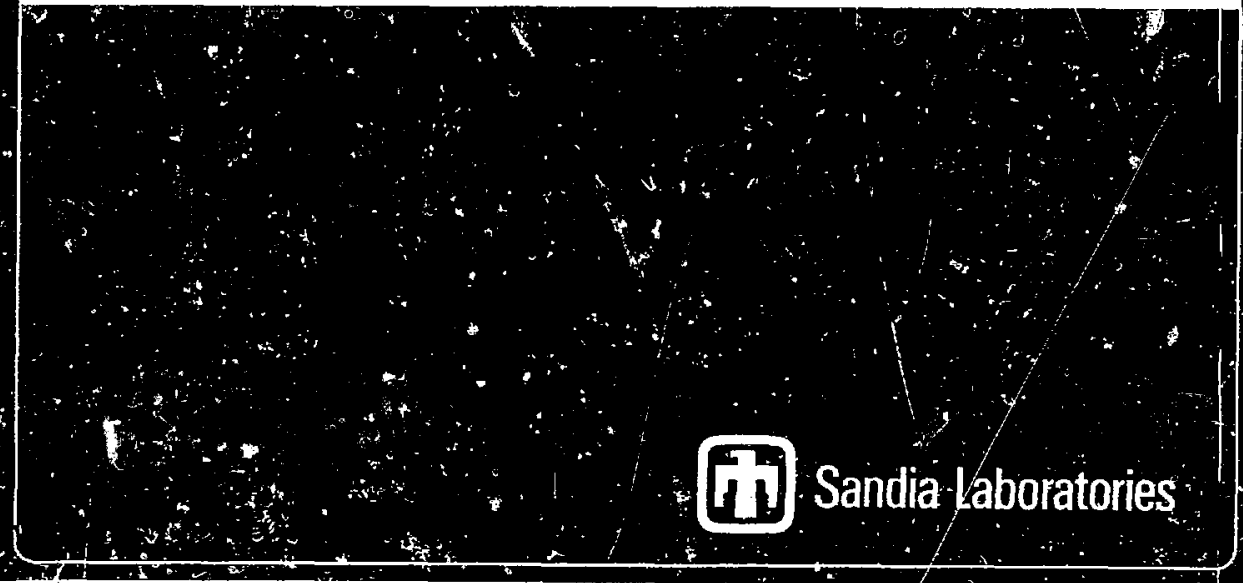




\section{SANDT8-2306 \\ Unlimited Release \\ Printed December 1978}

Distribution

Category UC-21

\section{LASER DEVELOPMENT FOR LASER FUSION APPLICATIONS \\ RESEARCH FROGRESS REPORT \\ April 1978 - September 1978}

Directorate of Physical Research 4200

Sandia Laboratories

Albuquerque, New Mexico 87185

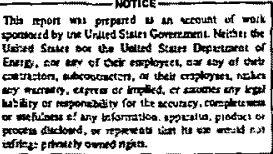

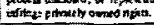




\section{CONTENTS}

$\underline{\text { Page }}$

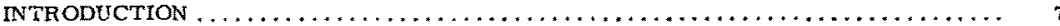

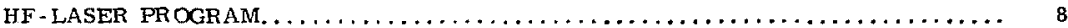

Overview $\ldots \ldots \ldots \ldots \ldots \ldots \ldots \ldots \ldots \ldots \ldots \ldots \ldots \ldots \ldots \ldots \ldots \ldots \ldots \ldots \ldots, 8$

Oscillator-Amplifier Studies Using the $\lambda$-Geometry Electron-Beam -

Initiated HF Amplifier

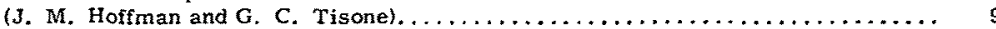

Bearn Quality Studies Using the Discharge Oscillator-Preamplifier

and the $\lambda$-Amplifier

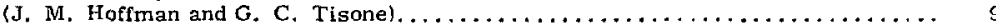

Short Pulse Amplification

(J. M. Hoffman and G. C. Tisone.$\ldots \ldots \ldots \ldots \ldots \ldots \ldots \ldots \ldots \ldots \ldots \ldots \ldots \ldots$

Energy and Pulse Width Characteristics of Phoenix I

(E. L. Patterson). . . . . . . . . . . . . . . . . . . . . . . . . . . . . .

Saturated Phoenix-[ Amplifier Experiment

(J. MI. Hoffman, E. L. Patterson, and G. C. Tisone) . . . . . . . . . . . . .

Plans for Two-Beam Angular Multiplexing Demonstration in a

Large-Volume HF $\wedge$ mplifier

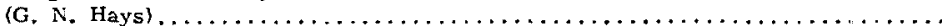

Diagnostic Experiments for Detailed Code Comparison

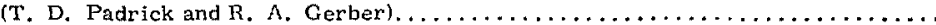

Numerical Modeling of HF Laser Performance

(J. B. Moreno)

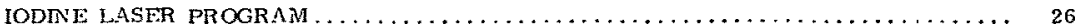

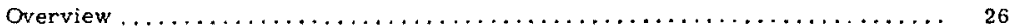

Control of Self-Focusing in the $\Lambda$ tomic Iodine Laser

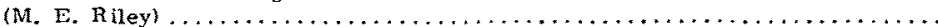

Chemical Regeneration

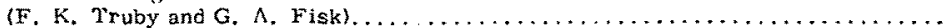

Metal-Doped Microsecond Xenon Flashlamps

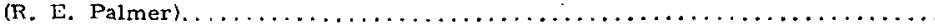




\section{CONTENTS (cont)}

KINETIC PROCESSES IN PHOTOLYTICALLY PRODUCED GROUP VI ${ }^{1} \mathrm{~S}$

Overview

Laser Photolysis of OCS at $\left.157 \mathrm{~nm} ; \mathrm{S}^{1} \mathrm{~S}\right)$ Production,

Photoionization, and Loss Kinetics

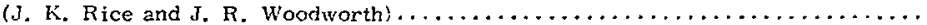

$\mathrm{Xe}_{2}$ "Driver for $\left.\mathrm{Se}^{1}{ }^{1} \mathrm{~S}\right)$ Kinetics Studies

(J. R. Woodworth).

Photoionization of the Group VI $(n s)^{2}(n p)^{4}{ }^{1} \mathrm{~S}_{O}$ Term via

Excitation of Autoionizing Levels

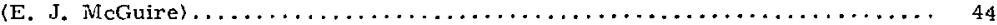

NEW-LASER RESEARCH AND DEVELOPMENT $\ldots \ldots \ldots \ldots \ldots \ldots \ldots \ldots \ldots \ldots \ldots \ldots .59$

Overview $\ldots \ldots \ldots \ldots \ldots \ldots \ldots \ldots \ldots \ldots \ldots \ldots \ldots \ldots \ldots \ldots \ldots \ldots \ldots \ldots$

Chemically Pumped Iodine Laser

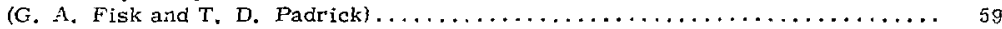

HgXe Exciplex Studies

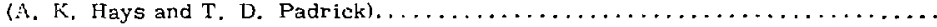

Oscillator Studies

(C. K. Miller and E. D, Jones) $\ldots \ldots \ldots \ldots \ldots \ldots \ldots \ldots \ldots \ldots \ldots \ldots \ldots \ldots \ldots$

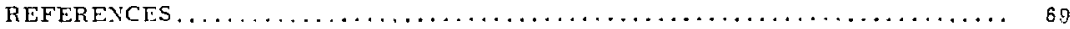

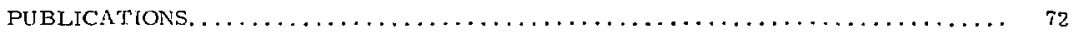

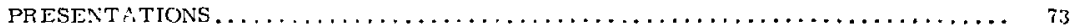




\section{LASER DEVELOPMENT FOR IASER FUSION APPLICATIONS RESEARCH PROGRESS REPORT April 1978 - September 1978}

\section{INTRODUCTION}

Advances in knowledge about inertialconfinement fusion (ICF) have been paced by the development of high-power drivers. The laser-driven option to ICF will continue to be paced by the development of advanced high-power lasers. The long-term goal of ICF, commercial power generation, will require an efficient and reliable highaverage-power driver. The near-term goal of our research is to provide an alternative to. $\mathrm{CO}_{2}$ and $\mathrm{Nd}$ :glass for large-system scientific demonstration studies; the long-term goal is to develop the laser technology that is necessary for commercialization of laserfusion energy.

Our program addresses three high-power laser syst:ms: iodine, hydrogen fluoride, and Group VI atoms. Both the iodine laser and the FIF liser have a demonstrated highpower capability, and experimental results indicate that there are probably no serious problems hindering development of either of these laser: for laser-fusion applications. In both of these technology-development programs, we are making steady technical progress.

The IIF kaser has a proven high electrical efficicticy, a projected overall efficiency of better than $4 T_{n}$, and staging of multimegajoule systems is felt to be possible. If laser-inergy-to-thermonuclear-energy gains of a few hundled can be realized, it is an attractire ICF driver. From a capital cost point of view, it is very attractive in comparison with other candidate lasers.

We now know int an iodine laser system can be built that would satisfy all near-term requirements of laser fusion including the driver of an experimental power reactor, but its efficiency needs to be improved before it can be considered as a driver for a commercial ICF power generator. With available technology the best electrical efficiency that can be realized for a $\sim 1-\mathrm{MJ}$. 10 -pps iodine laser is 0.4 to $0.5 \%$, and the overall efficiency including regeneration of laser medium starting chemicals is 0.35 to $0.4 \%$. This projected efficiency requires very high laser-energy-to-therm onuclearenergy gains for economically attractive electric power generation and its low electrical efficiency would require a prohibitively high capital investment in the pulse power source. We are investigating both surface discharges and $\mathrm{HgXe}$ exciplexes as ways to improve the efficiency (up to $2 \%$ ) of the iodine laser.

The class of lasers based on the excitation of the $\mathrm{p}^{4}{ }^{1} \mathrm{~S}$ state of Group VIA atoms le.g., $O, S$, Se, Te) with energy extraction on the $\mathrm{p}^{4} \mathrm{i}_{\mathrm{S}} \rightarrow \mathrm{p}^{4}$ 政 or $\mathrm{p}^{4} \mathrm{i}_{\mathrm{S} \rightarrow \mathrm{p}^{4}} 3 \mathrm{P}$ transition offers long energy-storage times since the Is state exhibits a long radiative lifetime and is resistant to deactivation by a wide variety of other species. NIso, these transitions occur at what ale thought to be excellent wavelengths (459 $\mathrm{nm}$ to $790 \mathrm{~nm}$ ) for laser fusion and exhibit stimulated emission cross sections that are low enough to inhibit parasitic amplified spontaneous emission but not so low that the medium cannot be saturated at reasonable energy fliences. The emphasis of our work on this clitis of lasers is to perform laboratory kinetic studies that will permit the development of a model that can be used to project large-system laser performance. According to what we know now, an overall 
efficiency of up to $3 \%$ may be possible.

The key highlights achieved curing this report period include:

1. Near-diffraction-limited beam quality was demonstrated for a switched-out 6-ns portion of a $H F$-laser amplified beam.

2. HF laser characteristics for highpressure operation were established.

3. Details of individual-line suppression of ASE in an HF amplifier were worked out.

4. Design of the Phoenix II HF amplifier cell was frozen and the experimental details were worked up for the first large-scale study of angular multiplexing: a pulsewidth compression scheme.

5. Establishing that iodine lasers can be stabilized against self focusing.

6. Demonstration of an efficient method to chemicali: regenerate iodine-laser-medium starling materials and showing that chemical regeneration will not be an important consideration in the overall efficiency of a large iodine laser system.

7. Thcoretical determination of the photoionization cross section for sulfur $(3 p)^{4}{ }^{1} S_{O}$ and seleniur. $(4 p)^{4} I S_{O}$.

8. Measurement of the yield of $S\left({ }^{1} S_{O}\right)$ by photolysis of OCS by $157-\mathrm{nm}$ laser light at intensities up to $0.1 \mathrm{~J} / \mathrm{cm}^{2}$.

9. Derionstration that photoionization of $S\left({ }^{I} S\right)$ and clectron runavay processes will not compromise the performance of the $S\left({ }^{1} S\right)$ laser if suitable precaution is exercised.

10. Modeling studies of the chemically numped iodine laser suggest that it may be an attractive candidate driver for commercial application of TCF.

i1. Measurements of fluorescence efficiencies for $\mathrm{HgXe}$ exciplexes excited by an elretric discharge.

\section{HF-LASER PROGRAM}

\section{OVERVIEW}

The HF laser is an attractive candidate driver for a large-system ICF scientific demonstration facility, for an ICF experimental power reactor and for a commercial laser-fusion power reactor. Its proven high electrical efficiency offers a relatively low capital cost and high reliability, and staging of multimegajoule systems is felt to be possible. Also, its overall efficiency is high enough and its projected capital cost is low enough to make it look attractive from a cost-of-electricity point of view if laserenergy-to-thermonuclear-energy gains of a few 100 can be realized. The near-term goal of the HF-laser program is to develop a technology and engineering data base so that a meaningful tradeof analysis for the various candidate ICF advanced drivers can be made on a time scale consistent with $D O F$ planning.

Previous accomplishments of our program have included demonstrations of high efficiency and high energy capability, efficient energy extraction from HF amplifiers, good beam quality and focusability, and shortpulse generation and amplification. In this reporting period, beam quality has been determined to be near'-diffraction limited for a short pulsewidth ( $6 \mathrm{~ns}$ to $25 \mathrm{~ns}$ ) oscillator-amplifier chain, su'pression of amplified spontaneous emission has been demonstrated on an individual spectral line, high-pressure characteristics have been determined for the Phoenix I amplifier, and detailed comparisons between the kinetic code and experiments have been made.

Details of two major upcoining experiments are also included in this report. The first is energy extraction and beam quality measurements on the Phoenix I amplifier operating under saturated output power conditions. The second experiment, using a newly designed amplifier (Jhoenix II), is designed to demonstrate the concept of angular-multiplexing: it pulse wicthcompression scheme. 
OSCILLA TOR - AMPLIFIER STUDIES USING THE A-GEOM ETRY ELECTRON-BEAMINITLATED HF AMPLIFIER

In the last report, the radially dependent eiectron-beam-energy deposition profile of the $\lambda$-geometry amplifier vas prosented and compared with the lascr output ridiul energy density distribution when the system was operated as an oscillator. We have also made comparisons of the radial energy variation of laser-amplifier output with its level of excitation counterpart. The input intensity to the amplifier was essentially uniform over its aperture, The energy density in the input bearn was about $32 \mathrm{m.} / \mathrm{cm}^{2}$ in a pulse width (FWMM) of about $100 \mathrm{~ns}$. The radial distribution of the amplifier output energy density is shown in Fig. 1 for two different total pressures. These results confirm that the electron-beam deposition in the $\lambda$ geometry amplifier ( $\lambda$-amplifier $\rangle$ is highly nonuniform in the radial direction. The differenve between the 620 -torr data and the 775-torr data seems to indicate that the electron-beam was slightly off axis, toward the outside of the laser tube, as the beam propagated around the corner. This may mean that the magnetic field used to guide the electron-beam into the amplifier tube should be adjusted for eact. operating pressure to assure a more nearly symmetrical deposition profile.

Since the electron-beam-energy deposition is radially nonunifor $m$, the rate of ainmic fluorine production and, hence, the production rate of excited FIF molecules will be radial nonuniform. This should result in the temporal behavio* of the amplified pulse also having a radial variation. The radial variation of the pulse with (FWHW) is shown in the upper curve of Fig. 1. These results show a radial variation of pulse width (FWHM) of about $50 \%$ with the $\lambda$-geometry amplifier.
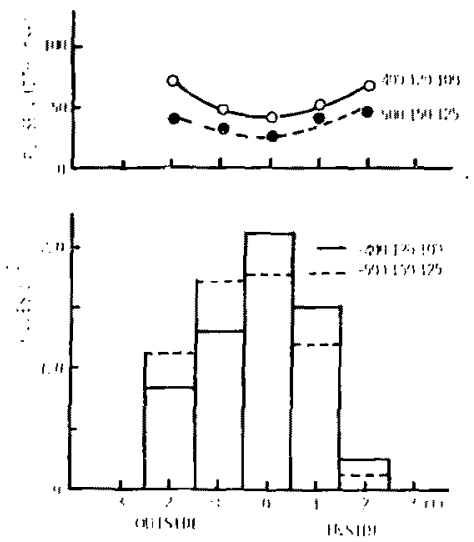

Fig, 1. Pulse width and radial output energy profile from an axinl ampli fier for two different pressures. These results were obtained for an input intensity of $10^{5} \mathrm{~W} / \mathrm{cm}^{2}$. These results confirm the nonuniform electron-beam energy depcsition.

B:AN QUALTY STUDIES USLG THE DISCEIARGE OSCILLATOR-PRFAMPLIFIER AND TIIE $\lambda$-AMPLIFIER

The electron-beam-initiated $\lambda$-geometry amplifier which is initiated by a PI Model1 ton electron-beam machine will be used in fulure experiments as a preamplifier. This system will be used to saturate the Phoenix I amplificr and for angular multiplexing experiments with the Phoenix II amplifier. The experiments described here were to determine the optical quality of amplified bearns and to further determine if a short pulse ( $5 \mathrm{~ns}$ to $25 \mathrm{~ns}$ ) could be amplified 
without degrading the beam quality. Previous experiments with a transverseinitiated cell (Phoenix I) indicated that a high-optical-quality beam could be amplified without degrading the beam. However, the $\lambda$-amplifier is excited nontniformly in the radial dimension. Extraction experiments using thisi amplifier and the $\mathrm{SF}_{6}$-HI fueled oscillator -amplifier system have shown that about $50 \%$ of the energy can be extracted from the cmplifier. 2

The first measurements of the beam quality were made by using a 25-ns pulse that was generated by the polarization rotation method destribed previously. The beam quality of the input bean was measured by using lateral shearing interferometry, where reflections from the front and rear surfaces interfere to form a fringe pattern. Information about the radius of curvature of the beam and the plase front distortion is contained in such patterns. ${ }^{3}$ Fringe patterns for the input beam were measured by using the pyroelectric vidicon system that has been described in a previous report. The beam quality measured was in agreement with beam quality measurements previously reported. The cutput beam was recorded as a burn pattern on unexposed developed Polaroid film. The resulting measurement is shown in Fig. 2 where it appears that the wavefront distortion is less than $\lambda / 2$ over the diameter of the beam. The tilt of the fringes indicates the curvature of the wavefront at the point of measurement. The curvature can be adjusted by using the beam expanders in the system. However, the tilt in the fringes indicate that the curvature of the wavefront or the divergence of the beam was approximately $400 \mu \mathrm{rod}$. Comparison of the input and output beams indicates that the beam through the axially initiated amplifier was not degraded to a measurable degree.

A more quantitative measurement of the beam quality is the measurement of the energy that can be focused through a pinhole. These measurements have been made for the Phoenix I and have been previously clescribed. Measurements of output optical quality from the $\lambda$-geometry amplifier were made by using a 5-m-fr.cal-length mirror. The beam intensity was reduced by using front surface reflections from quartz wedges in order to eliminate the possibility of air breakdown at the pininole. The pulse length for these experiments was $25 \mathrm{~ns}$. The results are shown in Fig. 3 where the pinhole size has been converted to an equivalent angle. Data were taken down to $40 \%$ transmission which corresponded to a $0,8-\mathrm{mm}$ pinhole.

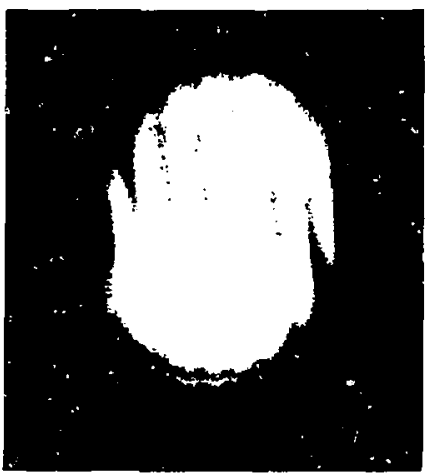

Fig. 2. Lateral shearing interferograms from an axial initiated amplifier. This interferogram shows very little phase-front degradation of the beam from the amplifier.

The beam quality was further examined with a short focal lergth mirror $(45.7 \mathrm{~cm})$ in a vacuum. The vacuum was necessary in this case to prevent air breakdown. The apparatus used here was the same as that described previously. 4 The pulse length was reduced to $\sim 6 \mathrm{~ns}$ in width for this set of experiments. The minimum pinhole for this experiment was 200 microns where the measured maximum transmission was $92 \%$.

The data from this experiment are shown in Fig. 3.

From a comparison of this data at the $84 \%$ transmission point, it appears that the beam is approximately two to three times diffraction-limited, which implies the input beam is not seriously degraded by the axially initiated amplifier. 


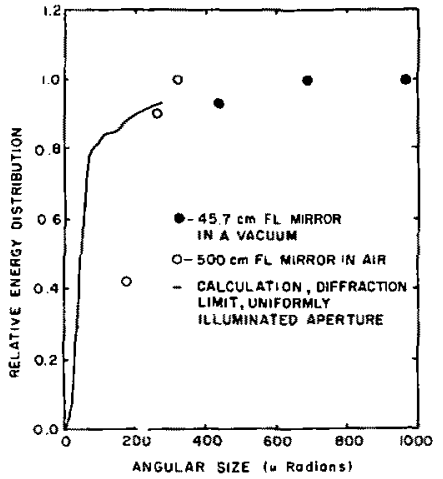

Fig. 3. Focal spot energy distribution obtained from the axially initiated amplifier. A long focal length focusing mirror was used to focus in air and a short focal length $\mathrm{mir}^{-}$ror ins used to focus in a vacuum.

\section{SHORT PULSE AMPLIFICATION}

In order to ariplify a short pulse $\{\sim 5 \mathrm{~ns}\}$ with the $\lambda$-geometry amplifier, a polarizationrotation technique is used. This technique is selected because HF is a nonstorage laser system and requires a signal in the amplifier during the total time of positive gain to suppress amplified spontaneous emission.
The technique of polarization rotation is illustrated in the schematic diagram shown in Fig. 4. The output from the oscillator is passed through a polartzer to produce $p$ polarization and then through an electrooptical crystal. This crysta' which is $\mathrm{CdTe}$ in the present system, can then be used to rotate the polarization and produce a short pulse with s-polarization. This signal is then amplified and the output is incident onto a small-angle-wedge beam splitter oriented at the Brewster angle. The long puise with p-polarization is transmitted through the Brewster angle plate, but during the short period of time when the polarization is rotated to s-polarization, some fraction of this signal is reflected from the two surfaces of the Brewster angle plate. Only the reflection from the front surfaces of the wedged plate is used.

The reflection efficiency for the s-polarized light will depend upon the index of refraction of the material. Sorne oi the materials which have or are being considered for use are listed below.

\begin{tabular}{lcccc} 
Material & $\begin{array}{c}\text { Refractive } \\
\text { Index } \\
(\lambda \sim 3 \mu)\end{array}$ & $\begin{array}{c}\text { Brewster } \\
\text { (deg) }\end{array}$ & $\begin{array}{c}\text { Reflectance } \\
(\%)\end{array}$ \\
\cline { 1 - 1 } Quartz & 1.419 & 54.8 & 11.3 \\
ZnSe & 2.44 & 67.7 & 50.7 \\
$\mathrm{Si}$ & $\sim 3.0$ & 71.6 & 64 \\
$\mathrm{Ge}$ & 4.057 & 76.2 & 78.4
\end{tabular}

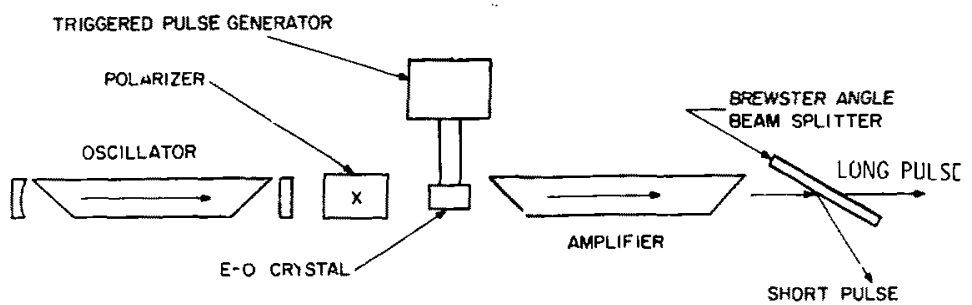

Fig. 4. Schematic diagram showing technique for generation and amplification of short pulses using polarization rotation. 
With the polarization-rotation technique described in the preceding section, we have amplified a nominal 6-ns pulse. The Brewster angle beam splitter was quartz.

The results of amplifying a short pulse utilizing the polarization technique are shown in Fig. 5. The upper curve shows the temporal behavior of the s-polarization input pulse. The p-polarization component of the input pulse is not shown, but it has a pulse width (FWHM) of about 100 ns. The long pulse started at about $40 \mathrm{~ns}$. The amplified pulse (s-polarization) is shown in the lower curve. There is essentially no distortion of the puise with both the input and output having a pulse width of $6 \mathrm{~ns}$. The contrast ratio, that is the ratio of the signal prior to the amplified pulse to the peak pulse signal, is estimated to be greater than 20. Additional measuremenı $:$ ill be necessary to deter mine the best contrast ratio that can be obtained with this technique.

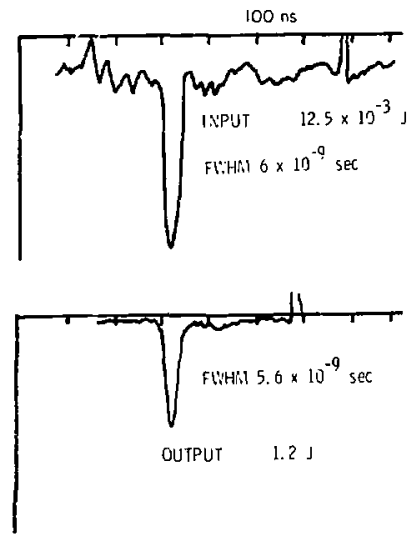

Fig. 5. Input and amplified pulse using an axially initiated $\mathrm{H}_{2}-\mathrm{F}_{2}-\mathrm{O}_{2}$ amplifier. The energy gain of this system was about 96. The full width at half $\max$ (FWHM) of the input pulse was $6 \mathrm{~ns}$ and the FWHM of the output pulse was $5.6 \mathrm{~ns}$.
Suppression of Amplified Spontaneous Emission

Measurements of amplified spontaneous emission (ASE) which were obtained during the energy extraction experiments on the Phoenix I amplifier 5 indicated that the ASE was reduced only a factor of three for an input intensity of $10^{4} \mathrm{~W} / \mathrm{cm}^{2}$. Increasing the input power above this level did not further reduce the $\Lambda S E$. These results are not in agreement with the HFOX code which predicts a much larger suppression.

Measurements of the ASE radiated by the $\lambda$ geometry amplifier have also been made. These measurements have been made under two conditions: 15-degree windows and Brevister angle windows on the amplifier. The salorimeters used in the ASE measurements were arranged so that they could detect the energy within a solid angle of 1.5 $\times 10^{-2}$ sterdians. This was about twice the geometric solid angle subtended by the amplifier.

With an input intensity of about $1 \times 10^{5} \mathrm{~W} /$ $\mathrm{cm}^{2}$ from an oscillator-preamplifier system the ASE reduction was a factor of 1.5 with 15-degree windows and 1.9 with Brewster angle windows. The magnitude of the energy radiated by ASE with Brewster angle windows was a factor of two less than it was with 15-degree windows. These results would seem to indicate that there is some feedback from the 15-degree windows resulting in increased ASE, but if this is the case, then we would have expected a greater reduction in ASE with the Brewster angle windows.

Since the HF laser operates on about 50 $v$ ibration-rotation transitions, it was felt that a better understanding of $\mathrm{AS}^{\top}$, suppression could be obtained by niaking measurements on a single transition. A schematic diagram of the experimental arrangement used to monitor the $A S E$, on the $P_{1}(7)$ transition is shown in Fig. 6 . The intensity of the incident $P_{1}(7)$ radiation was monitored with a beam splitter and a monochromator. The ASE radiated at a small angle to the amplifier optic axis (2-degrees) was monitored by a monochromator. 


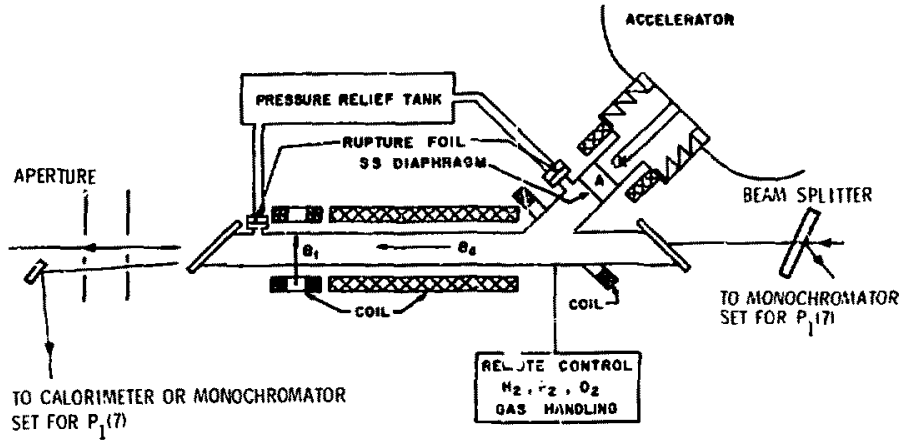

Fig, 6. Schematic diagram of the experimental set up to investigate amplitied spontaneous emission. The beam splitter was used to monitor the input intensity of the $P_{1}(7)$ lines. The apertures were used to allow only radiation at 2 -degrees from the centerline to be monitored.

The results of these measurements with Brewster angle windows on the amplifier are illustrated in Fig. ?. Curve (b) shows the temporal behavior of the incident $P_{1}(7)$ line. The peak intensity is estimated to be about $2 \times 10^{2} \mathrm{~W} / \mathrm{cm}^{2}$. Curve (d) shows the temporal behavior of the $P_{1}(7)$ line with no incident radiation. Curve (c) illustrates the suppression of $P_{1}(7)$ ASE with an incident $P_{1}(7)$ radiation. The ASE on the $P_{1}(7)$ transition show's a 'arge decrease as soon as the $P_{1}(7)$ radiation is incident.

These same experiments were done with 15degree windows on the amplifier. In this case, with an incident intensity of about $10^{3}$ $W / \mathrm{cm}^{2}$, the reciuction of ASE on the $P_{1}(7)$ lime was not as good as when the amplifier had Brewster angle windows. These results seem to indicate that with 1.5-degree windows there is some feedback which allows parasitic oscillation to occur in the amplifier.

These preliminary results indicate that to reutuce ASE from an amplifier it will probably be necessary to achieve the following:

1. Good temporal match on all spectral lines between oscillator and amplifier. This also means that it will be necessary to achieve a good sfectral match between the oscillator and amplifier.

2. Reduction of feedback which might allow parasitics oscillation to occur in the amplifier.

ENERGY AND PUISE WITTH CHAR ACTERISTIC'S OF PHOENIX I

Measurements of laser energy output and laser puise width as a function of $\mathrm{H}_{2}-\mathrm{F}_{2}-\mathrm{O}_{2}$ pressures for the Phoenix I amplifier configured as an oscillator have been described in a previous progress report. ${ }^{6}$ In those measurernents, the pressure ratio of $\mathrm{F}_{2}: \mathrm{O}_{2}: \mathrm{H}_{2}$ was held fixed at 1.0:0.3:0. 25. With flat total reflector on one end of the laser cell and a sapphire output coupler on the opposite end, the output energy increased from $150 \mathrm{I}$ at an $F_{2}$ pressure of 400 torr to $220 \mathrm{~J}$ at an $\mathrm{F}_{2}$ pressure of 1200 turi. Over this pressire range the pulse width remained rearly constant at $-50 \mathrm{~ns}$. It is desirable to obt 3 in amplifier inversion times of the order of 20 ns so that angular multiplexing staring, that will reduce the pulsewidth to about $10 \mathrm{~ns}$, is simple and inexpensive. Calculations indicate that the use of 
hydrogen-lean mixtures at higher total pressures should reduce pulse widths and at the same time increase the chemical efficiency of the amplifier.

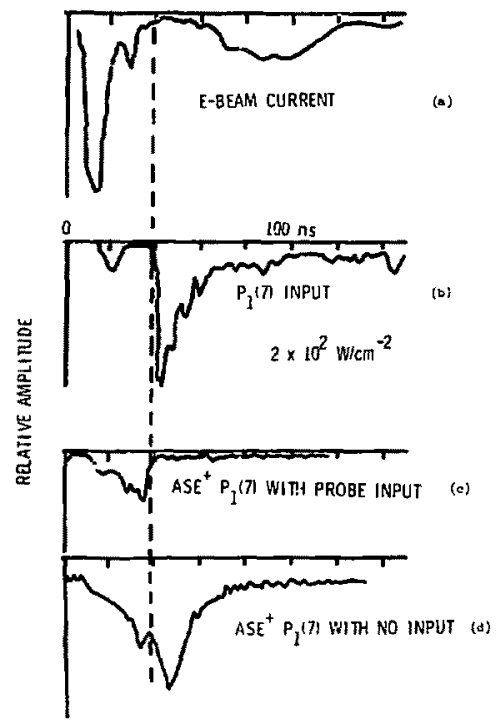

Fi $i_{i} .7$. Suppression of amplified spontaneous emission $\left(P_{1}(7)\right.$.line). The upper curve shows the temporal behavior of the electron-beam current. The next curve shows the temporal behavior of the $P_{1}(7)$ input. The next curve shows the suppression of the $P_{1}(7)$ line from the amplifier. These data were obtained at 2degrees from the amplifier optical axis. The bottom curve shows the $P_{1}(7)$ amplified spontaneous emission from the amplifier with no input.
For the experiments reported here, Phoenis I was configured as an oscillator to investigate the laser characteristics as a function of $F_{2}$ pressure for a hydrogen-iean mixture. In these experiments, the $\mathrm{H}_{2}$ pressure was held constant at 200 torr while the $\mathrm{F}_{2}$ pressure was varied from 380 to 3040 torr. In order to reduce the probability of mixture predetonation the $O_{2}$ pressure was varied as $\mathrm{P}_{\mathrm{O}}=240+0.05 \mathrm{PF}_{\mathrm{F}}$ where $\mathrm{P}_{\mathrm{O}}$ is the oxygen pressure and $P_{F}$ is the fluorine pressure.

For these measuremeats, the amplifier cell was fitted with a flat gold mirror on one end and a sapphire output coupler on the opposite end. The multimode output energy was measured by using a $20-\mathrm{cm}$-diameter surface calorimeter, collecting the energy reilscted from a quartz beam splitter. The temporal history of laser radiation was recorded with a AuGe $(77 \mathrm{~K})$ detector.

Figure 8 shows the laser energy output as a function of pressure. The pressure, shown o: the abscissa, consisted of $95 \%$ fluorine and $5 \%$ oxygen. The laser output energy monotonically increased for pressures from 400 to 2800 torr, then decreasec slightly at a pressure of 3200 torr. The large scatter in data may be due to variations in mixture homogeneity since the 200 torr of hydrogen vas added last and turbulence of the injected gas was the predominant mixing mechanism. The laser output energy shown in Fig. 8 does not increase as rapidly with pressure as does the anticipated electron-beam deposition. Cyltran ${ }^{7}$ calculations indicate that for a total pressure of one atmosphere about $2 \%$ of the available electron-beam, energy is deposited in the gas mixture. Therefore, it is expected that the deposited energy should increase about linearly with increasing pressure. The decrease in electrical efficiency with increasing pressure is accountable in part to the burn being completed before the end of the electron-beam pulse at the higher pressures. Computer calculations using Sandia's HF laser code are planned to compare with the measured output laser variation with pressure. 


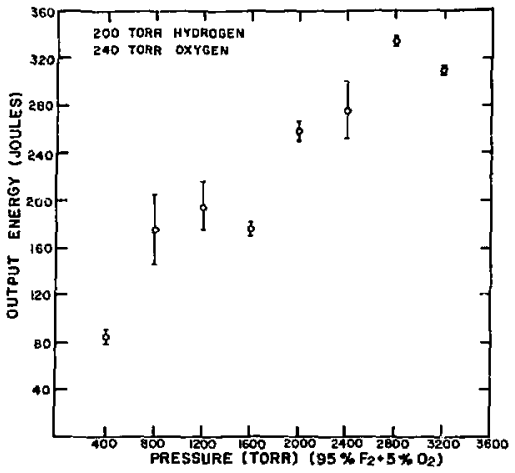

Fig. 8. Laser output energy as a function of pressure.

Laser pul.e width (FWHIM) as a function of pressure is shown in Fig. 9 for the same conditions that were used in Fig. 8 . The pulse width decreased from $\sim 50$ ns at 400 torr to $24 \mathrm{~ns}$ at 3200 torr. While this latter value is near the desired $20 \mathrm{~ns}$, the variation in pulse width with pressure also needs to be comparsu with computer calculations.

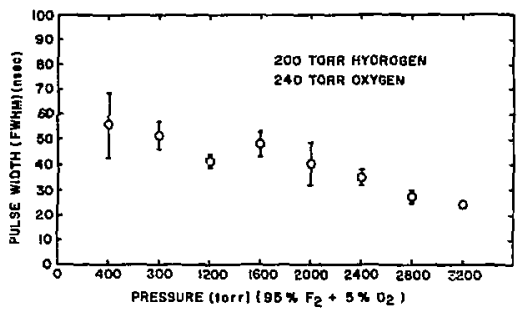

Fig. 9. Laser pulse width as a function of pressure.

The maximum chemical efficiency (laser energy output divided by total exothermic energy released in the $\mathrm{H}_{2}-\mathrm{F}_{2}$ reaction) achieved with the 200 tor $\mathrm{H}_{2}$ mixtures was approximately $3 \%$. This value is based on an excited volume of 41 .
A limited number of measurements was also inacie by using the same cavity geometry as for the above measurements but with even less hydrogen in the mixture. Pressure ratios of $\mathrm{F}_{2} / \mathrm{O}_{2} / \mathrm{H}_{2}$ of $800 / 240 / 100$ and $3200 /$ $403 / 100$ torr were used. For the 800 -torr $\mathrm{F}_{2}$ case, the laser energy was $149 \mathrm{~J}$ and the pulse width (FWHM) was 88 ns. At $3200-$ torr $\mathrm{F}_{2}$ the laser snerky was $226 \mathrm{~J}$ and the pulse width was $45 \mathrm{~ns}$. Laser burn patterus for these low-hydrogen pressure cases indicated a very nonuniform initiation over the amplifier cross section. Intense film damage was observed in a region around the horizontai diameter with consicierably less damage through the remainder of the aperture. This suggests that, for these conditions, the electron-beam did not spread sufficiently to completely fill the cross section of the amplifier.

The maximum chemical efficiency obtained with the 100-torr $\mathrm{H}_{2}$ mixtures was about $4 \%$, assuming uniform initiation of the entire cell volume.

Experiments were also done on Phoenix I to investigate effects of ronuniform electronbeam distribution on lase: pulse width. Electron-beam energy distribution along the optical axis of the laser cell has previously been measured to have a FWHM of $44 \mathrm{~cm} .8$ To investigate whether slower $\mathrm{H}_{2}-\mathrm{F}_{2}$ reactions at the ends of the laser cell where the energy density is smaller contribute to a longer pulse width, re-entrant window holders wele used on each end to shorten the active iength from $91 \mathrm{~cm}$ to $46 \mathrm{~cm}$. The arrangement is shown schematically in Fig. 10. For these measurements, a gas mixture of $F_{2}: \mathrm{O}_{2}: \mathrm{HI}_{2}$ of 800:240:200 torr was used and the results with the re-entrant windows were compared with measurements when sapphire windows were placed directly on the ends of the Phoenix I cell. With the winduws on the ends of the cell, the average eriergy output (sum of both ends) was $168 \mathrm{~J}$ and the average laser pulse width was $43 \mathrm{~ns}$. With the $46-\mathrm{cm}$-Iong cavity using re-entrant windows, the total energy (both ends) was $71 \mathrm{~J}$ arid the average pulse width was 56 ns. The reason for the increase in pu!se width with the short cavity is not understood at this 
time. However, it is apparent that the smaller electron-beam energy density near the ends of the amplifier cell is not responsible for a lengthening of the laser pulse. The ratio of the energy output with the 46 $\mathrm{cm}$ cavity to the output with the $91-\mathrm{cm}$ cavity is 0.42 , while the ratio of the areas of the apertures for the two cavities is 0.44 . Therefore, if the laser radiation were propagating predominantly parallel to the cavity axis, the energy measurements would be consistent with both cavities containing the same laser energy. Further measurements would be required to determine if this is indeed the case.

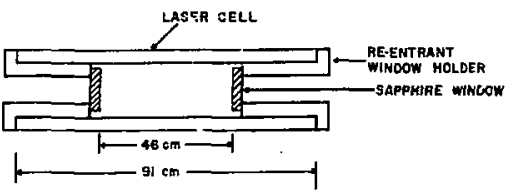

Fig. 10, Re-entrant window configuration for Phoenix I.

The output energy of the amplifier configured as an oscillator was compared for two differ ent values of cavity coupling to estimate extractable energy. For these comparisons, the $\mathrm{F}_{2} / \mathrm{O}_{2} / \mathrm{H}_{2}$ pressures were $800 / 240 / 200$ torr. In the first case, the cavity reflectors, spaced at $91 \mathrm{~cm}$, consisted of a gold mirror and a sapphire flat. The product of reflectivities, $R_{0} R_{L}$, for this cavity was 0.134 . In the second case, sapphire flats vere placed on each end of the Phoenix cell giving a value of $R_{0} R_{L}$ of 0.019 . Figure 11 shows the normalized output energy for the two couplings. The output energy was constant, within experimental error, for these largely different couplings. This indicates that the energy measured with the amplifier configured as an oscillator gives a good estimate of the energy that can be extracted from Phoenix I operated as an amplifier.

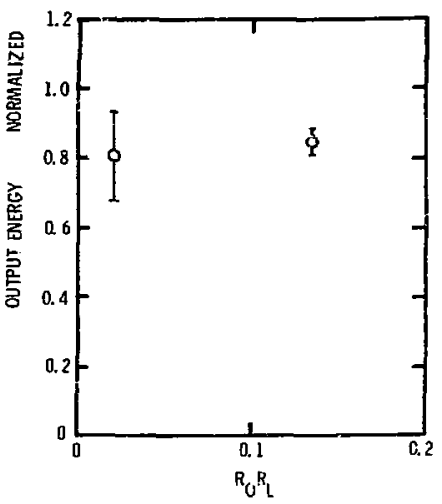

Fig. 11. Normalized output energy as a function of cavity coupling.

\section{SATURATED PHOENIX-I AMPLIFIER EXPERIMENT}

The objectives of the saturated amplifier experiment are to determine the efizciency of energy extraction at input levels up to $10^{7} \mathrm{~W} / \mathrm{cm}^{2}$ and to determine he optical bearr quality.

The experimental setup is shown schematically in Fig. 12. The output from a small pin discharge is amplified by two discharge driven preamplifiers. The output of this system is about $1 \mathrm{~J}$ in a pulse (FWHM) = $100 \mathrm{~ns}$ and consists of about $23 \mathrm{P}$-branch lines. These spectral lines are listed below:

$\begin{array}{ll}P_{1}(6-8) & P_{4}(4-9) \\ P_{2}(4-8) & P_{5}(4-7) \\ P_{3}(5-9) & \end{array}$




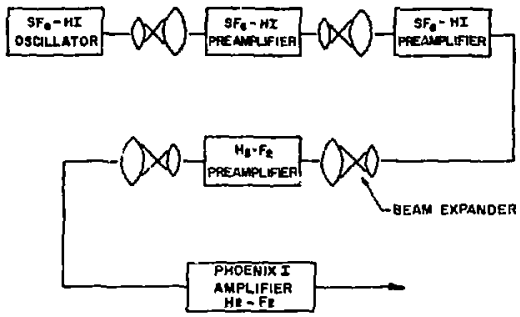

Fig. 12. Schematic diagram of saturated amplifier experiment.

The output from the oscillator-preamplifier system will drive an electron-beam-initiated intermediate amplifier operating with mixtures of $\mathrm{H}_{2}$ and $\mathrm{F}_{2}$. The output from this amplifier should be about $30 \mathrm{~J}$ with a FWHM of 40 ns. This optical beam will be expanded and directed into the Phoenix I final amplifier. The energy extracted from this amplifier will then be measured as a function of input intensity.

Measurements will also be made of the amount of total amplified spontaneous emission (ASE) radiated by the Phoenix amplifier and also the amount of ASE radiated on a single vibration-rotation transitior.

After the energy extraction part of the experiment is completed, the output beam will be focused througl small diameter pinnoles by using an off-axis parabolic mirror to determine the beam quality.

At present, the energy extraction experiment is being set up and timing of the various oscillator-amplifier drivers is underway. The present plans are for both parts of this experiment to be completed by the end of December 1978.

PLANS FOR TWO-BEAM ANGULAR MULTIPLEXING DEMONSTRATION IN A LARGEVOLUME HF AMPLIFIER

Angular multiplexing has been proposed as a technique for short pulse amplification in high-gain syst:ms. 9 Generally, the technique allows for the amplification of any number of pulses, sequentially arranged in time so that their summed pulse widths approximate the total gain time in the amplifier medium. By coding each beam in space in some manner, the beams can then, in principle, be separated after the amplifier and then recombined temporally ano spatially to create a single, short pulse. In practice, the coding can be accomplished by bringing in each beam at a slightly different angle with respect to the amplifier axis. The concept has been demonstrated on a small scale, using the high-gain infrared transition in xenon around 3.39 microns. 10 Using twe separate oscillator beams, this study showed that with pulses whose pulsewicths (FWHM) were approximately one-half the measured gain time of the amplifier each was amplified withont significant temporal distortion of the individual pulses. Also, the amplified spontaneous emission (ASE) was well suppressed. 10 The experiment descrited here is intended to evaluate the angular multiplexing technique in an electron-beam-initiated HF implifier of appropriate scale (several hundred joules per beam). This experiment is irtenced to commence in the spring of 1979.

\section{Design Considerations}

The amplifier cell (Phoenux II) will be driven by the Maxwell Poco Beam Electron-Bearn Machine, as is the current cell (Proenix I). In order to provide scaling information for the HF code and to allow for up to several hundred joules per beam in tin two-beam multiplexing experiment, th: size of the Phoenix II cell was chosen to be four to five times the size of the Phoenix I cell. Figure 13 shows a schematic illustration of the Phoenix II cell together with some of the pertinent characteristics. The dimensions of the two probe beams are shown considerably smaller than the optimum size in order to emphasize their individual spatial relationships within the amplifier. A rectangular cell was chosen in order to minimize the volume in the cell which is unprobed by either beam. For a given beam path length, a circular beam tends to fill a slightly 
smaller volume in a cylindrical cell than does a rectangular beam in a rectangular cell. The unprobed volume is not a severe design restraint, however, since it could be completely eliminated by a beam on axis or with suitably designed baffles.

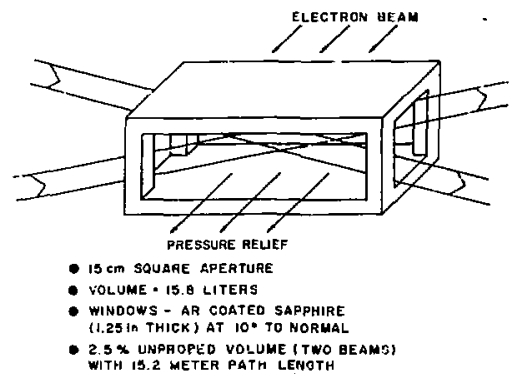

Fig. 13. Schematic of the Phoenix II cell. The two oscillator beams are shown smaller than their true sizes relative to the cell. The incident angles are exaggerated to illustrate the spatial relationships in two-beam angular multiplexing.

The electron-beam entrance foil and the overpressure blowout diaphragm structure are both designed to be in a re-entrant configuration. In this manner, the active volume is defined in part. by these two structures and any "dead" volume along the sides which is not accessible to the probe beams is almost eliminated.

For rectangular beams of height $\mathrm{W}_{\mathrm{a}}$ (equal to the amplifier height) and width $W_{b}$ and for a given optical path length L (measured from the cell center), the minimum angle $(\alpha)$ that one beam makes with respect to the amplifier axis is given by (for small $\alpha$ )

$$
\alpha=\frac{w_{b}\left(\frac{d}{W_{b}}+0.5\right)}{L}
$$

where $2 \mathrm{~d}$ is the separation of the beams at distance $L$ (determined from mirror mounting considerations) and $W_{b}$ is chosen to be as large as possible accounting for the vignetting created in the off-axis configuration:

$$
W_{b} \leq \frac{W_{a}}{1+\frac{L_{a}}{L}\left(\frac{d}{W_{b}}+0.5\right)}
$$

where $\mathrm{L}_{\mathrm{a}}$ is the overall length of the amplifier cell. From Eqs (1) and (2), one sees that the desired beam spacing at distance $L$ determines the appropriate beam width and relative input angle. This in turn determines the fraction of the amplifier volume which, for the two beam case, is not probed by either beam. For a rectangular cell this volume is given by

$$
\mathrm{V}=\frac{\mathrm{V}_{\mathrm{a}} \mathrm{L}_{\mathrm{a}} \operatorname{Tan} \alpha}{2 \mathrm{~W}_{\mathrm{a}}} \simeq \frac{\mathrm{V}_{\mathrm{a}} \mathrm{I}_{\mathrm{a}} \alpha}{2 \mathrm{~W}_{\mathrm{a}}}
$$

where $\mathrm{V}_{\mathrm{a}}$ is the amplifier voiume. For the Phoenix II cell ( $\mathrm{L}_{\mathrm{a}}=80 \mathrm{~cm}$ ) and for a path length of $15.24 \mathrm{~m}$ (50 ft), one obtains $\alpha=9.5$ $\mathrm{mrad}, \mathrm{v} / \mathrm{v}_{\mathrm{a}}=2.5 \%$ for $2 \mathrm{~d}=\mathrm{W}_{\mathrm{b}}$.

The energy deposition characteristics of Phoenix II will depend largely on the new diode operation which is currently in tha design stage. However, these characteristics are expected to be similar to those of Phoenix I (about $17 \mathrm{~J} / \mathrm{l}$-atm deposited for the "standard" mixture of $\mathrm{F}_{2}: \mathrm{O}_{2}: \mathrm{H}_{2}=$ 1:0.3:0,25). For a 2-atm mixture under these conditions, a trial run was done with Sandia's HF code and the results are shown in Fig. 14. The top graph shows the ASE time history under these conditions, and to bottom graph illustrates the input beams (solid lines) and the calculated anplifier outputs (dashed lines). For this case, the two input bearus were chosen to have a pulse width of $25 \mathrm{~ns}$ (FWHM) with relative time delays selected so that the sum of the input intensities in the region where the beams overlap was more or less constant. Inasmuch as the code does not distinguish 
between the two beams in the region where they overlap, the bottom curves in Fig. 14 were obtained by apportioning the computed output intensity anong the two beams in accordance with their relative input intensities at any given point. From this figure, if is clear that the two areas of concern regarding possible temporal pulse digtortion are at the leading edge of the first pulse and the trailing edge of the second pulse: these are the two periods of nonlinear gain in the amplifier. In order to perform the experiments at pulse widths in the range of $10 \mathrm{~ns}$ to $15 \mathrm{~ns}$ per beam, it is assumed that the Phoenix II amplifier can be scaled down in
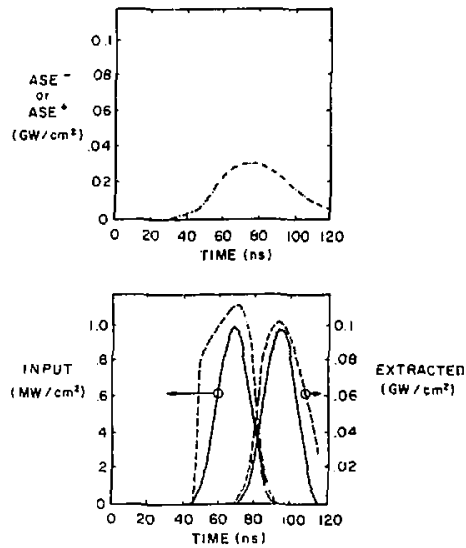

Fig. 14. Results of a preliminary run with Sandia's HF code applied to the Phoenix If experiment. The top curve shows the duration of the amplified spontaneous emission (ASE) in the forward (+) and backward $\langle-\rangle$ direction with no input beam. A two-atm mixture $\left(\mathrm{F}_{2} / \mathrm{H}_{2} /\right.$ $\mathrm{O}_{2}=800$ torr $/ 200$ torr $/ 240$ torr) with e-beam deposition similar to Phoenix I was assumed. The bottom curves show the two input beams (solid lines) and the resultant amplified signals (dash 2 dines). pulse width in accordance with Fig. 14. Figure 15 shows the experimental layout including the oscillator-preamplifier with a polarization switch to create the short (10 ns to $15 \mathrm{~ns}$ ) pulse. 11 This beam is amplified in the electron-beam-initiated preamplifier and the short pulse is switched out. This beam is subsequently filtered and beam expanded to match the Phoenix II cell. A 50-50 beam splitter splits this beam into two beams of approximately equal intensify. By translating this splitter, it is possible to create the desired path differences between the two beams. According to current estimates, we expect nearly $10^{7} \mathrm{~W} / \mathrm{cm}^{2}$ (single beam) input to the Phoenix II amplifier and nearly $5 \mathrm{x}$ $10^{6} \mathrm{~W} / \mathrm{cm}^{2}$ for the angular miltiplexing experiment.

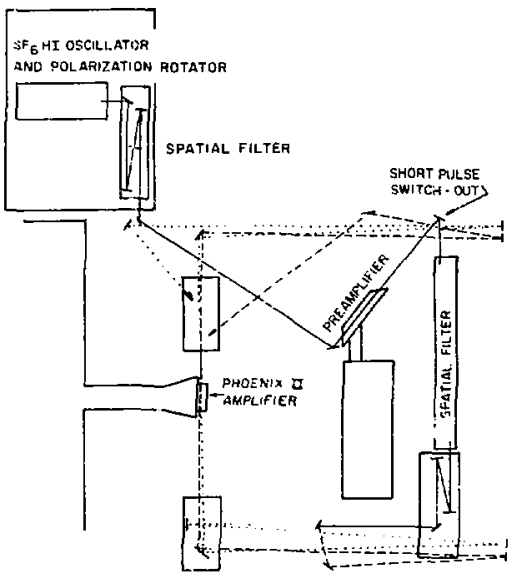

Fig. 15. Beam paths and principle equipment layout for the two-heam angular multiplexing experiment. The dots and dashes correspond to the two equally intense beam. which are created at a 50-50 beam splitter. The diagnostic layouts are not shown here. 


\section{Experimental Goals}

The two-bear. multiplexing experiment is intended to demonstrate efficient energy extraction from the Phoenix II amplifier while suppressing the ASE from this amplifier. The observed parameters will be evaluated against the single-beam oscillatoramplifier characteristics which are expected to cover a range of input intensities up to $10^{7} \mathrm{~W} / \mathrm{cm}^{2}$. Measurements vill include the contrast ratio of amplified pulses, beam quality using shear-plate interferometry, ASI (forward and backward), and spatial profiles of the beams. It is expected that each of these parameters will depend strongly on the individual pulse widths and relative time delays. Provisions have been made to allow the variation of both of these parameters over the expected range.

\section{DIAGNOSTIC EXPERIMEINTS FOR DETAILED CODE COMPARISON}

In an aitempt to explain some of the discrepancies that exist between the HF kinetic model and experiments, a small electronbeam-initiated laser is being constructed that will be used solely for diagnostic experiments. This laser will use an existing electron-beam system (Physics International Model 215 WR Pulserad). The laser cell is designed so that on the order of $100 \mathrm{~J} / \mathrm{l}$-atm will be deposited uniformly in the gas, which is similar to deposited energy of the larger electron-beam-initiated lasers. Detailed energy deposition measurements will be done with segmented totally stopping calorimeters.

The diagnostic experiments to better understand the kinetics of the laser will include measurements of (1) electron-beam deposition in $F_{2},(2)$ the density of fluorine atoms initially produced by the electron-beam,

(3) the rate of $F_{2}$ disappearance in a standard laser gas inixture, (4) the small-signal gain on scveral vibration-rotation transitions, and (5) time-resolved Jaser-output spectra.

The F-atom concentration will be measured by the HCl titration technique. This involves reaction of $\mathrm{F}$ with $\mathrm{HCl}$ to produce $\mathrm{HF}$. The number of HF n.slecules produced will then be determined by absorption spectroscopy. One potential problem could be the reaction of $\mathrm{Cl}$ with $\mathrm{F}_{2}$ to produce an additional $\mathrm{F}$ atom. However, evidence in the literature indicates that this second reaction vill be slow on the time scale of the experiment. A1so, there is data that suggest that electron-beam dissociation of $\mathrm{HCl}$ will be small.

The rate of $F_{2}$ disappearance, which $v$ ill yield the total chain-reaction time, will be monitored by using a frequency-doubled dye laser to measure absorption on the 285-nm band of $\mathrm{F}_{2}$. Potential problems here arise from the fact that in a standard laser $\mathrm{mix}$ the temperature increases significantly following electron-beam initiation. The $\mathrm{F}_{2}$ absorption cross section can be inferred at elevated temperatures, but a measurement may be required.

The other diagnostics on the experiment use well-established methods of measurement, and problems are not anticipated in obtaining these data.

\section{NUMERICAL MODELING OF HF LASER PERFORMANCE}

In the last semiannual report, electronbeam deposition nonuniformity was shown to be an important factoi in modeling two HF chemical laser oscillator experiments. When deposition nonuniformity was taken into account, previously noted discrepancies between experiment and prediction were significantly reduced. Most umportantly. reasonable results were then obtained by using an $\mathrm{F}$-atom production cost consistent with putlished values ( $5 \mathrm{eV})$.

Comparison has now been extended to an additional pressure regime for one of the above oscillator experiments and to include a third oscillator experiment and two amplifier experiments. Also, a sensitivity study has been carried out to assess the possibility that errors in the various rates explain the remaining discrepancies.

In the last report, it was shown that the observed long tail in the output power pulse 
of the Febetron 706 initiated laser can be predicted when deposition nonuniformity is taken into account. The correct prediction of output-energy dependence on oxygen pressure then follows ( $F$ ig. 16). Comparison at double the indicated partial pressures has since been completed (Fig. 17). The results show that doubling the pressure does not result in doubling the output energy and, in fact, leads to reduced output at the higher $\mathrm{O}_{2}$ fractions. The com uter mode? shows that this is a result of the chain terminating reactions which form $\mathrm{HO}_{2}$ and $\mathrm{FO}_{2}$, coupled with the relatively weak initiation strength. Had the init:ation strength in these experiments been sufficiently strong, the chain terminating reactions would not have been important in the time scale required for the chain reaction, and the reported oxygen effects would not have been seen.

As was reported in the last semiannual report, radial deposition profile measurements, obtained from the $\lambda$-geometry laser suggested that deposition nonuniformity must be accounted for in modeling these experiments. This was accomplished by dividing the cylindrical laser medium into concentric regions, each assigned a deposition energy density corresponding to its radial position.

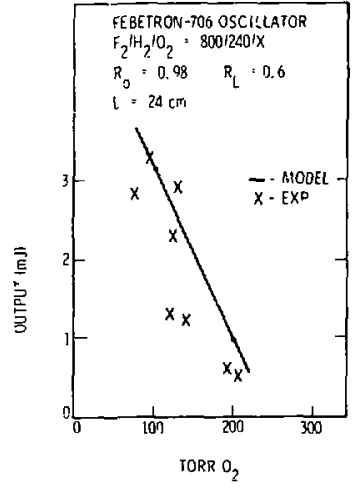

Fig. 16. Comparison of measureci and calculated output energy for the Febetron-706 experiments.
The model predictions for each region were added together with proper volume-based weightings, to obtain "composite solutions." Results were presented for an oscillator case, showing greatly improved agreement with experiment, at a reasonable $F$-cost of $5 \mathrm{eV}$.

The composite-solution approach has since been extended to amplifier cases. Figure 18 shows a set of input spectral time histories for a particular cisse. The amplitude scales are arbitrary in the figure, but measured scale factors were used for the calculation. Figure 19 shows the total inpur time history and the calculated and measured amplifier power output. The peak power is only mildly overpredicted, while the pulse width is

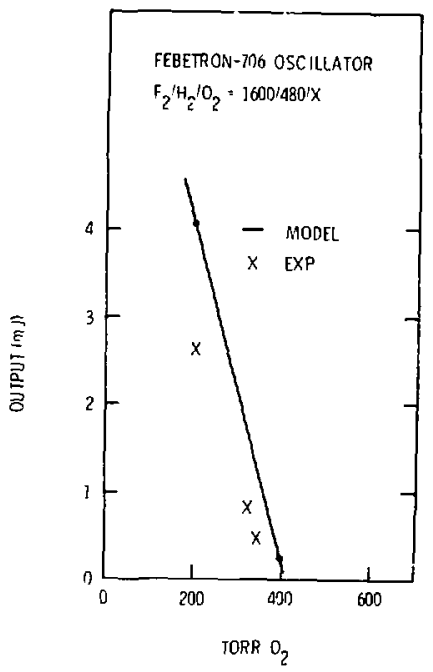

Fig. :7. Comparison of measured and calculated output energy for the Febetron-706 experiments at double the pressure of the previous figure. 
overpredicted by about a factor of two, as in the oscillator case. Only moderate ASE suppression is predicted, in agreement with the experiment. The calculations indicate that incomplete suppression is due to spectral and temporal mismatch of the oscillator and amplifier. Figure 20 shows (from another case) the effect of temporal mismatch on ASE suppression for a particular spectral line. The ASE in the absence of an input pulse is seen to persist from about $40 \mathrm{~ns}$ to $120 \mathrm{~ns}$ after the electron-beam current begins. The $P_{1}(0)$ input pulse only cover's the first hair of this period. During that time, the calculation shows very strong ASE suppression, even though the input intensity is less than $100 \mathrm{~W} / \mathrm{cm}^{2}$. As soon as the input cuts off, the $P_{1}$ (9) ASE rebounds to nearly the unprobed value. Similar results have been observed experimentally, as presented in another section of this report.

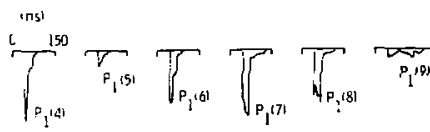

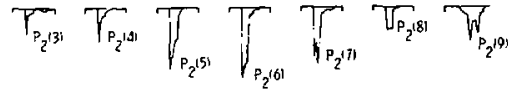

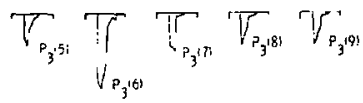

Fig. 18. Measured inpui spectral time histories as used in a $\lambda$-amplifier experirient. This experiment was chosen for comparison with calculation because a complate set of time histuries was available. The amplituce scales ô each line are in arbitrary units here, but measured scale factors were used in the code.

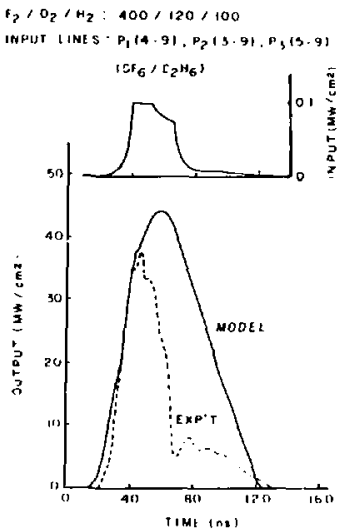

Fig. 19. Calculated and measured $\lambda$ amplifier response. A threeregion composite solutio.1 was used.
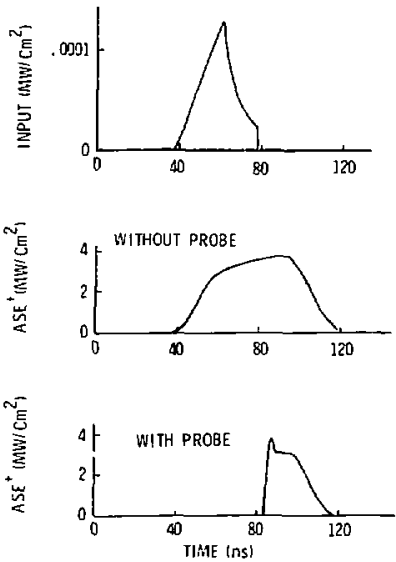

Fig. 20. Calculated effect of temporal mismatch on $P_{1}(9)$ ASE suppression for the $\lambda$-amplifier innermost annulus. 
For the Phoenix I laser experiments, less is known abnut deposition level and uniformity. The $t v$-dimensional Monte-Carlo CYLTRAN sugges's significantly lower depogition than in the $\lambda$-geometry core out with considerably more uniformity as depicted in Fig. 21. For the transverse excitation, uniform deposition is assumed. Figure 22 show's a comparison of computed and rneasured oscilllator power output. As ir, the $\lambda$-geometry cases, predicted peak power is slightly high, but the main difficulty is pulse-width overprediction. In the calculation, the second peak is caused by $\mathrm{FO}_{2}$ breakup with increasing temperature. For the Phoenix I amplifier extraction experiments, the $\lambda$-geometry oscillator output was used as input to Phoenix I. Since a complete set of spectral time histories was not available, the missing histories were

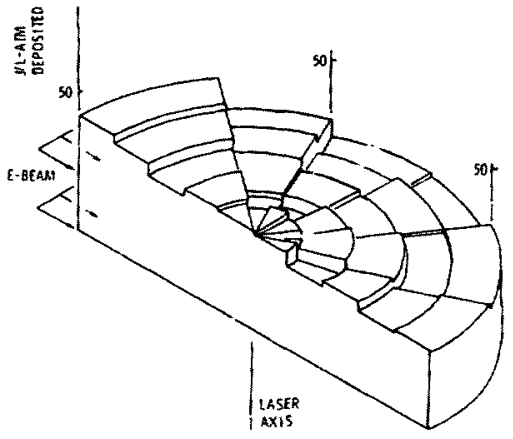

Fig. 21. Result of a two-dimensional MonteCarlo calculation (CYLTRAN) of electron-beam deposition in the transversely excited oscillator/ amplifier. assumed to be identical to those of nearestneighbor transitions. The resulting set is shown in Fig. 23. Experimentally determined scale factors for each line were used in the calculations. The predicted output power is compared with experiment in Fig. 24 for the case of an input intensity of $10^{7}$ $W / \mathrm{cm}^{2}$. In this case, the pulse width is not overpredicted because the input pulse is shorter than the predicted gain pulse width. Finally, in Fig. 25, the calculated and measured results of the energy exiraction experiment are shown. Energy extraction is overpredicted for very low input power levels possibly because of parasitic oscillations in the amplifier.

$$
\begin{aligned}
& \text { 1-ANETER CAVITY } \\
& R_{0}=.98 \quad R=0.06 \\
& \mathrm{~F}_{2} \mathrm{H}_{2} \mathrm{HO}_{2}=800 / 203 / 240 \mathrm{TORR} \\
& \text { 0.1 J'TORR JEPOSIIEO IN } 2 \text { LITERS } 5 \text { EUT } \\
& 5 \times 7.5 \times 4 \mathrm{Cm}^{3} \text { ACTIVE SHOLU: }
\end{aligned}
$$

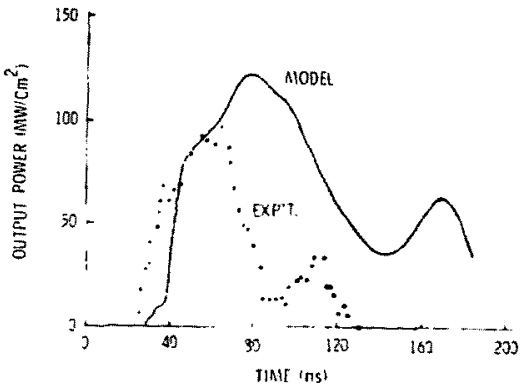

Fig. 22. Comparisor of calculated and measured Phoenix I oscillator output-power vs time. 

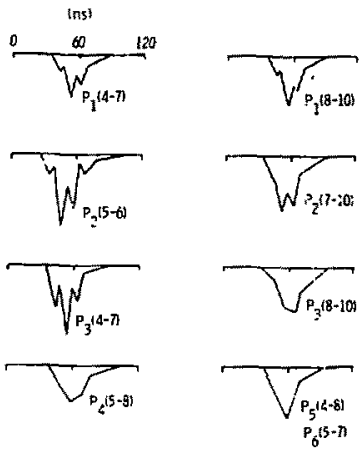

Fig, 23. Measured input spectral time histories uned in the $\lambda$-oscillator/ Ploenix I amplifier extraction exper inents and calculations. As shown, these are approximations to the oscillograms. The amplitude scales here are in arbitrary units; however, the experimentally determined scale factors are used in the calculations,

$\mathrm{F}_{2} \mathrm{H}_{2} \mathrm{iO}_{2} \cdot 2001200 / 240$ TORR

Q.) HTORR DEPOSIED IN 2 LIIERS: 5 ev/5 $5 \times 7.5 \times 45$ Cח 3 ACTIVE MEDIUM $10^{7}$ W/CM ${ }^{2}$ PEAK INPUT POWER

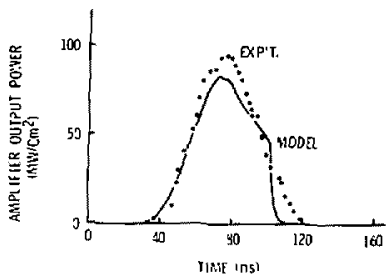

Fig. 24. Comparison of measured and calculated Phoenix I amplifier response.

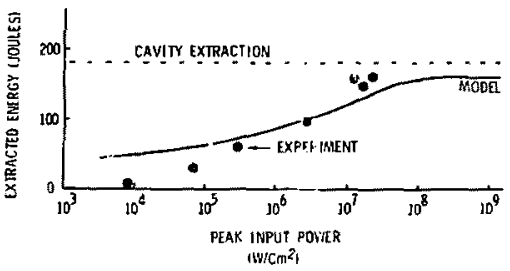

Fig. 25. Calculated and rneasured Phocnix! amplifier energy e:traction as a function of peak input power. Alse showr is the me:asured extraction by an optimized cavity.

Most recently, a sensitivity study has been ca.ried out to assess the effect of the various kinetic rates on the remaining discrepancies between model prediction and experiment. First, the molal kinetics were updated. The model prediction for the $\lambda$ geometry oscillator case was then shown to be in very good agreement with an equivalen aerospace calculation (Fig. 26). Finally, the $\lambda$-geometry oscillator case was recalculated a number of times, each time varying one of the groups of energy-exchange rotes by a factor of 3 to 5 . The pressure broaden ing coefficients were increased by a factor of 3 in one case. In was found that only an increase in $H F V-T$ deactivation equivalent to increasing the self-deactivation rate by a factor of 5 would elminate the pulsewidth overprediction. Figures 27 through 29 illustrate this effect. The Phoenix-I a nplifier case has not yet been $r u n$, but it is expected to be consistent with the other results. 


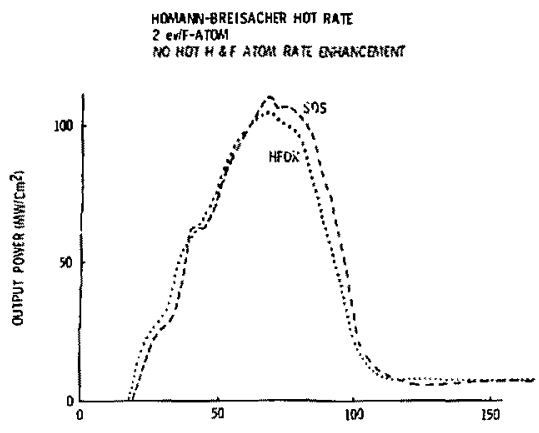

Fig. 26, Demonstration that the Sandia HFOX and Aerospace SOS calculations of one-point short-pulse oscillator output are the same for same input quantities. Shown is $\lambda$-oscillator output power vs time for a 400 torr $\mathrm{F}_{2}, 100$ torr $\mathrm{H}_{2}$, 120 torr $\mathrm{O}_{2}$ case.

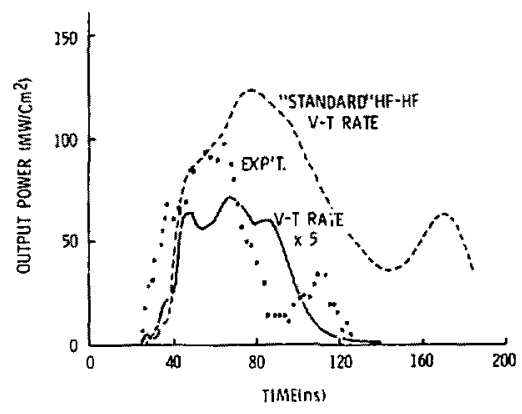

Fig. 28. Improved agreement between transversely excited oscillator experiment and calculation when a deactivation equivalent to increasing the HF-HF V-T rate by a factor of 5 is introduced. Updated hot and rotational-relaxation $r$ ates have also been used.

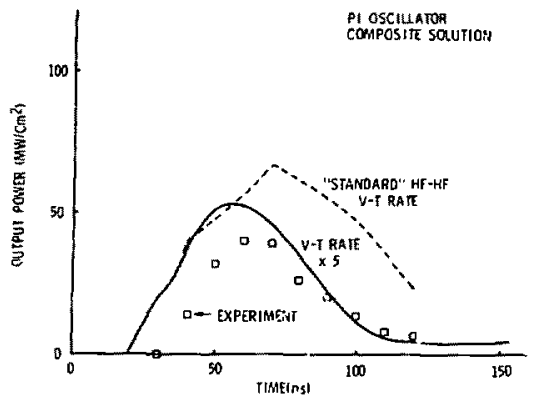

Fig. 27. Improved agreement between $\lambda$ oscillator experiment and composite calculation when a deactivation is introduced equivalent to increasing the HF-HF V-T rate by a factor of 5. Updated hot and rotational-relaxation rates have also been used.

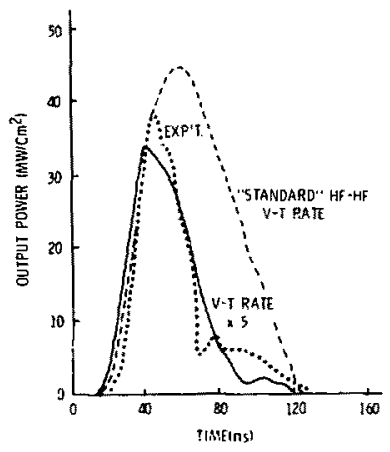

Fig. 29. Improved agreement between $\lambda$ amplifier experiment and composite calculation when a deactivation is introduced equivalent to increasing the HF-HF $V-T$ rate by a factor of 5 . Updated hot and rotational rates heve also been used. 


\section{IODINE LASER PROGRAM}

\section{OVERVIEW}

We now know that an lodine laser system can be built that would satisfy all near-term requirements of laser fusion including the driver of an experimental power reactor, but its efficiency needs to be improved before it can be considered as a driver for a commer. cial ICF power generator. With available technology, the best clectrical efficiency that can be realized for a $\sim 1-\mathrm{MJ}, 1$-to-10-pps iodine laser is 0.4 to $0.5 \%$, and the overall efficiency including regeneration of laser medium starting chemicals is 0.35 to $0.4 \%$. This low-projected efficiency requires very high laser-energy-to-thermonuclear-energy gains for economically attractive electric power generation and its low electrical efficiency would require a prohibitively high capital investment in the pulse power source. Surface discharges and $\mathrm{HgXe} \mathrm{F}^{*}$ exciplexes have been selected as the two most promising advanced pump sources for a more efficient (up to $2 \%$ ) iodine laser. Both of these sources will be evaluated in near-term studies.
CONTR OL OF SELF-FOCUSING IN THE ATOMIC IODINE LASER

The previoue semiannual report described the observations of whole beam self-focusing produced within the SAIJ- 1 main amplifier. 12 The six-level, two-dimensional, time-dependent Maxwell-Bloch code $1 \mathrm{STAR}^{13}$ predicted the self-focusing with good accuracy and for that reason ISTAR can be used to predict the amount of self-focusing in other iodine laser systems. The magnitude and sign of the saturation-dependent phase shift that leads to the self-focusing beampropagation instabiiity can be controlled by varying the homogeneous, pressureproduced linewidth.

To explore control of the self-focusing effect, series of ISTAR calculations are presented in Table I and Fig. 30. This series was run with varying linewidth asd inversion at fixed gain on the 3-4 line. The incident energy is also varied in the proper manner to maintain a fixed amount of saturation of the 3-4 line. Table $I$ shows that the average $R_{c}$ (radius of curvature) for the amplified pulse varies regularly with buffer pressure;

\section{TABLE I}

ISTAR Calculations Demonstrating Pressure Control of Self-Focusing in a $1-m$ Amplifier

\begin{tabular}{|c|c|c|c|c|c|c|}
\hline $\begin{array}{l}E_{0} \\
(J)\end{array}$ & $\left(10^{23} \mathrm{~m}^{\mathrm{n}} \mathrm{m}^{-3}\right)$ & $\begin{array}{c}\mathrm{P}_{\mathrm{Ar}} \\
\text { (ktorr) } \\
\end{array}$ & $\begin{array}{r}G_{3-4}^{S S} \\
(\text { PRE) } \\
\end{array}$ & $\begin{array}{l}\mathrm{G}^{\mathrm{ss}} \\
(\mathrm{PRE})\end{array}$ & G & $\begin{array}{l}R_{c} \\
(m) \\
\end{array}$ \\
\hline $10^{-9}$ & 1.0 & 1.0 & 13.8 & 21.2 & 17.6 & 21.83 \\
\hline 0.5 & 1.0 & 1.0 & 13.9 & 21.2 & 4.0 & 22.14 \\
\hline 1.0 & 2.0 & 2. 0 & 13.8 & 42,4 & 4.8 & 21. 92 \\
\hline 2.0 & 4.0 & 4.0 & 13. 8 & 123.0 & 6.2 & 21.51 \\
\hline 3.0 & 6.0 & 6.0 & 13.8 & 248.5 & 7.0 & 21.39 \\
\hline
\end{tabular}

"The incident Gaussian puls, has a temporal width of $225 \mathrm{ps}$ (FWHM) and the input amplifier face; $20 \mathrm{~m}$ from the minimum waist of $1.32 \mathrm{~mm}$. PRE denotes quantities evaluated from photon rate equations; $E_{O}$ is input energy, $n_{U}$ is initial $J=1 / 2$ popularion, $P_{A r}$ is broadener pressure, $G$ is gain, and $R_{c}$ is the average radius of curvature at exit. The first line is included as an undistorted (small-signal-gain) reference case. 
the average focusing power of the medium is seen to pass through zero between 2000 torr and 4000 torr of Ar. The radial dependence of $R_{c}$ for these cases is displayed in Fig. 30: the plotted quantity thus represents a tempo$r a l$, intensity-weighted averaging over the short pulse. The temporal average represents the maximum pulse aberration that can be corrected with passive optics. The important point is that the amplifiers van be stabilized against self-focusing (although there may be a time-cependent transverse dispersion of the puise) and should present no problem for further chained amplification as long as the linewidths are kept appropriately large by pressure broadening. In addition, it should be mentioned that the mechanism of self-focusing that is used here seems sufficient to describe all observations. The hypothesis of level-dependent polarizability does not appear necessary.

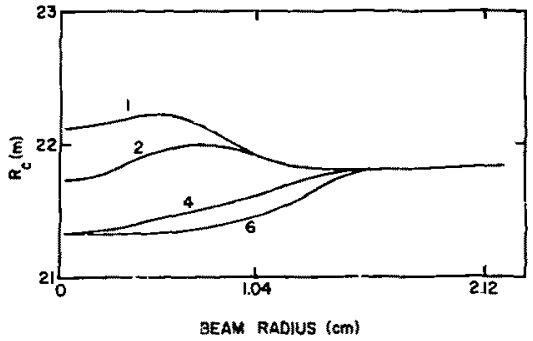

Fig. 30. Theoretical predictions (ISTAR) of the rodial variation in the temporally-average radius of curvature, $R_{c}$, of a pulse amplified by a $1-m$ preamplifier. Additional data related to these calculations are contained in Table;. The number by each curve denotes the $\Lambda r$ pressure in ktorr and corresponds to the same case of Table $\mathrm{T}$.

\section{CHEMICAL REGENERATION}

As is well known, the usual starting material employed in an iodine laser is a perfluoroalkyl iodide, RI, some of which "s converted lo $R_{2}$ and $l_{2}$ during the operation of the laser.
Economical ofieration oi a large fodine laser system requires that the $R_{2}$ and $I_{2}$ so formed be regenerated to $R I$ with an energy efficiency of at least a few percent. Previous reports 14,15 have dealt with the amount of $\mathrm{R}_{2}$ likely to be produced consequent to laser operation and with two schemes for converting $I_{2}$ plus the very stable $R_{2}$ molecules to RI. Recent experimenial results are presented in the following material, and projected chemical efficiency is given as a function of amplifier size.

\section{Laser Induced Chemistry Experimerts}

Reference 14 discusses experiments in which the formation of $\mathrm{CF}_{3}$ lit irom mixtures of $\mathrm{C}_{2} \mathrm{~F}_{6}$ and $\mathrm{H}_{2}$ was studied. The $\mathrm{C}_{2} \mathrm{~F}_{6} / \mathrm{H}_{2}$ system was investigated rather than the $\mathrm{C}_{2} \mathrm{~F}_{6} / \mathrm{I}_{2}$ system because the strong absorpiion coefficient of $\mathrm{CF}_{3} \mathrm{I}$ would have needless ly complicated initial experiments. It was found that the irradiation of $\mathrm{C}_{2} \mathrm{~F}_{6} / \mathrm{H}_{2} \mathrm{mix}$ tures with the $9.192-1 \mathrm{~m} \mathrm{R}$ (36) $\mathrm{CO}_{2}$ laser line at a fluence of $65 / \mathrm{cm}^{2}$ resulted in the formation of $\mathrm{CF}_{3} \mathrm{H}$. it is thought that the laser-induced formation of $\mathrm{CF}_{3} \mathrm{H}$ proceeds through the dissociation process

$$
5 \mathrm{~F}_{6}-2 \mathrm{CF}_{3}
$$

followed by reaction of $\mathrm{CF}_{3}$ with hydrogen, as is discussed in detail in Reference 16. The laser energy absorbed per molecule of $\mathrm{CF}_{3} \mathrm{H}$ formed was found to be $3.2 \mathrm{eV}$, a vilue only about $50 \%$ larger than can be explained by dissociation requirements alone. 16 More recently, the formation of $\mathrm{CF}_{3} \mathrm{Cl}$ in laserirradiated $\mathrm{C}_{2} \mathrm{~F}_{6} / \mathrm{Cl}_{2}$ mixtures was studied, and it was found that the absorbed energy per molecule of $\mathrm{CF}_{3} \mathrm{Cl}$ formed was $4.3 \mathrm{eV}$. Within experimental error, the energy requirements for formation of $\mathrm{CF}_{3} \mathrm{H}$ and $\mathrm{CF}_{3} \mathrm{Cl}$ are the same, as is to be expected if the dissociation of $C_{7} \Gamma_{6}$ defines the energy requirement. It is thus reasonable to project an energy requirement of about $4 \mathrm{eV}$ per molecule of $\mathrm{CF}_{3} \mathrm{I}$ for regeneration of $\mathrm{C}_{2} \mathrm{~F}_{6} / \mathrm{I}_{2}$ mixtures.

The figure of merit (or "efficiency") of a chemical regeneration process is defined as 


$$
\eta_{\mathrm{R}}=\frac{\text { extracted laser energy }}{\text { energy input to regeneration process }}
$$

and this may be expressed an

$$
\eta_{\mathrm{R}}=0.94 \eta_{\mathrm{s}} \varphi /[\mathrm{M} \mathrm{E} \mathrm{abs}(\mathrm{eVl})
$$

where $\eta_{S}$ is the efficiency of the energy source used to induce regeneration, $\varphi$ is the fraction of its output energy actually utilized, $E_{\text {abs }}$ is the absorbed energy per regenerated molecule, and $M$ is the number of $R I$ molecules converted to $R_{2}$ per photon extracted from the laser. Values of $M$ for different $R I$ molecules and laser operating conditions are tabulated in Ref. 15, where it is shown that the value of $M$ is 0.96 for a heavily saturated amplifier using 5-torr $\mathrm{CF}_{3} \mathrm{I}$ and 3000 -torr Argon. A photolytic pump pulse width of $1 \mu s$ and $47 \%$ photolysis are also assumed. For purposes of illustration, $\eta_{c}$ is taken to be 0.2 for the puised $\mathrm{CO}_{2}$ laser 17,18 and $\varphi$ is taken to be 0.5 . The value of $\eta_{\mathrm{R}}$ corresponding to the $4 \mathrm{eV}$ per molecule required for regeneration of $C_{3} I$ is then $\eta_{R}=0.025$. Thus, the laser-induced regener ation process does have a figure of merit of at least a few percent, but a better regeneration efficiency would clearly be desireable.

Several possibilities exist for obtaining larger values of $\eta_{R}$ as can be seen from Eq (6). A process having a larger value of the product $\eta_{\mathrm{S}} \varphi$ can be sought, and one such is described later in this report. Alternatively, regeneration by using the laser process can be attempted for RI species associated with values of $\mathrm{M}$ appreciably less than unity. From $R \in f$. 15, a typical value of $M$ for i-C $\mathrm{C}_{3} \mathrm{~F}_{7} \mathbf{I}$ is, for instance, about 0. 1. Accordingly, laser-induced chemistry was studied in $\mathrm{n}-\mathrm{C}_{4} \mathrm{~F}_{10} / \mathrm{H}_{2}$ and $\mathrm{n}-\mathrm{C}_{6} \mathrm{~F}_{14} / \mathrm{H}_{2}$ mixtures, as well as in some others. It was found that $\mathrm{n}-\mathrm{C}_{4} \mathrm{~F}_{10}$ dissociates to the stable molecules $\mathrm{C}_{2} \mathrm{~F}_{4}$ and $\mathrm{C}_{2} \mathrm{~F}_{6}$ rather than tc the radicals $\mathrm{C}_{2} \mathrm{~F}_{5}$, and that $\mathrm{n}-\mathrm{C}_{6} \mathrm{~F}_{14}$ dissociates in an analogous manner. These facts seem to preclude the use of laser-induced chemistry as a successful regeneration scheme for $\mathrm{C}_{2} \mathrm{~F}_{5} \mathrm{I}$ or $\mathrm{C}_{3} \mathrm{~F}_{7} \mathrm{I}$. It may be the case that $\mathrm{CF}_{3} \mathrm{I}$ is the only iodine-laser starting material to which laser-induced regeneration is applicable.

\section{Chemical Regeneration Using Electric Dis- charge Techniques}

The use of electric diecharges in chemical recovery of RI compounds from $\mathrm{k}_{2}$ compounds involves the selective breaking of the $\mathbf{R}-\mathbf{R}$ bond in a low-pressure gas discharge in such a manner that the resulting $R$ radicals can react with iodine to form the desired RI compound. The basic equipment for this study has been described in the previous semiannual report. 1 Briefly, the system consists of a gas handling system which allows the gas reactants to flow throligh a tube in which an electric discharge is produced. Down stream from the discharge tube, mass spectrometric analysis equipment allows the quantitative determination of gas products emanating from $t_{i}{ }_{-}$discharge region of the flow system. Initial studies described earlier were carried out by using a microwave discharge configuration. Much of the microwave energy was absorbed into the discharge tube rather than within the flowing gas. 1 Thus, the efficiency for producing $\mathrm{CF}_{3}$ radicals from $\mathrm{C}_{2} \mathrm{~F}_{6}$ was quite low. More recently, the microwave discharge equipment was replaced with an $r f$ discharge system operating at about $13 \mathrm{MHz}$. Attempts to couple $r f$ energy into the flowing gas have been much more successful.

Initial studies using $\mathrm{C}_{2} \mathrm{~F}_{6}$ showed that $\mathrm{CF}_{3}$ radicals can be produced in the electric discharge and reacted with $\mathrm{Cl}_{2}$ to yield $\mathrm{CF}_{3} \mathrm{Cl}^{1}$. The current set of measurements has involved the reaction of $\mathrm{CF}_{3}$ with $\mathrm{I}_{2}$ to produce $\mathrm{CF}_{3} \mathrm{I}$. However, initial attempts to form $\mathrm{CF}_{3} \mathrm{I}$ by using continuous wave $(\mathrm{cw}), \mathrm{rf}$ discharges resulted in very low product yields. The observed low yielos were found to result from the fact that the cw discharge was breaking up the prociuct before it could effuse from the discharge region. In fact, Eujen and Lagow ${ }^{19}$ have shown that $\mathrm{CF}_{3} \mathrm{I}$ is readily broken up into $\mathrm{CF}_{3}$ and I with $\mathrm{rf}$ discharges. In order to circumvent this problem, a technique involving short, relatively high peak power, rf pulses was utilized. The technique allows selective bond breakage in $\mathrm{C}_{2} \mathrm{~F}_{6}$ to produce $\mathrm{CF}_{3}$ radicals. The pulses, however, are terminated before 
significant amounts of $\mathrm{CF}_{3} \mathrm{I}$ are formed. If the time interval between rf pulses is long enough so that the $\mathrm{CF}_{3} \mathrm{I}$ formed after each rf pulse can be removed from the discharge region of the flow system before application of the next $r f$ pulse, then the product can be acquired without fur ther breakup. Utilization of the pulsed $r f$ discharge technique has resulted in greatly improved regeneration efficiencies.

The effect of utilizing rf pulses of various time duration where the time between pulses is held at a constant $2 \mathrm{~ms}$ is shown in Fig. 31 The data shown in this figure represent a plot of the absorbed rf energy within the discharge, in electron volts, required to form a $\mathrm{CF}_{3}$ I moiecule from $\mathrm{C}_{2} \mathrm{~F}_{6}$ and $\mathrm{I}_{2}$ as a function of $\mathrm{rf}$ pulse width. The flow conditions for the data shown are such that about 390 tor $\mathrm{cm}^{3} \mathrm{sec}^{-1}$ of $\mathrm{C}_{2} \mathrm{~F}_{6}+\mathrm{I}_{2}$ was flowing through the discharge tube and the gas pressure at the discharge was 1.2 torr with the iodine content baving a mole fraction of about 0.1. The results were not strongly sensitive to the $\mathrm{I}_{2}$ partial pressure so long as excess $I_{2}$ was present in the flow as a lower limit. Concerning an upper linit, best results were obtained if no more than about three times the actual amount of $\mathrm{I}_{2}$ consumed by the chemical reaction was present in the flow. Examination of the data shown in Fig. 31 reveals that the use of $\mathrm{rf}$ pulses as short as $20 \mu \mathrm{s}$ allows generation of $\mathrm{CF}_{3} \mathrm{I}$ with only about $15 \%$ of the energy required when the discharge is operated in the $\mathrm{CW}$ mode. The data obtained as shown in Fig. 31 were found to be essentially independent of the $r f$ average power used over a wide range in power so long as the peak power level was kept low enough that good if coupling of the power supply to the discharge tube could be maintained. For a gas pressure of 1.2 torr, peak $r f$ power levels of $5 \mathrm{~W}$ to $20 \mathrm{~W}$ were utilized. For the cw measurements, average power levels of $2 \mathrm{~W}$ to $4 \mathrm{~W}$ were used and the absclute product yields obtained were in the same range as those obtained for the case where pulsed rf discharges were used.

The minimum energy required for chemical regeneration, $5.8 \mathrm{eV}$ per $\mathrm{CF}_{3} \mathrm{I}$ molecule, was obtained for the case where $20-\mu$ sf pulses were used as shown in Fig. 31. By use of
Eq (6), a value for the figure of merit, $\eta_{\mathbf{R}}$, for chemical regeneration of $\mathrm{CF}_{3} \mathrm{I}$ from $\mathrm{C}_{2} \mathrm{~F}_{6}$ and $\mathrm{I}_{2}$ can be obtained. In the present, case, a value for the quantity $\eta_{S} \varphi$ of 0.4 is used. A value for $M$ of 0.96 is used and is appropriate for the case where a laser photolytic pump pulse width of $1 \mu \mathrm{s}$ is utilized. 15 With the above mentioned values, Eq (6) yields a value of $\eta_{R}=0.068$.

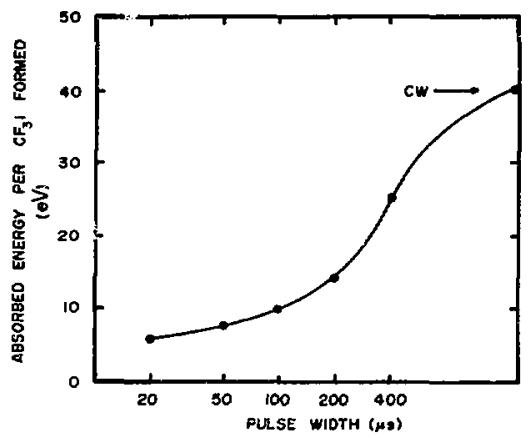

Fig. 31. The rf energy absorbed in the discharge in producing a $\mathrm{CF}_{3} \mathrm{I}$ molecule, as a function of $\mathbf{r} f$ puise width. The data apply for the case where the $r f$ puises occur every $2 \mathrm{~ms}$.

Studies concerning the possibie formation of side products using the pulsed $r f$ discharge technique have shown that two such products can form in the discharge along with the desired product, $\mathrm{CF}_{3} \mathrm{I}$. These products are $\mathrm{C}_{2} \mathrm{~F}_{4}$ and $\mathrm{C}_{2} \mathrm{~F}_{5} \mathrm{I}$. Both of these products exhibit relatively higher yields with respect to the $\mathrm{CF}_{3} \mathrm{I}$ yield as the average $\mathrm{rf}$ power level is increased. The effects of increasing the average rf power level upon the relative yields of $C_{2} F_{4}$ and $C_{2} F_{5} I$ are shown if $F$ igs. 32 and 33 , respectively. It is of interest to note that although the $\left[\mathrm{C}_{2} \mathrm{~F}_{4}\right] /\left[\mathrm{CF}_{3} \mathrm{I}\right]$ ratio is relatively low at the $1-W$ power level, decreasing the power to lower levels apparently would not allow this ratio to approach 7ero. Examination of data such as those presented in Fig. 33 reveals that urder conditions of the present experime: $t_{j}, C_{2} F_{5} I$ 


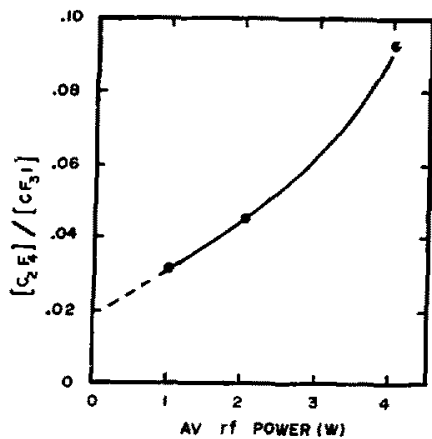

Fig. 32. The relative yield of $\mathrm{C}_{2} \mathrm{~F}_{4}$ with respect to $\mathrm{CF}_{3} \mathrm{l}$ as a function of average rf discharge power.

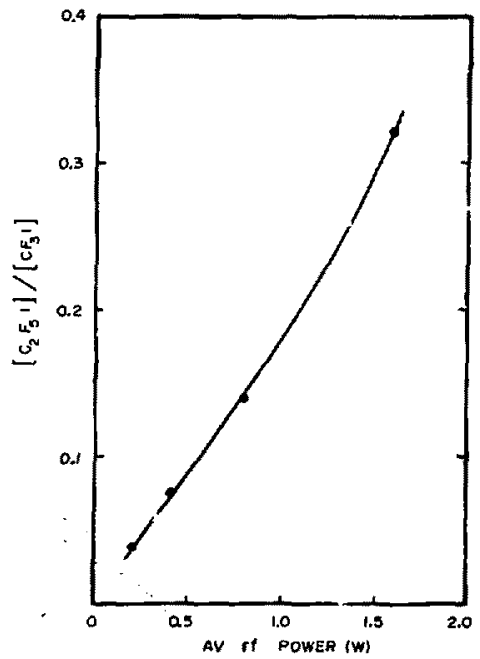

Fig. 33. The relative yield of $\mathrm{C}_{2} \mathrm{~F}_{5} \mathrm{I}$ with respect to $\mathrm{CF}_{3}{ }^{\mathrm{I}}$ as a function of average of discharge power. represents the major side product formed in the discharge for average power levels above about 0.25 W. For lower power levels and particularly under the conditions of short if pulse widths where efficiencies for the production of $\mathrm{CF}_{3} \mathrm{I}$ are highest, very low values for the $\left[\mathrm{C}_{2} \mathrm{~F}_{5} \mathrm{I}\right] /\left[\mathrm{CF}_{3} \mathrm{I}\right]$ ratio can be obtained.

Additional studies have been carried out concerning the regeneration of $R I$ from $R_{2}+I_{2}$ where $R_{2}$ is $n-C_{4} F_{10}$ or $n-C_{6} F_{14}$. These investigations have shown that nearly random $\mathrm{C}-\mathrm{C}$ bond breakage occurs when these molecules are passed through the discharge. Thus, there appears to be little selectivity in forming the desired RI compounds. The high-regeneration efficiency, $\eta_{R}=0.066$, and good selectivity achieved under optimum if discharge conditions for production of $\mathrm{CF}_{3}$ I from $\mathrm{C}_{2} \mathrm{~F}_{6}$ and $\mathrm{I}_{2}$ appear to make $\mathrm{CF}_{3} \mathrm{I}$ the best starting material for a photolytically pumped iodine laser.

The reslits obtained by using the rf regeneration technique are summarized in Fig. 34. Plotted is the chemical regeneration efficiency which can be projected for an iodine amplifier, utilizing $\mathrm{CF}_{3} \mathrm{I}$ as a function of

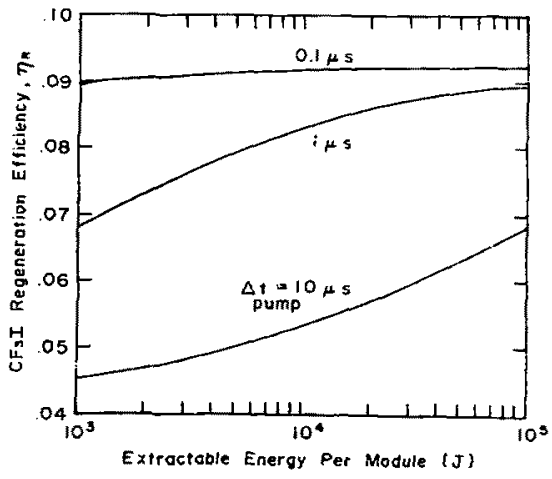

Fig. 34. Chemical regeneration figure of merit for an amplifier utilizing $\mathrm{CF}_{3} \mathrm{I}$, based on $\mathrm{rf}$ experimental results. 
extractable energy. $M$ is implicity dependent upon extractable energy through the scaling laws used to obtain operating conditions as a function of extractable energy per module, as detailed in Ref. 20 . The value of $\eta_{\mathrm{R}}$ depends on photolytic pump pulse width for the reason discussed in Ref. 15. From Fig. 34, it can easily be seen that, even for a pump pulse width of $10 \mu \mathrm{s}$, the projected chemical efficiency is much higher than the projected electrical efficiency for large modules. The information summarized in Fig. 34 indicates that the need for chemical regeneration will not be an important barrier to the economical operation of large atomic iodine laser systems.

\section{METAL-DOPED MICROSECOND XENON FLASHLAMPS}

The experimental investigation of $\mathrm{Te}$-doped xenon Flashlamps ${ }^{1}$ has essentially been completed. It is believed that the behavior of these lamps is now better understood, and that some of the controversy surrounding previous work has been cleared up.

The experimental setup described in Ref. 21 has been modified, and two new pulseforming networks have been used. The first consists of a $0.70-\mu \mathrm{F}$ storage capacitor, a $0.16-\mu \mathrm{H}$ total circuit inductance, a $10-\mathrm{cm}$ arc-length by $4-\mathrm{mm}$ bore flashlamp, and a Tachisto $30 \mathrm{t}$ spart gap. The current in this circuit is close to critically damped, and has a width (FWHM) of $-1 \mu \mathrm{s}$. The second consists of a $14.2-\mu \mathrm{F}$ storage caparitor, a $0.18-$ $\mu \mathrm{H}$ total circuit inductance, a $10-\mathrm{cm}$ arclength by $8-\mathrm{mm}$ bore flashlamp, and a Tachisto 101 spark gap. The current in this circuit is also close to critically damped, and has a width (FWHM) of $-5 \mu \mathrm{s}$. In both circuits, the width (FWHM) of the light :utput pulse is slightly shorter than that 0 : the current pulse.

\section{Experimental Resuits}

It was very difficult to obtain reproducible results from Te-doped flashlamps when the initial Te powder was vaporized by the main discharge itselis. Gusinow 22 observed that reliable results wore difficult to obtain in his experiments until phosphorus was introduced into his vacuum system for study as a copant. ILC reported that reproducible results with doped lamps were not obtainable in their experiment. ${ }^{23}$ Presumably, their vacuum system was quite clean. In the present experiment, the base pressure was $5 \times 10^{-7}$ torr (the system was not baked out due to the presence of teflon ferrules), and care was taken to avoid contamination by high-vapor pressure materials such as phosphorus. All this suggests that the good metal coatings obtained by Gusinow ${ }^{24}$ are probably somehow linked to the presence of phosphorus in his vaculim system.

Another approach was taken to produce good Te coatings. The simmer current used for the main discharge (which, by the way. enhancec the lamp efficiency considerably) was used to heat the lamp with the initial charge of powdered Te. P.s the lamp heated up, the Te would vaporize and coat the lamp inner wall. The proper choice of current and $X e$ back pressure for good coating was very unpredictable, and the whole process was essentially done by trial and error. However, once a good Te film was produced (as characterized by a shiny, opaque coating), quite reproducible experimental results were obtainable. The central $2 \mathrm{~cm}$ of the $10-\mathrm{cm}$ arc-length was then used for testing and the remaining area was masked off with black paper. All of the data discussed below were obtained in the above manner.

Figure 35 shows the spectral irradiance efficiency (defined as the spectral irradiance at $280 \pm 10 \mathrm{~nm}$ divided by the capacitor bank energy) for both doped and undoped lamps. The upper and lower dashed lines represent the values for $8-\mathrm{mm}$-bore and $4-\mathrm{mm}$-bore doped lamps, respectively. The spectral irradiance for doped lamps coated in the above described manner was practically Xe pressure independent. It is clear that the values for the doped lamps are close to the Xe high-pressure asymptotes. Most probubly the Te is vaporized and acts as a highdensity plasma and behaves like a highpressure lamp. This is supported by the observation (see below) that the spectrum from a doped lamp is mostly continuum and shows much less structure than an undoped 
lamp, which has several strong $\mathrm{Xe}$ and $\mathrm{Si}$ lines.

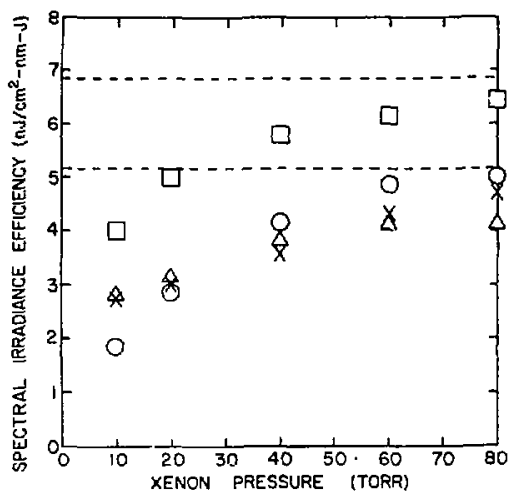

Fig. 35. Spectral irradiance efficiency of Xe flashlamps at $280 \pm 10 \mathrm{~nm}$ at a distance of $145 \mathrm{~cm}\left(19.6^{\circ}\right.$ from normal plane): $0--4-\mathrm{mm}$ bure, $0.70 \mu \mathrm{F}$, i0 $\mathrm{kV} ; \mathrm{X}--4-\mathrm{mm}$ bore, $0.70 \mu \mathrm{F}, 13.5 \mathrm{kV} ; \Delta-1-\mathrm{mm}$ bore, $0.70 \mu \mathrm{F}, 17 \mathrm{kV} ; \mathrm{D}-8-\mathrm{mm}$ bore, $14,2 \mu \mathrm{F}, 5 \mathrm{kV}$. The lower (upper; dashed line is the value for a Te-doped $4-\mathrm{mm}$ ( $8 \mathrm{~mm}$ ) bore flashlamp at all Xe pressures. All but the central $2 \mathrm{~cm}$ of the $10-\mathrm{cm}$ arc-length has been masked.

Figure 36 is a spectrum of a 20 -torr-Xe flashlamp. The vertical scale is film reflectance, but the film and complete spectrograph system hid n absolutely calibrated as a functio.: "wavelength in the region ranging from $250 \mathrm{~nm}$ to $300 \mathrm{~nm}$. Figure 37 is a spectrum of a 60 -tomr-Xe Tedoped lamp. Is noted above, a 20-torr-Xe Te-doped lamp has essentially the same spectrum, presumably because the Te plasma is opaque and blocks the Xe ernission, as weil as being the major source of radiation. It can be seen that, on the average, the spectral irradiance is enhanced appreciably in the region ranging from $250 \mathrm{~nm}$ to $300 \mathrm{~nm}$ by the addition of $\mathrm{Te}$ as compared to a
20-torr-Xe lamp. Ilowever, the enhancement is quite a bit less as compared to a lamp with 60 torr or more Xe.

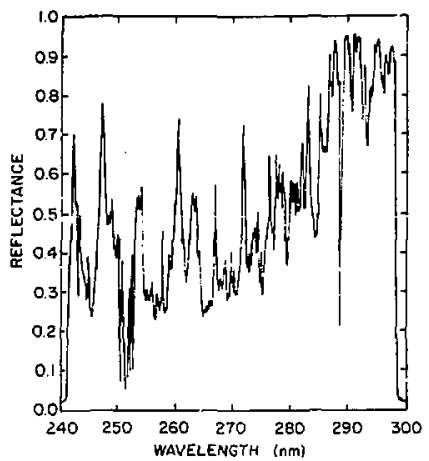

Fig. 36. Reflectance vs wavelength for 8-mm bore, 20-torr-Xe flashlamp. The charge voltage is $\overrightarrow{\mathrm{kV}}$ and the capacitance is $14.2 \mu \mathrm{F}$. The entrance slit width is $100 \mu \mathrm{m}$.

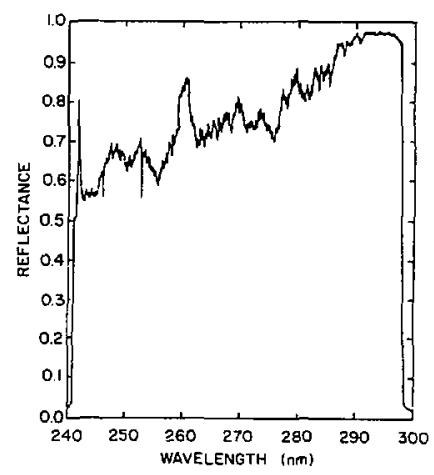

Fig. 37. Reflectance vs wavelength for 8-mm bore, 60-torr-Xe Te-doped flashlamp. The charge voltage is $5 \mathrm{kV}$ and the capacitance is $14.2 \mu \mathrm{F}$ The entrance slit width is $100 \mu \mathrm{r}$. 
Table II summarizes the determined spectral irradiance and net electrical efficiency of several indoped and doped lamps. The spectral irradiance is calculated for a distance of $145 \mathrm{~cm}$ normal to the lamp axis and at a wavelength of $280 \mathrm{~nm}$. The efficiency calculated is based on a tambertian spatial distribution and assumes a flat $400-\mathrm{nm}$ bandwidth. While it appears in Figs, 36 and 37 that the radiation intensity increases towards longer wavelengths, most of this is due to the increased efficiency of the spectrograph optical components, and the actual spectral irradiance is much flatter. The efficiencies; must be considered only as approximate, however, since they do not account for the rapidly varying structure in most of the spectra, especially those of the undoped lamps. By comparison, the more precise calculation of the efficiency of an $8-\mathrm{mm}$ bove 20 -torr-Xe undoped flashlamp lone in Ref. 25 is 0.045 for the same bandwidth and peak current density as the fourth entry in Table II. Reference 25 assumed that the radiation spatial distriburion was isotropic, because it was difficult to determine experimentally for the apparatus used. Ir the present experiment, the spatinl distribution wis measured up to 45 degrees from the normal to the lamp axis; a Lambertian distribution fit the data appreciably letter than an isotropic distribution. Given the experimental uncertainties $\left(\sim \pm 15^{\circ \%}\right.$ in the present experiment) the agreement is still reasonable, despite the different assumptions for the spatial distribution function.

TABLE II

Flashlamp Spectral Irradiances and Efficiencies

\begin{tabular}{|c|c|c|c|c|}
\hline $\begin{array}{c}\text { Lamp Size } \\
(\mathrm{cm})\end{array}$ & $\begin{array}{l}\text { Lamp } \\
\text { Fi11 }\end{array}$ & $\begin{array}{c}\text { Energy } \\
\langle\mathrm{J}\rangle \\
\end{array}$ & $\begin{array}{l}\text { Spcetral Irradiance } \\
\mathrm{J} / \mathrm{cm}^{2}-\mathrm{nm}\end{array}$ & Efficiency ${ }^{c, d}$ \\
\hline $10 \times 0.4$ & 20-torr Xe & 63.8 & $0.19,0.19$ & $0.024,0.024$ \\
\hline $10 \times 0.4$ & 60-torr Xe & 63.8 & $0.29,0.38$ & $0.038,0.036$ \\
\hline $10 \times 0.4$ & $\begin{array}{c}60 \text {-torr } \mathrm{Xe} \\
+\mathrm{Te}\end{array}$ & 63.8 & $0.35,0.32$ & $0.046,0.041$ \\
\hline $10 \times 0.8$ & 20-torr Xe & 177.5 & $0.94,1.0$ & $0.044,0.048$ \\
\hline $10 \times 0.8$ & 60-torr Xe & 177.5 & $1.2,1.3$ & $0.054,0.061$ \\
\hline $10 \times 0.8$ & $\begin{array}{l}\text { 60-torr Xe } \\
+\mathrm{Te}\end{array}$ & 177.5 & $1.3,1.4$ & $0.060,0.066$ \\
\hline
\end{tabular}

Arc-length $\mathrm{x}$ bore.

${ }^{b}$ Calculated for a wavelength of $280 \mathrm{~nm}$ and for a distance of $145 \mathrm{~cm}$ normal to lamp axis; first number is Irom photodiode, second is from ipectrograph.

${ }^{c} A$ flat $40-n m$ bandwidth and a Lambertian spatial distribution are assumed; first number is from photodiode, second is from spectrograph.

d The ratios of pholodiode results to spectrograph results for spectralirradiance compared to those for efficiency for a given lam, may differ slightly due to numerical roundoff. 
The results of the work on Te-doped-Xe flashlamps suggest that while metal additives clo enhance the near-uv output radiation the degree of enhancement is such that they do nct warrant further investigation at this ime with regard to application to the inertial confinement fusion program.

\section{KINETIC PROCESSES IN PHOTOLYTICALLY PRODUCED GROUP VI IS ATOMS}

\section{OVERVIEW}

The class of gas-laser systems based on the excitation of the $p^{4}{ }^{1} S$ state of Group VIA atoms (e.g., $O, S, S e, T e$ ) with energy extraction on the $p^{4}{ }^{1} S \rightarrow p^{4} 1_{D}$ or $p^{4} 1_{S} \rightarrow p^{4}$ $3 P$ transition is an extremely promising one for laser-fusion applications. Long energystorage times are possible since the $1_{S}$ state extibits a long radiative lifetime and is resistant to deactivation by a wide variety of other species. Also, these transitions occur at useful wavelengths $(459 \mathrm{~nm}$ to 790 $\mathrm{nm}$ ) and exhibit stimulated emission cross sections that are low enough to inhibit parasitic amplified spontaneous emission, but not so low that the medium cannot be saturated at reasonable energy fluences.

Previous work has shown that these excited atomic species can be produced with high quantum yield by the photodissociation of simple, triatomic molecules, e. g., $\mathrm{N}_{2} \mathrm{O}$, OCS, or OCSe. Those studies were performed with weak illumination which produced a small iractional photolysis of the triatomic and low excited ${ }^{2} S_{0}$ - atom densities. For these conditions, the quenching of 's atoms is dominated by two-body collisions with the part it triatomic and/or added diluents. High-i, tensity photolysis of OCS with 146-nm radiation and OCSe with $172-\mathrm{nm}$ radiation has produced $\mathrm{S}\left({ }^{1} \mathrm{~S}\right)$ and $\mathrm{Se}\left({ }^{{ }^{1}} \mathrm{~S}\right)$ densities ncar $10^{16} \mathrm{~cm}^{-3}$. However, rapid quenching of both $\mathrm{S}\left({ }^{\prime} S\right)$ and $\mathrm{Se}\left({ }^{1} \mathrm{~S}\right.$ ) has been observed for these conditions, and electrons, produced initially by photoionization of the excited atoms, have been inferred as the quenching agent, In the ren:ainder of this section, we tescribe the use of the $F_{2} *$ laser to photolytically produce high densities of
$S\left({ }^{1} S\right)$ atoms, our examinations of electron production and the photoionization cross section at $157 \mathrm{~nm}$ and the quenching kinetics of $S\left({ }^{1} S\right)$ atoms.

LASER PHOTOLYSIS OF OCS AT $157 \mathrm{~nm}$; $S\left({ }^{1} S\right)$ PRODUCTION, PHOTOIONIZATION, AND LOSS KINETICS

\section{soparatus}

The apparatus used for the present measurements is shown in Fig. 38. An electronbeam pumped molecular iluorine laser which we developed and have described in detail in previous reports ${ }^{1,5}$ is used as the photolysis source to dissociate $O C S$ to $S\left\langle{ }^{1} S\right\rangle$ at $157 \mathrm{~nm}$. This laser was vacuum-coupled to a separate cell which contained the OCS to be photolyzed. The laser output was apertured to illuminate uniformly a $1,8-\mathrm{cm}^{2}$ area of the OCS-containing cell. A cross-sectional view of this cell is shown in Fig. 39. The laser energy, which could be varied from $1 \mathrm{~mJ} /$ $\mathrm{cm}^{2}$ to $100 \mathrm{~mJ} / \mathrm{cm}^{2}$, was measured by a calibrated Scientech calorimeter mounted on the laser axis at the back of the cell. A 35$\mathrm{GHIz}, \mathrm{cw}$, microwave generator provided approximately $5 \mathrm{~mW}$ of power through a waveguide on one side of the cell to a detector mounted on the opposite side of the cell at right angles to the $\mathrm{F}_{2}{ }^{* \text { kt }}$ laser axis. Reentrant $\mathrm{MgF}_{2}$ wincows on the ceil along the microware axis confined the microwave to pass thr ough the laser-illuminated volume. The volume probed by the microwave was approximately $1.4 \mathrm{~cm}$ in diameter and $1 \mathrm{~cm}$ in length, centered $1.2 \mathrm{~cm}$ from the laser entrance window. An RCA 48362 Photomultiplier (PMT) was mounted at right angles to both the laser and microwave axis. Apertures in front of the PMT were used to confine its field of view to a small, nearly cylindrical volume, $0.5 \mathrm{~cm}$ in diameter by $1.5 \mathrm{~cm}$ in length, situated $0.7 \mathrm{~cm}$ from the $\mathrm{MgF}_{2}$ window through which the $\mathrm{F}_{2}$ laser entered the cell. Several different interference filters were placed in front of the photomultiplier to isolate radiation from the pressure-induced $S\left({ }^{1} S \rightarrow{ }^{1} D\right)$ transition near 7727. The photomultiplier was careiully shielded from $x$-ray and electromagnetic effects associated with firing the electron 
beam machine. The effectiveness of this shield was determined by measuring the dynamic response of PMT to a pulsed light source with and without firing the electron beam machine. The responses of the various PMT/filter combinations were calibrated against the output of a $250-W$ quartz-iodine standard lamp, which had been calibrated ivy the Epply Fesearch. Laboratories.

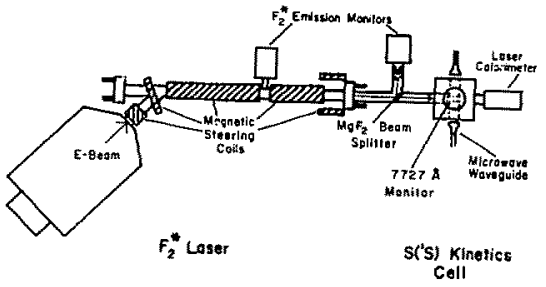

Fig. 38. Schematic diagram of the apparatus for $F_{2}{ }^{*}$ laser pumping of $\mathrm{S}^{1} \mathrm{~S}$ ).

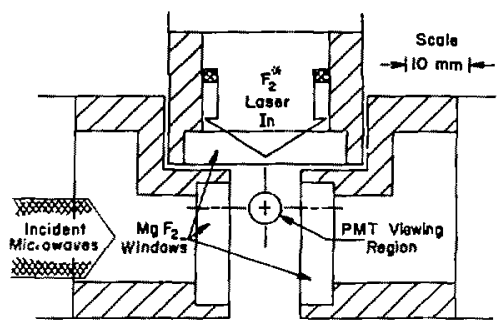

Fig. 39. Scale drawing of the interior of the OCS containing cell.

We obtained the emissicn spectrum of laserirradiated mixtures of OCS and added diluconts by replacing the microwave detector with a 1/4-m Jarrell Ash spectrometer/PMT combination and recording the intensity of emitted light as a function of wavelength for many sequential shots. This relative spectral sensitivity of this system was determined by measuring its response to the same standard lamps noted above.

\section{Results and Discussion}

In the first part of this section we present our data on electron densities vs time in 157-nm photolyzed mixtures of OCS, and OCS with various diluents, demonstrating the manner in which the electron quenching problem can be overcome. As a result of these measuremsnts, we are able to infer an experimental value for the photoionization cross section of $S\left({ }^{1} S\right)$ by 157-nm light. In the second part of this section, we present our results for time histories of the formation and decay of $S\left({ }^{1} S\right)$ concentrations in photolyzed mixture during and after the 157nm photolysis pulse. These data, combined with the electron density measurements, allow us to construct a simple kinetic model of the production and quenching of $S\left({ }^{1} S\right)$ in these mixtures. In the final part of this section, we present our value for the quantum yield of $S\left({ }^{l} S\right)$ by $157-\mathrm{nm}$ phctons on OCS and, as a necessary adjunct to these mezsurements, our data on the pressureinduced spectrum of $S\left({ }^{1} S\right)$ in $N_{2}$ and $\mathrm{Kr}$ diluents.

The output of the $F_{2}$ laser consists of three narrow lines at $157.6 \mathrm{~nm}, 157.5 \mathrm{~nm}$, and $156.7 \mathrm{~nm}$, each containing approximately one-third the total energy in a pulse width of about 80 ns. The effective absorption cross section of OCS for the laser radiation was measured by fitting data on low-intensity laser $t$ ansmission vs OCS pressure to a Beer's law plot and found to be $7 \pm 0,5 \times 10^{-17}$ $\mathrm{cm}^{2}$, in good agreement with the literature value. ${ }^{26}$ This value of the cross section implies an energy saturation fluence for the dissociating transition of about $18 \mathrm{~mJ} / \mathrm{cm}^{2}$. The transmission of the microwave power through the OCS cell depends parametrically on several variables, including the electron density $\mathrm{N}_{e}$ and the effective electron collision frequency $\nu$. For an idealized slab plasma with sharp boundaries in which coherence effects are ignored, the expected power transmission is given by

$$
T=\frac{(1-r)^{2} \exp (-2 \alpha d)}{1-r^{2} \exp (-4 \alpha d)}
$$


where

$$
\begin{aligned}
& r=\frac{(1-\mu)^{2}+x^{2}}{(1+\mu)^{2}+x^{2}} \\
& \mu^{2}=\frac{1}{2}(1-\mathrm{A})+\frac{1}{2}\left[(1-\mathrm{A})^{2}+\left(\frac{\nu \mathrm{A}}{\omega}\right)^{2}\right]^{1 / 2} \\
& x^{2}=-\frac{1}{2}(1-\mathrm{A})+\frac{1}{2}\left[(1-\mathrm{A})^{2}+\left(\frac{\nu \mathrm{A}}{\omega}\right)^{2}\right]^{1 / 2} \\
& A=\frac{(\mathrm{N} / \mathrm{N})}{1+(\nu / \omega)^{2}}
\end{aligned}
$$

and

$$
\alpha=\chi \omega ! \mathrm{c} .
$$

The quantity $d$ is the slab thickness, $\omega$ is the micro.vave frequency, and $\mathrm{N}_{c}$ is the electron density for which the electron plasma frequency equals the incident microwave frequency. For the present case,

$$
N_{c}=1.5 \times 10^{13} \mathrm{~cm}^{-3} .
$$

Equation (7) shows that if the electron collision frequency is small cornored to the microwave frequency, the plasma will be opanue for electron df..ısities $N \geq N_{c}$. However, the addition of diluents, as was done for the present study, insures tirat the electron collision frequency is of the same order as $\omega$. For those conditions, the plasma is expected to be partially transmitting even for $\mathrm{N}$ considerably greater than $\mathrm{N}_{\mathrm{c}}$.

Several examples of the measured microwave transmission ys time are shown in Fig. 40. In each case, the particular gas sample was irradiated with an $80-\mathrm{ns} 60-\mathrm{mJ} /$ $\mathrm{cm}^{2}$ pulse of $157-\mathrm{nm}$ laser light. This intensity is sufficient to bleach more than $90 \%$ of the initial OCS in the volume probed by the microwaves. It is evident that electron densities greater than $10^{13} \mathrm{~cm}^{-3}$ are produced by the photolysis and that the electrons persist for a time that depends on the added diluent.
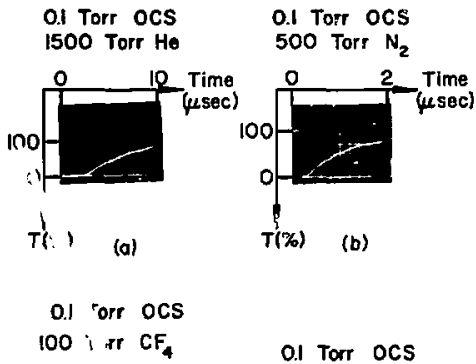

\subsection{Torr OCS}

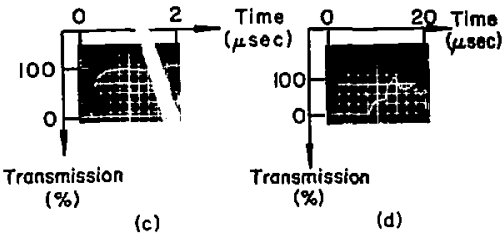

Fig. 40. Microwave transmission vs time following the $F_{2}$ iaser pulse for several mixtures. Incident laser energy was $60 \mathrm{~mJ} / \mathrm{cm}^{2}$ in all cases.

With added diluents such as helium (case (a) in Fig. 40) or nitrogen (case (b) in Fig. 40), the electron density reaches a maximum at the end of the photolysis pulse and decreases slowly thereafter. If an electror attaching gas much as $\mathrm{CF}_{4}$ (case (c)) or $\mathrm{SF}_{6}$ is used as a diluent, the microwave transmission, and, therefore, the electron density, tracks the incident laser pulse. This behavior is consistent with the supposition that photoionization of $\mathrm{S}\left({ }^{1} \mathrm{~S}\right)$ is the primary source of electrons. If no diluent is added to the OCS, the microwave transmission exhibits the erratic behavior of case (d) in which high-electron densities persist for relatively long times. With the aid of $\mathrm{Eq}(7)$, data such as those in Fig. 40 (a) or (b) can be unfolded to infer an 
electron density vs time behavior. Such inferences are most meaningful for cases in which several hundred torr of a molecular gas such as $\mathrm{N}_{2}$ is added to relatively low OCS concentrations and for times following the end of the incident laser pulse. $A N_{2}$ buffer insures rapid cooling of the initially produced $0.26-\mathrm{eV}$ photoelectrons, and the electron collision frequency with $\mathrm{N}_{2}$ is well known, With added nitrogen, the electron density derived via Eq (7) from the measured microwave transmissions exhibits a time dependence, following the laser pulse, of the form

$$
\frac{1}{N_{e}}=\frac{1}{N_{o}}+\beta t
$$

that is characteristic of simple electron-ion recombination. The constant $\beta$ depends on the pressure of added nitrogen, increasing by about an order of magnitude as $\mathrm{X}_{2}$ pressure increases from 259 torr to 1500 torr. The value of $\mathrm{N}_{O}$, the electron density remaining at the end of the laser pulse, is proportional to the incident laser fux. For case (b) of Fig. 40 the peak electron density is calculated to be about $2 \times 10^{13} \mathrm{~cm}^{-3}$.

These data of microwave transmission through photolyzed mixtures of OCS and $\mathrm{N}_{2}$ can also be used to estimate the value of the photolonization cross section of $S\left({ }^{1} \mathrm{~S}\right)$ at 157 $\mathrm{nm}$. The analysis, which is complicated by the fact that the incident $157-\mathrm{nm}$ radiation írst produces $S\left({ }^{l} S\right)$ and then photoionizes it under conditions for which the dissociating transition is partially bleached, proceeds as follows.

Since the laser energy is much higher than the level required to bleach the medium, a first order estimate of the photoionization cross section can be obtained by assuming that all of the OCS has been converted to $S\left({ }^{1} \mathrm{~S}\right)$ at time zero and that all $60 \mathrm{~mJ} / \mathrm{cm}^{2}$ of the laser beam is available to photoionize the $S\left({ }^{1} s\right)$. The number of photoclectrons produced $\left(N_{e}\right)$ is then;

$$
N_{e}=N_{0}\left(1-e^{-\sigma_{i} I_{1}}\right.
$$

where

$$
\begin{aligned}
& N_{0}=\text { initial } s\left({ }^{l} S\right) \text { density } \\
& \sigma_{i}=\text { photoionization cross section } \\
& I=\text { laser fluence } / \mathrm{cm}^{2}
\end{aligned}
$$

This approximation yields a value of $1.2 \mathrm{x}$ $10^{-19} \mathrm{~cm}^{2}$ for the photoinization cross section.

$A$ more careful approach utilizes the radiative transport equation of the $157 \mathrm{~nm}$ laser light in the OCS medium

$$
\begin{aligned}
\frac{\partial I}{\partial x}(x, t) & +\frac{1}{c} \frac{\partial I}{\partial t}(x, t)= \\
& -\sigma_{d} I(x, t) P(x, t)-\frac{\partial \rho}{\partial t}(x, t)
\end{aligned}
$$

in which $I$ is the laser intensity, $\rho$ is the OCS density, and $\sigma_{d}$ is the cross section for dissociating OCS. We assume that photoionization has a negligible effect on the radiation transport, i.e., the photoionization cross section is assumed to be much smaller than $\sigma_{\mathrm{d}}$. (As shown below, this assumption is quite reasonable. I Equation (8) can be solved exactly to give

$$
\begin{aligned}
& I(x, t)=\frac{I_{0}(t-x / c) \exp \left[0_{d} \int_{-\infty}^{t-x / c} d u l_{o}(u)\right]}{L} \\
& \rho(x, t)=\frac{\rho_{o}(x) \exp \left[\sigma_{d} \int_{-\infty}^{x} d u \rho_{o}(u)\right]}{U}
\end{aligned}
$$




$$
\begin{aligned}
U & =\exp \left[\sigma_{d} \int_{-\infty}^{t-x / c} d u I_{o}(u)\right] \\
& +\exp \left[\sigma_{d} \int_{-\infty}^{x} d u \rho_{o}(u)\right]-1
\end{aligned}
$$

where $I_{0}$ is the input laser pulse intensity at $x=0$ and $\rho_{0}$ is the density distribution of OCS at $t=0$.

The ciensity of electrons $\mathrm{N}_{e}$ produced by photoionization of $S\left(^{1} S\right)$ is given by

$$
\begin{aligned}
\frac{\partial N e^{(x, t)}}{\partial t} & =\sigma_{i} I(x, t) \rho^{* t}(x, t) \\
& -[\text { electron lass rate] }
\end{aligned}
$$

where $\sigma_{\dot{1}}$ is the photoionization cross section and $p$ is the $S(I S)$ density. In terms of the OCS density,

$$
\rho^{*}(x, t)=\varphi\left[\rho_{0}(x)-\rho(x, t)\right]
$$

where $\varphi^{* *}$ is the quantum yield for $S\left({ }^{1} S\right)$ production. The reiationship between the electron density at any position $\mathrm{x}$ and the photoionization cross section is obtained by integrating $\mathrm{Eq}(9)$ in time.

Examination of Fig. 40 (b) shows the photoelectrons are produced on a time scale that is short compared to the electron-ion recombination time. Therefore, the maximum electron density occurs near the end of the laser pulse and is not reduced very much by recombination during the pulse. For this reason, we can neglect the electron-loss term in $\mathrm{Eq}(9)$, and obtain the maximum electron density ij integrating $\mathrm{Eq}(9)$ in time to the end of the laser pulse. The result is

$$
\begin{aligned}
N_{e}(x) & =\frac{\sigma_{i} \varphi \rho_{o}}{\sigma_{d}}\left\{\ln \left[V / \exp \left(\sigma_{d} \rho_{o} x\right)\right]\right. \\
& \left.+\left[1-\exp \left(\sigma_{d} E_{o} / h \nu\right)\right] / v\right) \\
V & =\exp \left(\sigma_{d} E_{o} / h \nu\right)+\exp \left(\sigma_{d} \rho_{o} x\right)-1
\end{aligned}
$$

where $I_{0}$ is the incident laser flux and $h \nu$ is the photon energy. In deriving $\mathrm{Eq}_{\mathrm{q}}(10)$, we assumed a temporally rectangular laser pulse and a uniform initial density of OCS. For an input fluence of $60 \mathrm{~mJ} / \mathrm{cm}^{2}$ and an OCS pressure of 0.1 torr, we infer a peak electron density of $2 \pm 1 \times 10^{13} \mathrm{~cm}^{-3}$ from our microwave transmission data at a variety of added $\mathrm{N}_{2}$ pressures between 250 torr and 1500 torr. The microwave probe is centered at $\mathrm{x}=1.2 \mathrm{~cm}$. As will be shown later, $\varphi^{-*}=$ 0.85 . Substitution of these values in $\mathrm{Eq}$. (10) implies a photolonization cross section of

$$
\sigma_{i} \approx 2.3 \times 10^{-19} \mathrm{~cm}^{2} .
$$

We believe this value, which represents an average over the three lines in the laser spectrum, to be accurate to within a factor of 2, based primarily on the uncertainty in the derived electron density.

There are no other experimental determinations of $\sigma_{i}$ and only two theoretical ones with which we can compare our result. McGure has performed calculations of the photoionization cross sections for the 15 states of all the Group VI atoms via excitation to autoionizing levels. Both configuration and spinorbit interaction were included, and the term eneryies were adjusted to agree with experimental values. Near $157 \mathrm{~nm}$, McGuire's calculated cross sections are sharply pcaked with a value of $4 \times 10^{-18} \mathrm{~cm}^{2}$ at $157.5 \mathrm{~nm}$, falling to $1.5 \times 10^{-18} \mathrm{~cm}^{2}$ at $157.6 \mathrm{~nm}$ and 
$<10^{-19} \mathrm{~cm}^{2}$ at $156.7 \mathrm{~nm}$. His predicted value, averaged over the three laser lines, is $1.8 \times 10^{-3} \mathrm{~cm}^{2}$, about an order of magnitude larger than our measured value.

A second major effort of the present experiment was to monitor the $\left.S{ }^{1} S\right\}$ density as a function of time during and after the photodissociating laser pulse in coincidence with the microwave transmission measurements. Radiation from the $S\left({ }^{1} S \rightarrow{ }^{1} D\right)$ transition near $773 \mathrm{~nm}$ was used as a direct indicator of the $S\left({ }^{l} S\right)$ density.

Figure 41 contains three examples of the various time dependent signals we observed during and immediately following the incident 157-nm laser pulse. The circles were obtained with a mixture of 1 -torr OCS and 1500 -torr $\mathrm{Kr}$ at a low incident fluence of $3.2 \mathrm{~mJ} / \mathrm{cm}^{2}$. No detectable electrons are produced in this use, and, indeed, $\mathrm{Eq}(10)$ predicts an $r_{e}=10^{10} \mathrm{~cm}^{-3}$. The $S(' S)$ density rises to a peak in about $100 \mathrm{~ns}$, which is consistent with the time scale for passage of the laser pulse through the region viewed by the photomultiplier. As the laser fluence is increased to the value for saturation and beyond, the $S\left({ }^{1} S\right)$ density rises to its peak value before the entire laser pulse passes through the viewing region, and significant numbers of photoelectrons are detected by the microwave probe. The signal denoted by $X ' s$ ic a mixture of 1-torr OCS and 1500-tor $\mathrm{N}_{2}$ irradiated with $45 \mathrm{~mJ} / \mathrm{cm}^{2}$ of $157-\mathrm{nm}$ radiation. The microwave transmission shows electron densities $>1.5 \times 10^{13} \mathrm{~cm}^{-3}$ (total absorption) persisting for about $150 \mathrm{~ns}$ following the start of the laser pulse. The PMT signal in Fig. 41 shows that consider able quenching of the $S\left({ }^{1} S\right)$ density occurred during that time of high-electron density and that the quenching rate decreases markedly at later times for which the microwave transmission indicated considerably fewer electrons $\left(=10^{12} \mathrm{~cm}^{-3}\right)$. The presumption is that the rapid quenching is due to electrons.

However, the rate constant for electron quenching of $S\left({ }^{1} S\right)$ is estimated to be about $10^{-8} \mathrm{~cm}^{3} \mathrm{~s}^{-1}$, which requires an electron density of wout $10^{15} \mathrm{~cm}^{-3}$ to account ior the quenching we observe. Equation (10) predicts electron densities from direct photojonization of only $5 \times 10^{13} \mathrm{em}^{-3}$. It may be that under these particular conditions, electron multiplication and loss of $\mathrm{S}\left({ }^{1} \mathrm{~S}\right)$ is occurring through superelastic heating of the electrons, and subsequent ionization of S(IS).

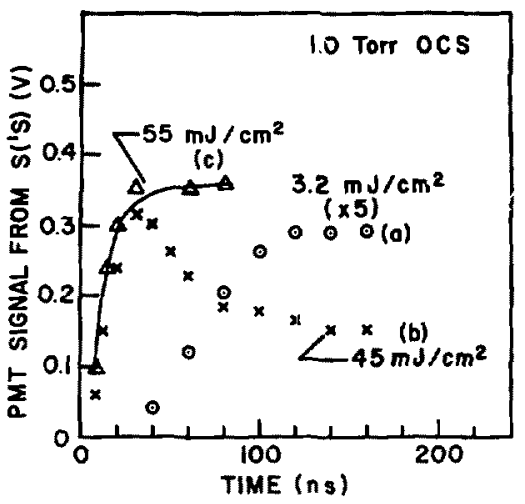

Fig. 41. Photomultiplier signal near $773 \mathrm{~nm}$ vs time following the start of the $\mathrm{F}_{2}^{*}$ laser pulse. The conditions are as follows: curve a: 1-torr OCS, 1500-torr $k r$ at an incident laser fluence of $3.2 \mathrm{~mJ} / \mathrm{cm}^{2}$; curve b: 1-torr OCS, 1500-torr $\mathrm{N}_{2}$ at $45 \mathrm{~mJ} / \mathrm{cm}^{2}$; curve $\mathrm{c}$ : 1 -torr OCS, 200-torr $C F_{4}, 1300$-torr $\mathrm{N}_{2}$ at $55 \mathrm{~mJ} / \mathrm{cm}^{2}$.

The final set of data in Fig. 41, the triangles, show the effect on the time dependence of the $S\left({ }^{l} S\right)$ density when a mixture of 1.0 -tort OCS, 200-torr $\mathrm{CF}_{4}$, and 1300-torr $\mathrm{N}_{2}$ is irradiated with $55 \mathrm{~mJ} / \mathrm{cm}^{2}$ of $157-\mathrm{nm}$ light. Again, the S( ${ }^{l} S$ ) density rises to its peak in a time that is short compared to the duration of the laser pulse. The expected rise time of the $\mathrm{S}\left({ }^{1} \mathrm{~S}\right)$ density is determined by the propagation of the bleaching wave through the region viewed by the PMT. From Eq (8), this rise time is given approximately by $t_{r}=$ $1 / \mathrm{I} \sigma_{\mathrm{d}}$ or $\approx 25 \mathrm{~ns}$ in the present case, which agrees quite well with the measured rise time of Fig. 41. The more significant feature of these data is that the addition of $\mathrm{CF}_{4}$ has eliminated the rapid quenching that is 
evident when $\mathrm{N}_{2}$ alone is used. The trangmitted microwave signal for this case appears very similar to that of Fig. $40 \mathrm{c}$; that is, electron densities $\geq 1.5 \times 10^{13} \mathrm{~cm}^{-3}$ are abserved only during the laser pulse with a rapid decrease to lower values at the termination of the pulse.

Figure 42 contains the late-time behavior of the $S\left({ }^{1} S\right)$ density for nearly the same ronditions depicted in Fig, 41, For low-incident laser fluence, the quenching of $S\left({ }^{1} S\right)$ is quite slow; curve (a) exhibits an electron-folding time of $9 \mu \mathrm{s}$.

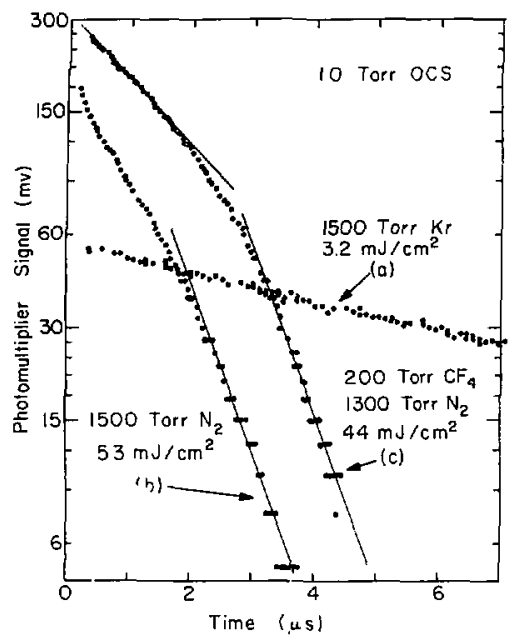

Fig. 42. Same as Fig. 41 except for the indicated incident fluences.

$\therefore \equiv$ t: $E$ incident fluence level is increased, $\therefore \leq 5, \mathrm{~S}\left({ }^{1} \mathrm{~S}\right)$ density increases as expected, $\because \therefore$ a guenching rate increases also. If $\because 3:$ : 3 ded to control the electron quenchTr $\because:-\cdots \in(c))$, then we observe an initial sis tow tollowed by a faster one at later inst. the stow decay $\therefore$. . ins same peak signal as is war the taken on the early time scale of Fig. 41. If the photoelectrons are not controlled, (curve (b)), the quenching of $S\left({ }^{1} S\right)$ is more rapid than case (c) during the early part of the decay, but the quenching rates for cases (b) and (c) are nearly the same at late times. .

A series of decay curves similar to case (c) above, in which electron quenching of the $S\left({ }^{1} S\right)$ is not important, were obtained at a variety of incident fluence levels and OCS densities. In each case, the curves were analyzed in terms of an early and late time decay frequency. Figure 43 contains a plot of these decay frequencies vs the amount of OCS dissociated by the incident $157-\mathrm{nm}$ laser pulse in the volume viewed by the photomultiplier. The initial $\left.\mathbf{S}^{1} \mathbf{S}\right)$ density is directly proportional to the amount of OCS photolyzed. Within the scatter in the data, both decay frequencies increase linearly with increasing photolysis, regardless of the initial OCS pressure or incident fluence level. That is, high-fluence shots into lowOCS concentrations and low-fluence shots into high-OCS concentrations which give the same photolyzed amount also exhibit the same early and late time decay frequencies. The observed linearity of the early-time decay frequency with increasing initial $S\left({ }^{1} S\right)$ density is evidence that self-quenching of $\mathrm{S}\left({ }^{\mathrm{I}} \mathrm{S}\right)$ is not important, at least for densities $\approx 3 \times 10^{16} \mathrm{~cm}^{-3}$.

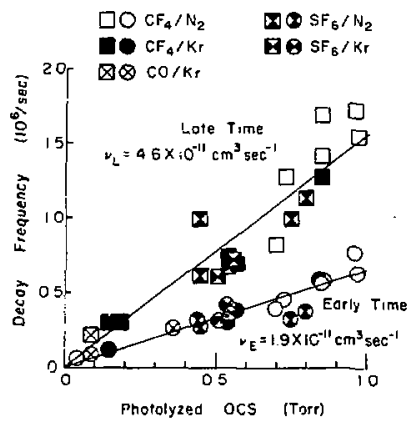

Fig. 43. Decay frequency of the $S\left({ }^{1} S\right)$ density $v s$ the fraction of OCS phototyped. 
The behavior of the $\mathrm{S}\left({ }^{1} \mathrm{~S}\right)$ densit $/$ with time exemplified by the data contained in Figs. 4 I and 42 can be explained with the aid of a simple kinetic model. For OCs dissociation by $157-\mathrm{nm}$ photons, there are three energetically allowed channels leading to different electronic states of the sulfur atom and a fourth channel leading to CS formation:

$$
\begin{aligned}
\mathrm{OCS}+\mathrm{hy}(157 \mathrm{~nm}) & \left.\stackrel{\varphi^{*}}{\longrightarrow} \mathrm{CO}+\mathrm{Si}^{1} \mathrm{~S}\right) \\
& \stackrel{\varphi_{\mathrm{d}}}{\longrightarrow} \mathrm{CO}+\mathrm{S}\left({ }^{1} \mathrm{D}\right) \\
& \left.\stackrel{\varphi_{\mathrm{p}}}{\longrightarrow} \mathrm{CO}+\mathrm{Si}^{3} \mathrm{P}\right) \\
& \stackrel{\varphi_{\mathrm{m}}}{\longrightarrow} \mathrm{CS}+\mathrm{O}\left({ }^{3} \mathrm{P}\right)
\end{aligned}
$$

Each channel is labr ?od with its respective quantum yield; the latier two dissociation channels are spin-forbidden.

Following the laser pulse, any or all of the above species, in addition to the parent compounà, added diluents, and electrons can possibly influence the quenching of $S\left({ }^{1} S\right)$. However, the data in Fig. 43 indicate that the major influence must be by species produced in direct proportion to the amount of OCS photolyzed, It any time following the laser pulse, when $\mathrm{CF}_{4}$ or $\mathrm{SF}_{6}$ is included as a diluent, deactivation by electrons does not appear to be imporiant, at least for incident fluence levels $\leq 100 \mathrm{~mJ} / \mathrm{cm}^{2}$ and $\mathrm{S}\left({ }^{1} \mathrm{~S}\right)$ densities $\leq 3 \times 10^{16} \mathrm{~cm}^{-3}$. Another potential quencher, $S\left({ }^{1} D\right)$, is itself deactivated to $S\left({ }^{3} P\right)$ by the added diluents so quickly under our conditions that it, too, can be neglected. The quenching of $\left.S^{1}{ }^{1} S\right)$ by $\mathrm{CO}$ has been measured previously and is negligibly small for the conditions of Fig. 43. The species that are most likely to be responsible for the observed decay rates are $S\left({ }^{3} P\right), C S$, and $\left.\mathrm{O}^{3} \mathrm{P}\right)$. The association rates for removing these atomic and radical species are too slow to appreciably affect their concentrations during the lifetime of $\mathbf{S}\left({ }^{1} S\right)$. Thus, at early times following the laser pulse, the $\left.S i^{1} S\right)$ decay frequency can be represented by

$$
v_{E}=\left[k_{p}\left(\varphi_{d}+\varphi_{p}\right)+\left(k_{m}+k_{m}^{\prime}\right) \varphi_{m}\right][\text { [OCS }
$$

where $f$ is the fraction of the initially present OCS, [OCS] $]_{0}$ dissociated, $k_{p}$ is the rate constant for $S\left({ }^{1} S\right)$ quenching by $S\left({ }^{3} \mathrm{P}\right)$, and $\mathrm{k}_{\mathrm{m}}$ and $\mathrm{k}_{\mathrm{m}}$ ' are the rate constants for deactivation by $C S$ and $O\left({ }^{3} \mathrm{P}\right)$, respectively. As time progresses, the $S(\mid \mathbf{S})$ is quenched to $S\left({ }^{3} \mathrm{P}\right)$, which in turn accelerates the quenching of $S\left({ }^{1} S\right)$, leading to the rollover in the measured decay curve. At late times, for which little $S\left({ }^{1} S\right)$ remains, the decay frequency is expected to reach a constant va. -e given by

$$
\nu_{\mathrm{L}}=\mathrm{k}_{\mathrm{p}} \varphi \mathrm{f}[\mathrm{OCS}]_{\mathrm{o}}+v_{\mathrm{E}}
$$

From the data in Fig. 43, we obtain directly that

$$
\varphi_{p}=2.7 \times 10^{-11} \mathrm{~cm}^{3} \mathrm{~s}^{-1}
$$

and

$$
\begin{aligned}
& \varphi_{\mathrm{m}}\left(\mathrm{k}_{\mathrm{m}}+\mathrm{k}_{\mathrm{m}}^{\prime}\right)= \\
& 1.9 \times 10^{-11}\left\{1-1.5 \frac{\left(\varphi_{\mathrm{d}}+\varphi_{\mathrm{p}}^{\prime}\right)}{\varphi}\right\} \mathrm{cm}^{3} \mathrm{~s}^{-1}
\end{aligned}
$$
From the quantum-yiets a to be presented
later, $\varphi^{*}-0.8$ so that

$$
\mathrm{k}_{\mathrm{p}}=3 \times 10^{-11} \mathrm{~cm}^{3} \mathrm{~s}^{-1}
$$

This value of the rate constant for $S\left({ }^{3} P\right)$ quenching of $S\left({ }^{1} S\right)$ can be compared to the analogous rate constant for $O\left({ }^{3} \mathrm{P}\right)$ quenching of $O\left(\mathrm{IS}_{\mathrm{S}}\right.$ measured by slanger and $\mathrm{Black}^{27}$ of $1.8 \times 10^{-11} \mathrm{~cm}^{3} \mathrm{~s}^{-1}$. 
Since $\varphi^{\text {kt }}$ is approximately 0.8 , then $\varphi_{\mathrm{m}}+$ $\left.\varphi_{\mathrm{d}}+\varphi_{\mathrm{p}}\right)=0.2$ and

$$
k_{m}+k_{m}^{\prime} \approx \frac{2 \times 10^{-11}}{\varphi_{m}} \mathrm{~cm}^{3} \mathrm{~s}^{-1} .
$$

If $\varphi_{m}$ were about 0.1 , then our present data would be consistent with $k_{m}+k_{m}=2 \times 1 \sigma^{10}$ $\mathrm{cm}^{3} \mathrm{~s}^{-1}$, a value that is not unreasonably large.

Curve (b) of Fig. 42 can also be interpreted in terms of this kinetic model. During very early times following the laser pulse $(100 \mathrm{~ns}$ to $200 \mathrm{~ns}$, the electrons quench approximately half of the $S\left({ }^{1} S\right)$ to $S\left({ }^{3} P\right)$ before they themselves are removed by recombination (see Fig. 4lb). Thus, the early decay shown in Fig. $42 \mathrm{~b}$ is faster than that of Fig. $4 \mathrm{lb}$ because of the added $S\left({ }^{3} P\right)$ density at early time. Both curves exhibit nearly the same late-time decay, as expected, since they correspond to nearly the same dissociation fraction of the initial OCS.

A final goal of the present study was to measure the effective quantum yield of $S\left({ }^{1} \mathrm{~S}\right)$ from OCS at $157 \mathrm{~nm}$ under a variety of conditions. For our experimental conditions, the effective quantum yield is given by the expression

$$
\varphi^{* *}=\frac{7.8 \times 10^{16} v_{\text {PMT }}}{R_{\text {PMT }} V \Omega A_{\text {eff }} \Gamma[D C S]}
$$

Where $\mathrm{V}_{\mathrm{PMT}}$ is the peak voltage attributed to $S\left({ }^{2} S \rightarrow\right.$ D) radiation, $R$ PMT is the calibrated response of the PMT at $\cdot 73 \mathrm{~nm}, V$ is the volume from which $S\left({ }^{1} S \rightarrow 1 D\right)$ radiation is detected, $\Omega$ is the solid angle subtended by the detection system, $A_{\text {eff }}$ is the effective pressure-induced spontaneous emission coefficient, and $\Gamma$ is the fraction of $S\left({ }^{1} S \rightarrow{ }^{1} D\right)$ radiation transmitted to the PMT by our optical filter arrangements.
The value of $\mathrm{A}_{\text {eff }}$ with a $\mathrm{N}_{2}$ diluent has been measured by previously. 28 By comparing the $S\left({ }^{1} S \rightarrow 1_{D}\right)$ emission intensity with added $\mathrm{CF}_{4}$ to that with pure $\mathrm{N}_{2}$, we determined that $A_{\text {eff for }} \mathrm{CF}_{4}$ is the same as that for $\mathrm{N}_{2}$, to within our experimental accuracy $( \pm 10 \%)$. Similarly, we determined that $\mathrm{CO}$ is 0.8 times as effective as $\mathrm{N}_{2}$ in pressure-inducing $1_{S} \rightarrow 1_{D}$ emission. The quantity $T$ is the overlap integral between our filters and the pressure-induced emission spectrum of $S(1 \mathrm{~S})$

$$
\Gamma=\frac{\int_{0}^{\infty} \epsilon(\lambda) T(\lambda) d \lambda}{\int_{0}^{\infty} \epsilon(\lambda) d \lambda}
$$

where $\epsilon(\lambda)$ is the pressure-induced ${ }^{1} S \rightarrow{ }^{1} \mathrm{D}$ emission intensity as a function of wavelength and $T(\lambda)$ is the transmission function of the particular optical filter arrangement. We determined $E(\lambda)$ for the case in which $\mathrm{CF}_{4}$ and $\mathrm{N}_{2}$ were edded as diluents. The reeulting emission spectrum is shown in Fig. 44. Figure 45 contains the emission spectrum if $\mathrm{Kr}$ is used as diluent in place of $\mathrm{N}_{2}$. We used three different optical filter combinations for $T(\lambda)$ which overlapped from 20 to $63 \%$ of the emission spectrum shown in Fig. 44.

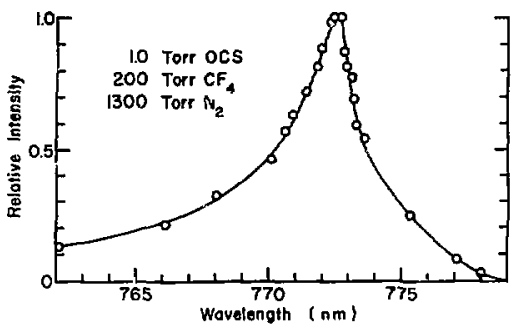

Fis, 44. Collision-induced emission near $773 \mathrm{~nm}$ from $\mathrm{S}\left(\mathrm{I}_{\mathrm{S}}\right) / \mathbb{N}_{2}$. 


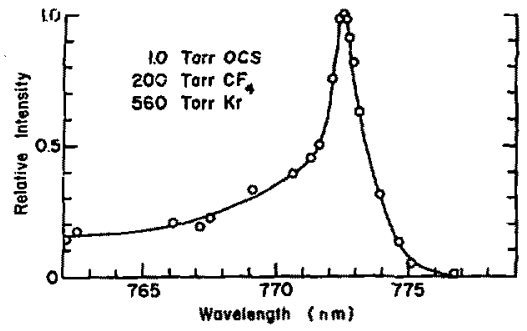

Fig. 45. Collision-induced emission near $773 \mathrm{~nm}$ from $\mathrm{S}\left({ }^{1} \mathrm{~S}\right) / \mathrm{Kr}$.

Table II contains the results of our deter mination of $\varphi^{*}$ for several different conditions of incident fluence and added diluents.
Within the scatter of these data, all of these various conditions exhibut the same high effective quantum yield. In addition, the average value is in good agreement with the value measured by Black, Sbarpless, and Slanger.

\section{Conclusions}

We have shown that $S\left({ }^{1} S\right)$ is produced with high efficiency by photolysis of OCS by $157-$ $\mathrm{nm}$ laser iight at laser intensities up to $0.1 .7 \mathrm{~cm}^{2}$ and $s\left({ }^{1} s\right)$ densities up to $-3 x$ $11^{16} \mathrm{~cm}^{-3}$. An experimental value for the photoionization cross section of $\mathrm{S}\left({ }^{1} \mathrm{~S}\right)$ by $157-\mathrm{nm}$ light of $2.3 \times 10^{-19} \mathrm{~cm}^{2}$ has been obtained. We have also shown that photoionization produced electrons and that eleciron runaway processes can be controlled by the addition of proper electron cooling

TABLF: III

Quantum Yields of $\left.\dot{j}^{1} \mathrm{~S}\right\rangle$ at $157 \mathrm{~nm}$

\begin{tabular}{|c|c|c|c|c|c|}
\hline $\begin{array}{c}\text { OCS } \\
\text { (torr) }\end{array}$ & $\begin{array}{c}N_{2} \\
\text { (torr) } \\
\end{array}$ & $\begin{array}{r}\text { Add } \\
\quad(\mathrm{t} \\
\end{array}$ & $\begin{array}{c}\text { Cas } \\
\text { Cr) } \\
\end{array}$ & $\begin{array}{l}E_{0} \\
\left(\mathrm{~mJ} / \mathrm{cm}^{2}\right) \\
\end{array}$ & $\theta^{*}$ \\
\hline 1.0 & 620 & 200 & $\mathrm{CF}_{4}$ & 32 & 0.85 \\
\hline 1.0 & 620 & 200 & $C F_{4}$ & 52 & 0.88 \\
\hline 1.0 & 1340 & 200 & $\mathrm{CF}_{4}$ & 55 & 0.71 \\
\hline 1.0 & 620 & 400 & $\mathrm{CO}$ & 38 & 0.80 \\
\hline 1.0 & 620 & 400 & $\mathrm{CO}$ & 57 & 0.77 \\
\hline 1.0 & 1503 & & & 45 & 0.85 \\
\hline 1.0 & 980 & & & 36 & 0.94 \\
\hline 0.6 & 1500 & & & 3.2 & 0.71 \\
\hline 0.5 & 760 & & & 35 & 0.90 \\
\hline 0.5 & 760 & & & 95 & 0.88 \\
\hline 0.5 & 760 & & & 106 & 0.89 \\
\hline
\end{tabular}

Note: Average $\varphi^{* / *}=0,83 \pm 0.08$ 
$\left(\mathrm{N}_{2}, \mathrm{CO}\right)$ and electron attaching $\left(\mathrm{CF}_{4}, \mathrm{SF}_{6}\right)$ diluents. We have examined the kinetics of quenching of the $S\left({ }^{1} S\right)$ populations in cases in which quenching by electrons is not important. Finally, we have demonstrated that $S$ (IS) densities of $\sim 3 \times 10^{16} \mathrm{~cm}^{-3}$ can be efficiently produced and stored for times on the order of a microsecond. These production efficiencies and storage times are consistent with the possible use of the $S\left({ }^{1} S\right) \rightarrow$ $S\left({ }^{1} D\right)$ transition as an efficient, high-energy storage.

\section{$\mathrm{Xe}_{2}$ DRTVER FOR $\mathrm{Se}^{\left({ }^{1} \mathrm{~S}\right)}$ KINETICS STUDIES}

One area of recent interest in the Group VI program has been the development of small, short pulse (< $100 \mathrm{~ns}$ ) $\mathrm{Xe}_{2}$ driver for use in OCSe kinetics experiments. Currently, the $\mathrm{Xe}_{2}$ * driver is excited by a Febetron 705 pulser (1.7 MeV, $80 \mathrm{~ns},-300 \mathrm{~J})$ with the laser resonator contained in a "lambda geometry" cell. In order to work at the highXenon pressures $(3,000$ torr) necessary for efficient $\mathrm{Xe}_{2}$ " lasing, it was necessary to add a re-entrant window holder for the $75-\mu$ thick titanium electron beam foil (Fig. 46). The re-entrant window holder reduces the length of high-pressure gas traversed by the electron beam before reaching the gas in the resonator cavity from $10.5 \mathrm{~cm}$ to $2.5 \mathrm{~cm}$. Preliminary experiments with this apparatus have demonstrated that this system can generate $\mathrm{Xe}_{2}$ " laser pulses at $1720 \AA$ with pulsewidths on the order of $50 \mathrm{~ns}$ and energy densities of at least $30 \mathrm{~mJ} / \mathrm{cm}^{2}$. Further parameterization and optimization of the system are in progress.

\section{PHOTOIONIZATION OF THE GROUP VI $(n s)^{2}(n p)^{4}{ }^{1} S_{O}$ TERM VIA EXCITATION $J F$ AUTOIONIZING LEVELS}

At wavelengths of interest for photodissociating OCS and OCSe with near unity yield of $5\left({ }^{1} S_{O}\right)$ and $S e\left({ }^{1} s_{O}\right)$, the rross section for direct photoionization of the ${ }^{1} \mathrm{~S}_{\mathrm{O}}$ ierm is small ( $\leq 10^{-20} \mathrm{~cm}^{2}$ ). However, indirect photoionization (photoexcitation followed by autoionization) could be significant if the transitions are in the photodissociation purapband, if the linewidth were large, and if the

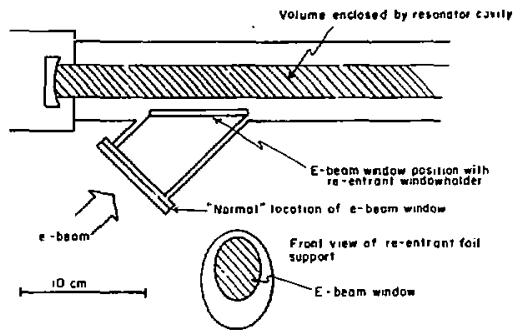

Fig. 46. $\mathrm{Xe}_{2}$; driver cell showing re-entrant electron-beam foil holder.

oscillator strength resulted in an effective photoionization cross section $>10^{-19} \mathrm{~cm}^{2}$. To examine this possibility we have diagonalized a $67 \times 67$ interaction matrix for 67 odd parity levels with $\mathrm{J}=1$. The matrix includes both configuration interaction and spin-orbit interaction. Details on the calculation of the matrix elements are given in the previous semiannual report. 1 The interaction matrix contains both bound and autoionizing levels, and, where possible, spectroscopic parameters are chosen to bring the calculated energy of bound state levels into agreement with experimental measurements. These spectroscopic parameters are used to locate alitoionizing levels.

In Tables IV, $\mathrm{V}$, and $\mathrm{VI}, \because \mathrm{c}$ list the energies of the various odd parity levels with $J=1$ for $\mathrm{S}, \mathrm{Se}$, and $\mathrm{Te}$. In these Tables, column 1 numbers the levels, roughly in order of increasing energy, measured in $\mathrm{cm}^{-1}$ relative to the ground state level of the ion; column 2 lists the designation of the levels in LS coupling; column $3\left(\mathrm{~K}_{\mathrm{i}}\right)$ lists the diagonal entry in the interaction matrix; and column $4\left(\mathrm{~K}_{\mathrm{f}}\right)$ lists the eigenvalue resulting from the matrix diagonalization (the shift between columns 3 and 4 is the result of configuration und spin-orbit interaction). Column 5 is the experimental energy level from Moore's tables. 29 For $S$ the entries in parentheses are measurements on autoionizing levels by $T$ ondello, 30 while for $T e$ the entries in parentheses are tentative identifications by Bartelt. 31 For $S$, column 6 lists 
the energy levels in a close-coupling calculation of Conneely, Smith, and Lipsky. 32 The remaining two columns list the calculated autoionizing level widths and oscillator strengths from (ns) ${ }^{2}(n p)^{4}{ }^{1} S_{O}$. For $S$, there ar: idditional columns listing level widths measured by Tondello 30 and calculated by Conneely, Smith, and I.ipsky. ${ }^{32}$

In Figs. 47,48 , and 49 the calculated indirect photoionization cross sections are shown for $\mathrm{S}, \mathrm{Se}$, and $\mathrm{Te}$, respectively. For $\mathrm{Te}$, the calculated cross section is large with few windows. For Se, the calculations indicate a window $\left(\sigma<1 \times 10^{-19} \mathrm{~cm}^{2}\right)$ at $1725 \AA$, where $X_{2}$ can be used as a photodissociation pump. For $S$, the calculations indicate a cross section of $10 \times 10^{-19} \mathrm{~cm}^{2}$ at $1575 \AA$ (the wavelength of the $F_{2}^{4:}$ laser) and $=6 \times 10^{-19} \mathrm{~cm}^{2}$ at $1460 \AA$ (the wavelength of the $\mathrm{K}_{2}$ laser. The dotted curve in Fig. 47 near $1460 \AA$ is the result of "fine tuning" (varying $\mathrm{K}_{\mathrm{i}}$ ) the calculation to reproduce Tondello's measurements.

The calculations are sensitive to the choice of $K_{i}$ values. The results reported here are semiempirical in that we have used spectroscopic parameters chosen to reprciduce the observed energies of bound levels. Currently, we are examining the possibility of ab initio calculations. They require the inclusion of additional configuration inter action effects from the (ns) $(n)^{4}\left(n^{+} p^{\prime}\right.$ configurations with $n^{\prime}>n$.

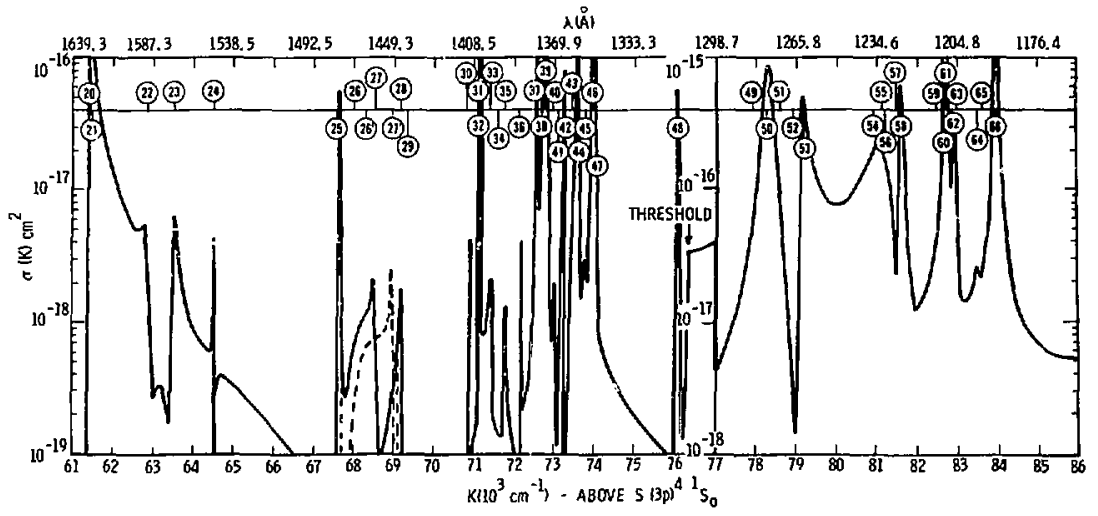

Fig. 47. The effective photoionization cross section of sulphur $(3 p)^{4}{ }^{1} S_{O}$ for $1640 \AA \leq \lambda \leq 1163 \AA$. The numbers in circles refer to the autoionizing levels in Table IV contributing to the cross section. The thrishold at $76270 \mathrm{~cm}^{-1}$ corresponds to $(3 p)^{3}{ }^{2} \mathrm{D}$ level of the ion. 


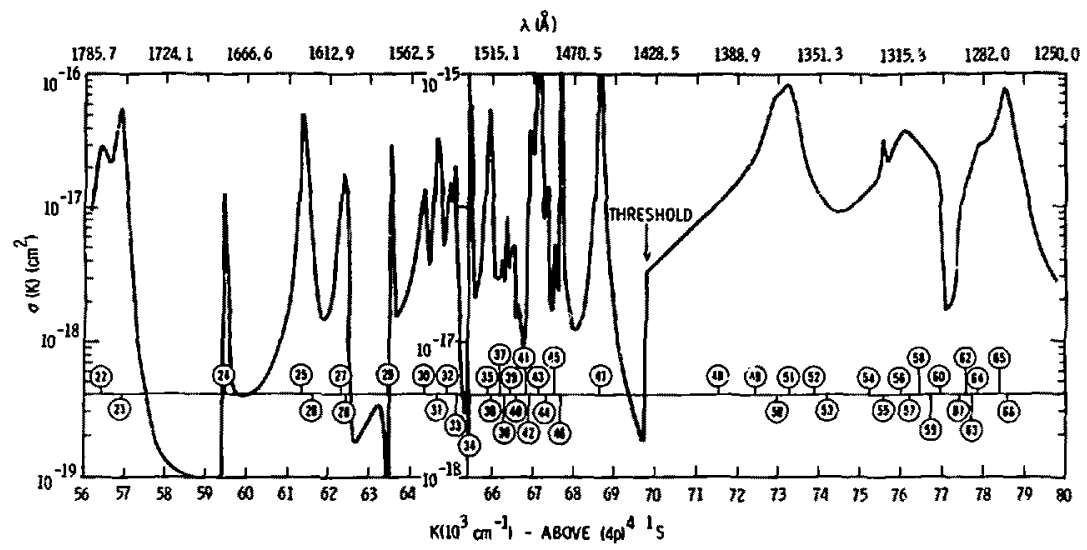

Fig. 48. The effective photoionization cross section of selenium $(4 p)^{4}{ }^{1} \mathrm{~S}_{\mathrm{O}}$ for $1785 \AA \leq \lambda \leq 1250 \AA$. The numbers in circles refer to the autoinnizing levels in Table $\mathrm{V}$ contributing to the cross section. The threshold at $69,750 \mathrm{~cm}^{-1}$ corresponas to the $(4 \mathrm{p})^{3}{ }^{2} \mathrm{D}$ level of the ion.

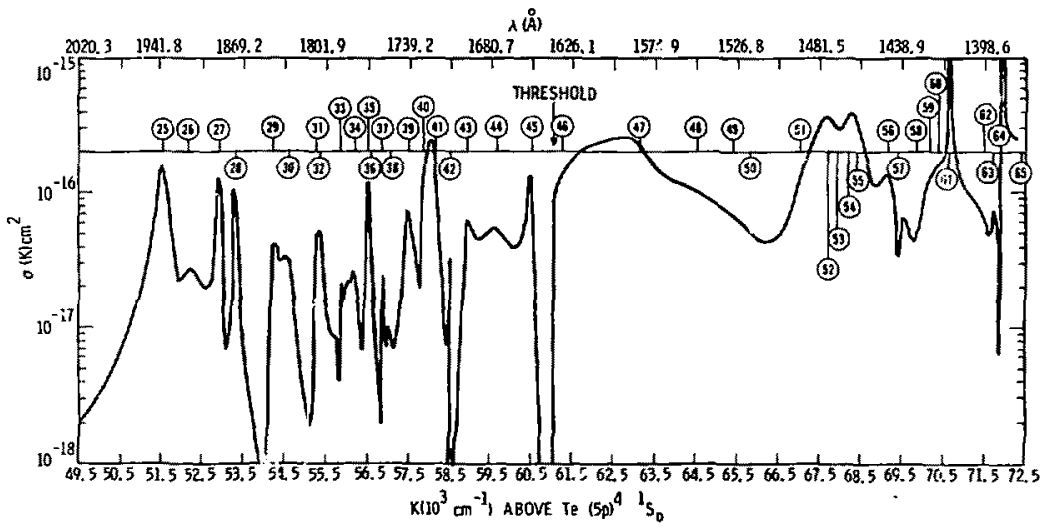

Fig. 49. The effective photoionization cross section of tell:urium $(5 p)^{4}{ }^{1} S_{O}$ for $2020 \AA \leq \lambda \leq 1383 \AA$. The numbers in circles refer to the autoionizing levels in Table VI contributing to the cross section. The threshold at $61050 \mathrm{~cm}^{-1}$ corresponds to the $(5 \mathrm{p})^{3}{ }^{2} \mathrm{p}$ level of the ion. 
TABLE IV

Energies, Levelwidths, and Oscillator Strengths from. $(3 p)^{4} 15$ in Sulphur for 67 Odd Parity Levels with $\mathrm{J}=1$ *

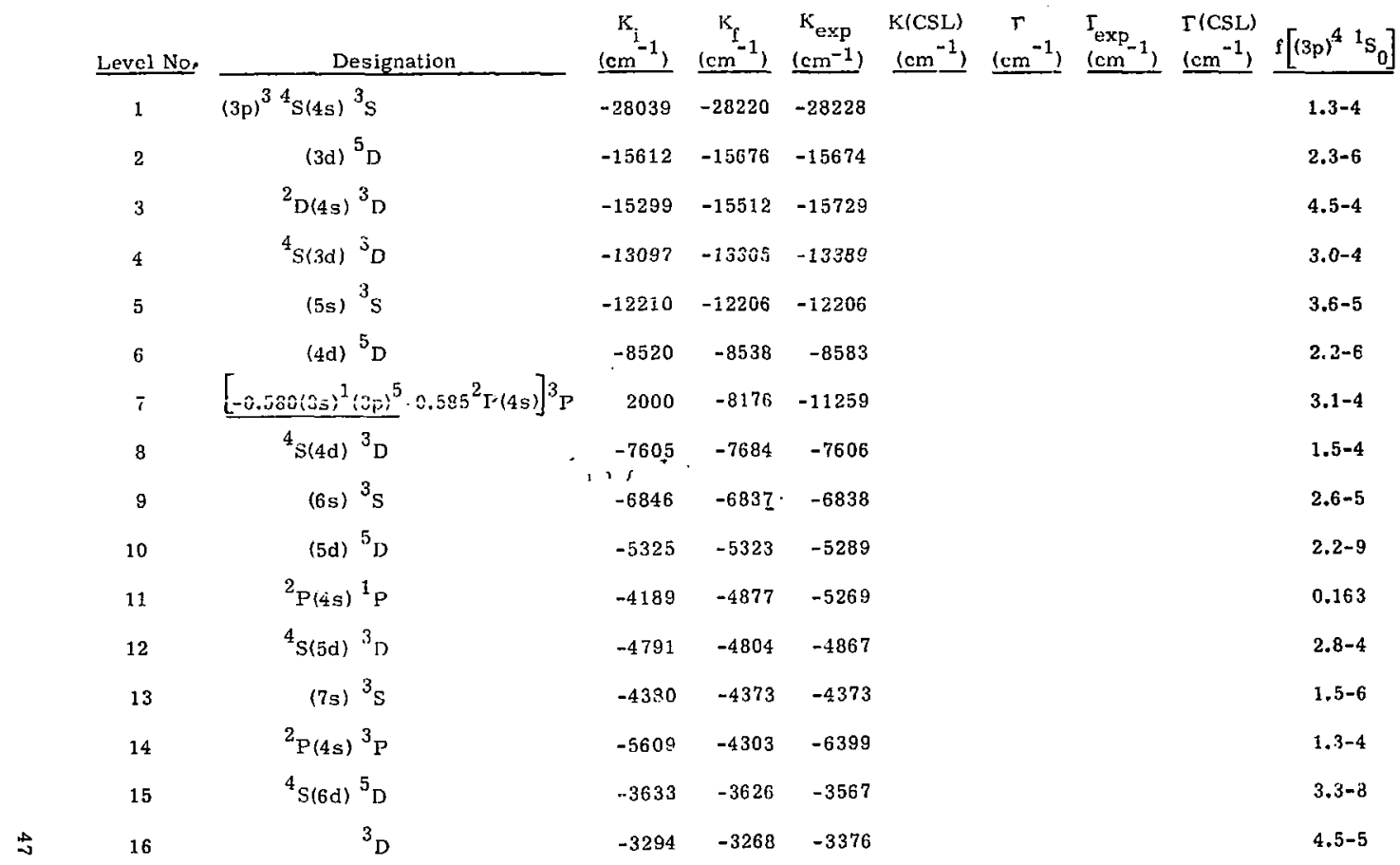




\begin{tabular}{|c|c|c|c|c|c|c|c|c|c|}
\hline Level No. & Designation & $\begin{array}{r}\mathrm{K}_{\mathrm{i}} \\
\left(\mathrm{cm}^{-1}\right) \\
\end{array}$ & $\begin{array}{r}\mathrm{K}_{\mathrm{I}} \\
\left(\mathrm{cm}^{-1}\right) \\
\end{array}$ & $\begin{array}{l}K_{\exp } \\
\left(\mathrm{cm}^{-1}\right) \\
\end{array}$ & $\begin{array}{l}\mathrm{K}(\mathrm{CSL}) \\
\left(\mathrm{cm}^{-1}\right) \\
\end{array}$ & $\begin{array}{c}\Gamma \\
\left(\mathrm{cm}^{-1}\right) \\
\end{array}$ & $\begin{array}{l}\Gamma_{\exp } \\
\left(\mathrm{cm}^{-1}\right) \\
\end{array}$ & $\begin{array}{l}\Gamma(\mathrm{CSL}) \\
\left(\mathrm{cm}^{-1}\right) \\
\end{array}$ & {$\left[(3 p)^{4}{ }^{1} s_{01}^{-}\right.$} \\
\hline 17 & $(8 \mathbf{s})^{3} s$ & -3046 & -3037 & -3037 & & & & & $9.8-7$ \\
\hline 18 & (7d) ${ }^{5} D$ & -2564 & -2551 & -2564 & & & & & $5.8-10$ \\
\hline 19 & ${ }^{3} \mathrm{D}$ & -2296 & -2179 & -2477 & & & & & $9.1-5$ \\
\hline 2 & ${ }^{2} \mathrm{D}(3 \mathrm{~d}){ }^{1} \mathrm{P}$ & 469 & 40 & & & 180 & & & 0.0151 \\
\hline 21 & $3_{D}$ & 96 & 106 & (123) & 1514 & 85.7 & B & 724 & 0.0057 \\
\hline 22 & $3_{5}$ & 1586 & 1500 & $(1872)$ & 2534 & 166 & 95 & 59 & $3.1-4$ \\
\hline 23 & $(5 s)^{3} \mathrm{D}$ & 2174 & 2149 & $(2121)$ & 2764 & 88.7 & 81 & 102 & $2.9-4$ \\
\hline 24 & $(3 \mathrm{~d})^{3} \mathrm{P}$ & 1004 & 3164 & (2927) & & 0.74 & N & & $1.0-4$ \\
\hline 25 & $(4 d)^{1} p$ & 6970 & 6282 & & & 0.61 & & & 0.0013 \\
\hline 26 & ${ }^{3} \mathrm{D}$ & 6654 & 6663 & $(6>3 y)$ & 7239 & 665 & B & & 2.3-4 \\
\hline 27 & ${ }^{3} \mathrm{~S}$ & 7195 & 7174 & (7628) & 7974 & 94.0 & 62 & 16 & $1.4-4$ \\
\hline 28 & $(6 s)^{3} \mathrm{D}$ & 7837 & 7802 & $(7822)$ & 8182 & 48.3 & 100 & 19 & $5.8-5$ \\
\hline 29 & (4d) ${ }^{3} \mathrm{p}$ & 6985 & 7978 & (7935) & & 0.014 & $\mathbf{N}$ & & $1.9-4$ \\
\hline 30 & $(5 d)^{1} p$ & 9801 & 9468 & & & 0.30 & & & $1.8-4$ \\
\hline 31 & ${ }^{3} \mathrm{D}$ & 9722 & 9720 & (10338) & 9838 & 435 & B & 123 & $8.2-5$ \\
\hline 32 & ${ }^{2} \mathrm{P}(3 \mathrm{~d}){ }^{3} \mathrm{p}$ & 9530 & 9760 & & & 1.33 & & & $2.5-4$ \\
\hline
\end{tabular}


TABLE IV

(cont)

Level No,

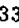

34

35

36

37

38

39

40

41

42

44

45

46

47

48

40

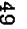

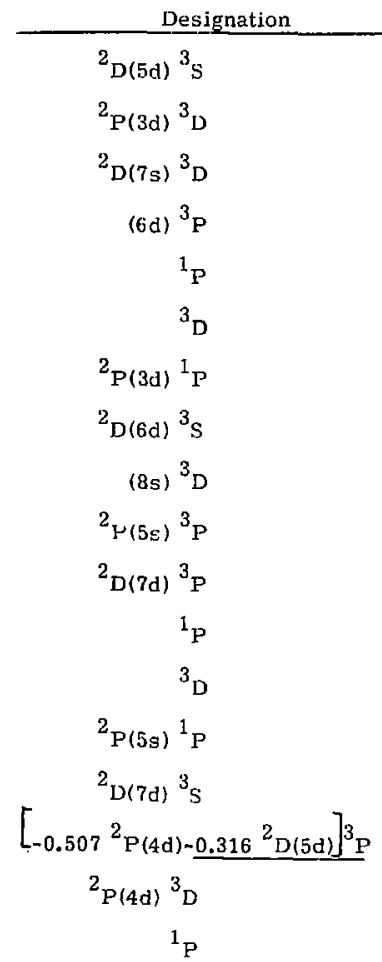

$\underline{\left.\left(\mathrm{cm}^{\mathrm{i}}\right)^{-1}\right)}$

10038

10159

10401

1147

$11400 \quad 11170$

$11349 \quad 11340$

$11765 \quad 11380$

$11550 \quad 11579$

$11779 \quad 1174$ ?

$11864 \quad 11891 \quad$ (11631)

$12491 \quad 12057 \quad$ (12082)

$12435 \quad 12206 \quad(12316)$

$12395 \quad 12385$

$12188 \quad 12558$

$12553 \quad 12649$

$9914 \quad 14649$

16480

16533

$17064 \quad 16909$

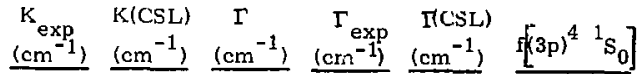

$\begin{array}{llll}10485 & 58.8 & 13 & 5.2-5\end{array}$

642 B $\quad 7.9 \sim 5$

$49.1 \quad$ B $\quad 33 \quad 7.1-5$

$1.11 \quad 4.8-5$

$\begin{array}{ll}0.47 & 0.0117\end{array}$

236

3.97

0.0037

0.144

$1.7-4$

$3.9-9$

$3.4-4$

$1.2-4$

0.0332

$4.8-4$

0.0889

0.0015

7.7-4

$1.6 \sim 5$

0.135 
(cont)

\begin{tabular}{|c|c|c|c|c|c|c|c|c|c|}
\hline Level No. & Designation & $\left(\mathrm{cm}^{-1}\right)$ & $\stackrel{\mathrm{K}_{\mathrm{f}}}{\left(\mathrm{cm}^{-1}\right)}$ & $\begin{array}{r}\mathrm{K}_{\exp } \\
\left(\mathrm{cm}^{-1}\right) \\
\end{array}$ & $\begin{array}{l}\mathrm{K}(\mathrm{CSL}) \\
\left(\mathrm{cm}^{-1}\right)\end{array}$ & $\begin{array}{c}\Gamma \\
\left(\mathrm{cm}^{-1}\right)\end{array}$ & $\begin{array}{l}\Gamma_{\exp } \\
\left(\mathrm{cm}^{-1}\right)\end{array}$ & $\begin{array}{r}\Gamma(\mathrm{CSL}) \\
\left(\mathrm{cm}^{-1}\right) \\
\end{array}$ & {$\left[\begin{array}{lll}3 p)^{4} & 1_{1}\end{array}\right]$} \\
\hline 51 & ${ }^{3} \mathrm{P}$ & 16251 & 17263 & & & 7707 & & & $5.4-4$ \\
\hline 52 & $(6 s)^{3} \mathrm{P}$ & 17257 & 17560 & $(17461)$ & 17747 & 551 & B & 800 & $5.4-4$ \\
\hline 53 & ${ }^{1} \mathrm{P}$ & 17652 & 17738 & & 17889 & 134 & & 30 & 0.0393 \\
\hline 54 & $(5 d)^{3} \mathrm{D}$ & 19491 & 19530 & (19587) & & 278 & B & & $5.7-5$ \\
\hline 55 & ${ }^{1} p$ & 19832 & 19773 & & & 628 & & & 0.0743 \\
\hline 56 & ${ }^{3} \mathrm{P}$ & 19358 & 19812 & & 19775 & 2117 & & 55 & 0.0125 \\
\hline 57 & $(7 s)^{3} p$ & 20091 & 20108 & $(20068)$ & 20203 & 51.5 & B & 47 & 0,0012 \\
\hline 58 & ${ }^{1} P$ & 20150 & 20216 & & 20269 & 77.6 & & 16 & 0.0225 \\
\hline 59 & $(6 d)^{3} \mathrm{D}$ & 21090 & 21123 & (21186) & & 192 & 79 & & $2.4-4$ \\
\hline 60 & ${ }^{3} \mathrm{p}$ & 21005 & 21291 & & 21289 & 1557 & & 44 & 0.0057 \\
\hline 61 & ${ }^{1} \mathrm{P}$ & 21307 & 21327 & & & 72.0 & & & 0.0587 \\
\hline 62 & $(8 s)^{3} \mathrm{P}$ & 21469 & 21482 & $\{21461\}$ & 21530 & 22.3 & B & 17 & 0.0025 \\
\hline 63 & ${ }^{1} \mathrm{P}$ & 21499 & 21564 & & 21464 & 62.5 & & 9 & 0.0193 \\
\hline 64 & $(7 \mathrm{~d})^{3} \mathrm{D}$ & 22125 & 22158 & (22116) & & 177 & 61 & & $2.6-4$ \\
\hline 65 & ${ }^{3} \mathrm{P}$ & 22058 & 22267 & & & 1262 & & & $3.8-5$ \\
\hline 66 & ${ }^{1} P$ & 22296 & 22594 & & & 25.8 & & & 0.233 \\
\hline 67 & $(3 s)^{1}(3 p)^{5} \quad{ }^{1} P$ & 55539 & 57905 & & & 104850 & & & 0.976 \\
\hline
\end{tabular}

The column entries are explained in the text. The notation $B$ and $N$ in column 8 are for broad and narrow levelwidths, respectively. 
Energies, Levelwidths, and Oscillator Strengths From $(4 \mathrm{p})^{4}{ }^{1} S_{0}$ in Se for 67 Odd Parity Levels with $J=1 *$

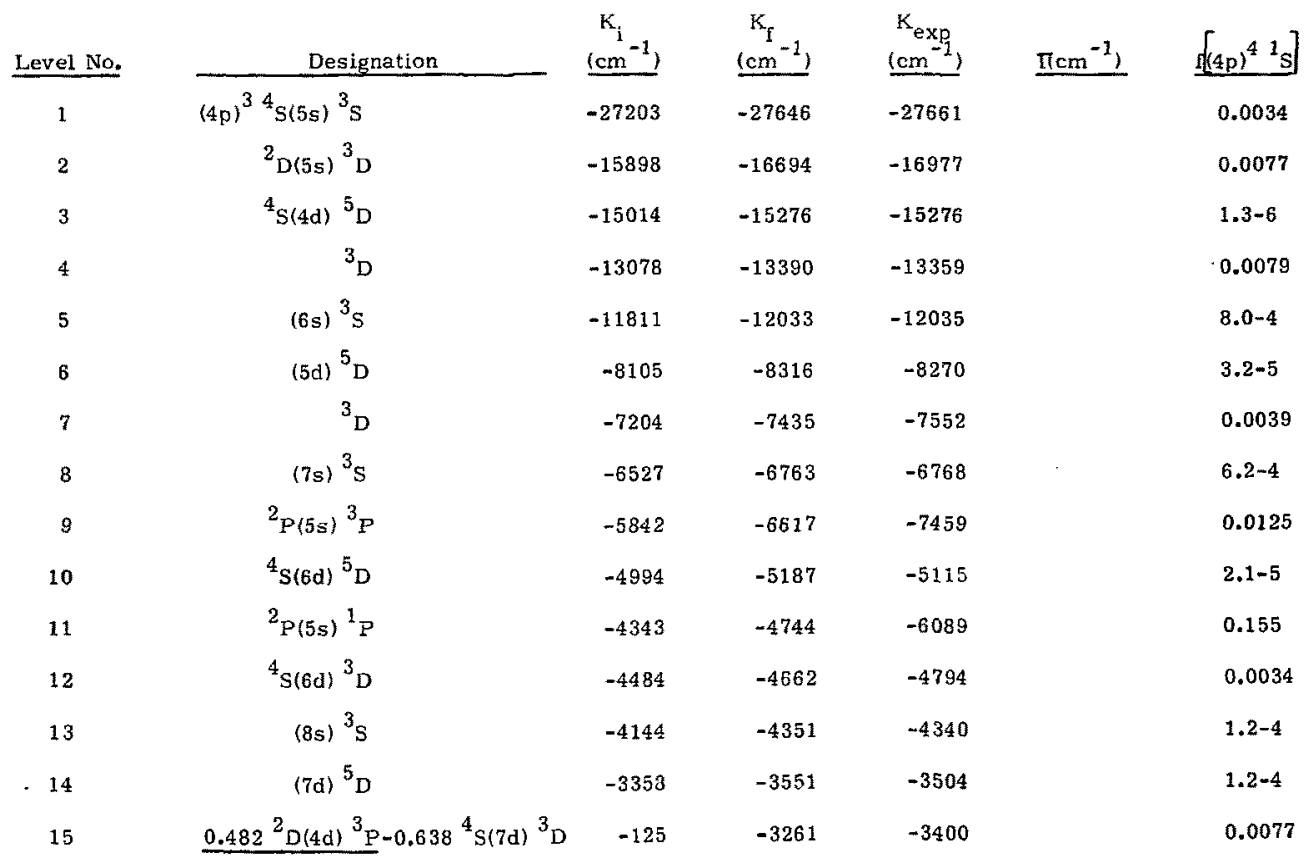


(cont)

\begin{tabular}{cc} 
Level No. & Designation \\
\cline { 2 - 2 } 16 & $0.423^{2} \mathrm{D}(4 \mathrm{~d}){ }^{3} \mathrm{P}+0.695{ }^{4} \mathrm{~S}(7 \mathrm{~d}){ }^{3} \mathrm{D}$ \\
17 & ${ }^{4} \mathrm{~S}(9 \mathrm{~s}){ }^{3} \mathrm{~S}$ \\
18 & $(8 \mathrm{~d})^{5} \mathrm{D}$ \\
19 & ${ }^{3} \mathrm{D}$ \\
20 & ${ }^{2} \mathrm{D}(4 \mathrm{~d})^{3} \mathrm{D}$ \\
21 & ${ }^{1} \mathrm{P}$ \\
22 & ${ }^{3} \mathrm{~S}$ \\
23 & $(6 \mathrm{~s}){ }^{3} \mathrm{D}$ \\
24 & ${ }^{2} \mathrm{D}[-0.469(4 \mathrm{~d})+0.695(5 \mathrm{~d})]^{3} \mathrm{P}$ \\
25 & ${ }^{2} \mathrm{D}(5 \mathrm{~d}){ }^{1} \mathrm{P}$ \\
26 & ${ }^{3} \mathrm{D}$ \\
27 & ${ }^{3} \mathrm{~S}$ \\
28 & $(7 \mathrm{~s}){ }^{3} \mathrm{D}$ \\
29 & ${ }^{2} \mathrm{D}[0.551(5 \mathrm{~d})-0.661(6 \mathrm{~d})]^{3} \mathrm{P}$ \\
30 & ${ }^{2} \mathrm{D}(6 \mathrm{~d})\left(-0.645^{3} \mathrm{D}-0.690{ }^{1} \mathrm{P}\right)$ \\
31 & ${ }^{2} \mathrm{D}(6 \mathrm{~d})\left(-0.701{ }^{3} \mathrm{D}+0.591{ }^{1} \mathrm{P}\right)$ \\
32 & ${ }^{2} \mathrm{D}(8 \mathrm{~s}){ }^{3} \mathrm{D}$ \\
33 & $(6 \mathrm{~d}){ }^{3} \mathrm{~S}$ \\
&
\end{tabular}

\begin{tabular}{|c|c|c|c|c|}
\hline $\begin{array}{r}\mathrm{K}_{\mathrm{i}} \\
\left(\mathrm{cm}^{-1}\right) \\
\end{array}$ & $\begin{array}{r}\mathrm{K}_{\mathrm{i}} \\
\left(\mathrm{cm}^{-1}\right)\end{array}$ & $\begin{array}{c}\mathrm{K}_{\mathrm{I}} \\
\left(\mathrm{cm}^{-1}\right)\end{array}$ & $\Gamma\left(\mathrm{cm}^{-1}\right)$ & 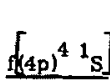 \\
\hline$-30 \div 9$ & -3165 & -3293 & & $8.8-4$ \\
\hline-2813 & -3017 & -3020 & & $1,9-4$ \\
\hline-2398 & -2587 & -2497 & & $1.7-6$ \\
\hline-2190 & -2290 & -2442 & & 0.0016 \\
\hline-819 & -1281 & & & 0.0149 \\
\hline-532 & -900 & & & 0.0327 \\
\hline 321 & 190 & & 341 & 0.0072 \\
\hline 1198 & 710 & & 175 & 0.0076 \\
\hline 6068 & 3228 & & 27.3 & $2.5-4$ \\
\hline 5880 & 5168 & & 126 & 0.0054 \\
\hline 5746 & 5418 & & 326 & 0.0012 \\
\hline 6274 & 6126 & & 176 & 0.0030 \\
\hline 6764 & 6233 & & 98.4 & 0.0016 \\
\hline 8908 & 7264 & & 8.62 & $3.4-4$ \\
\hline 8803 & 8162 & & 234 & $6.4-1$ \\
\hline 8727 & 8460 & & 134 & 0.0028 \\
\hline 9269 & 8727 & & 73.6 & 0.0011 \\
\hline 9026 & 8896 & & 97.0 & 0.0011 \\
\hline
\end{tabular}


TABLE V

(cont)

\begin{tabular}{|c|c|c|c|c|c|c|}
\hline Level No. & Designation & $\begin{array}{c}\mathrm{K}_{\mathrm{i}} \\
\left(\mathrm{cm}^{-1}\right)\end{array}$ & $\begin{array}{l}\mathrm{K}_{\mathrm{f}} \\
\left(\mathrm{cm}^{-1}\right)\end{array}$ & $\begin{array}{l}\mathrm{K}_{\exp _{1}}, \\
(\mathrm{~cm}) \\
\end{array}$ & $\Gamma\left(\mathrm{cm}^{-1}\right)$ & 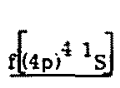 \\
\hline 34 & {$\left[0.494^{2} \mathrm{P}(4 \mathrm{~d})+0.57 \mathrm{i}^{2} \mathrm{D}(6 \mathrm{~d})\right]^{3} \mathrm{P}$} & 9040 & 9256 & & 10.2 & 0.0070 \\
\hline 35 & $-0.433^{2} P(4 d){ }^{3} \mathrm{P}^{3}+0.512^{2} \mathrm{D}(7 \mathrm{~d})^{1} \mathrm{P}$ & 10343 & 9704 & & 60.8 & 0.0149 \\
\hline 36 & ${ }^{2} D(7 d){ }^{3} D$ & 10297 & 9752 & & 309 & 0.0049 \\
\hline 37 & {$\left[0.528^{2} \mathrm{D}(9 \mathrm{~d})+0.551^{2} \mathrm{P}(4 \mathrm{~d})\right]^{3} \mathrm{D}$} & 9524 & 10028 & & 158 & 0.0010 \\
\hline 38 & ${ }^{2} \mathrm{D}(9 s)^{3} \mathrm{D}$ & 10630 & 10105 & & 2.69 & $4.3-4$ \\
\hline 39 & 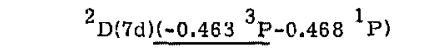 & 10407 & 10248 & & 298 & 0.0025 \\
\hline 40 & ${ }^{2} \mathrm{D}(7 d)^{3} \mathrm{~S}$ & 10478 & 10352 & & 43.1 & $3.5-4$ \\
\hline 41 & ${ }^{2} \mathrm{D}\left[-0.437(7 \mathrm{~d})^{3} \mathrm{~S}-0.652(8 \mathrm{~d})^{3} \mathrm{P}\right]$ & 11298 & 10668 & & 66.7 & 0.0095 \\
\hline 42 & ${ }^{2} D(8 d){ }^{3} D$ & 11224 & 10682 & & 79.5 & $3.0-4$ \\
\hline 43 & ${ }^{2} P(4 d){ }^{3} I^{2}$ & 10760 & 10939 & & 48.1 & 0.133 \\
\hline 44 & ${ }^{2} \mathrm{D}(8 \mathrm{~d})\left(0.4399^{3} \mathrm{P} \div \underline{\left.0.626{ }^{1} \mathrm{P}\right)}\right.$ & 11255 & 11147 & & 39.6 & 0.0045 \\
\hline 45 & ${ }^{2} D(8 d)^{3} S$ & 11345 & 11327 & & 102 & 0.0032 \\
\hline $4 \hat{\mathrm{o}}$ & ${ }^{2} P(6 s){ }^{3} P$ & 11254 & 11431 & & 7.69 & 0.0573 \\
\hline 47 & ${ }^{1} \mathrm{P}$ & 11617 & 12453 & & 41.1 & 0.127 \\
\hline 48 & {$\left[0.355(4 s)^{1}(4 p)^{5} \div 0.697^{2} P(5 d)\right]^{3} P$} & 15711 & 15322 & & 9959 & 0.0236 \\
\hline 49 & ${ }^{2} P(5 d){ }^{3} D$ & 15936 & 16258 & & 2179 & 0.0080 \\
\hline 50 & ${ }^{2}{ }_{\mathrm{P}}\left[-0.675(7 \mathrm{~s})^{3} \mathrm{P}-0.442(5 \mathrm{~d}){ }^{1} \mathrm{P}\right]$ & 16820 & 16777 & & 449 & 0.0188 \\
\hline
\end{tabular}


(cont)

\begin{tabular}{|c|c|}
\hline Level No. & Designation \\
\hline 51 & {$\left[\begin{array}{ll}2 & \left.P .571(7 s){ }^{3} \mathrm{P}-\underline{0.696(5 \mathrm{~d})}{ }^{1} \mathrm{P}\right]\end{array}\right.$} \\
\hline 52 & ${ }^{2} \mathrm{P}(7 \mathrm{~s}){ }^{1} \mathrm{P}$ \\
\hline 53 & {$\left[-0.375(4 s)^{1}(4 p)^{5}+0.5399^{2} P(5 d]^{3} F\right.$} \\
\hline 54 & ${ }^{2} P(6 d){ }^{3} D$ \\
\hline 55 & $(8 s)^{3} \mathrm{P}$ \\
\hline 56 & (6d) ${ }^{1} \mathrm{P}$ \\
\hline 57 & ${ }^{3} \mathrm{P}$ \\
\hline 58 & ${ }^{2} P(8 \mathrm{~s})\left(-0.445^{3} \mathrm{P}-\underline{\left.0.6799^{1} \mathrm{P}\right)}\right.$ \\
\hline 59 & ${ }^{2} \mathrm{P}(7 \mathrm{~d}){ }^{3} \mathrm{D}$ \\
\hline 60 & $(9 s){ }^{3} \mathrm{P}$ \\
\hline 61 & ${ }^{2} P(7 \mathrm{~d})\left(0.498{ }^{3} \mathrm{D}-\underline{\left.\underline{0.520}{ }^{1} P\right)}\right.$ \\
\hline 62 & ${ }^{2} \mathrm{P}\left[-0.381(9 \mathrm{~s}){ }^{1} \mathrm{P}-\underline{\left.0.696(7 \mathrm{~d}){ }^{3} \mathrm{P}\right]}\right.$ \\
\hline 63 & 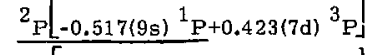 \\
\hline 64 & ${ }^{2} \mathrm{P}\left[0.477(9 \mathrm{~s}){ }^{1} \mathrm{P}+0.627(8 \mathrm{~d}){ }^{3} \mathrm{D}\right]$ \\
\hline 65 & ${ }^{2} \mathrm{P}(8 d){ }^{3} \mathrm{~F}$ \\
\hline 66 & ${ }^{1} P$ \\
\hline 67 & $(4 s)^{1}(4 p)^{51} P$ \\
\hline
\end{tabular}

\begin{tabular}{|c|c|c|c|c|}
\hline $\begin{array}{l}\left.\mathrm{K}_{\mathrm{i}}-1\right) \\
\left(\mathrm{cm}^{-1}\right)\end{array}$ & $\begin{array}{r}\begin{array}{r}\mathrm{K}_{\mathrm{f}} \\
\left(\mathrm{cm}^{-1}\right)\end{array} \\
\end{array}$ & $\begin{array}{l}\mathrm{K}_{\exp _{1}} \\
(\mathrm{~cm}) \\
\end{array}$ & $\Gamma\left(\mathrm{cm}^{-1}\right)$ & 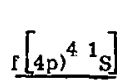 \\
\hline 16510 & 17063 & & 477 & 0.111 \\
\hline 16995 & 17680 & & 2282 & 0.0230 \\
\hline 10000 & 18019 & & 9476 & 0.0312 \\
\hline 18859 & 19050 & & 1474 & 0.0185 \\
\hline 19325 & 19356 & & 62.6 & 0.0010 \\
\hline 19184 & 19780 & & 843 & 0.0669 \\
\hline 18732 & 19980 & & 2257 & 0.0035 \\
\hline 19418 & 20218 & & 1237 & 0.0271 \\
\hline 20399 & 20555 & & 891 & 0.0269 \\
\hline 20686 & 20731 & & 188 & 0.0083 \\
\hline 20596 & 21199 & & 300 & 0.0116 \\
\hline 20322 & 21358 & & 568 & 0.0197 \\
\hline 20759 & 21492 & & 1855 & 0.0016 \\
\hline 21311 & 21625 & & 427 & 0.0866 \\
\hline 21259 & 22236 & & 2330 & $7.2-4$ \\
\hline 21443 & 22372 & & 461 & 0.234 \\
\hline 51000 & 53209 & & 79260 & 1.043 \\
\hline
\end{tabular}

The column entries are explained in the text. 


\section{TABI,E VI}

Energies, Levelwidths, and Oscillator Strengths From $(4 \mathrm{p}){ }^{4}{ }^{1} \mathrm{~S}_{0}$ in Te for 67 Odd Parity Levels With $J=1^{* *}$

\begin{tabular}{|c|c|c|c|c|c|c|}
\hline Level No. & Designation & $\left.\mathrm{K}_{\mathrm{i}}^{\mathrm{Cr}^{-1}}{ }^{-1}\right)$ & $\begin{array}{l}\mathrm{K}_{\mathrm{f}_{1}} \\
\left(\mathrm{~cm}^{-1}\right) \\
\end{array}$ & $\begin{array}{l}\mathrm{K}_{\exp } \\
\left(\mathrm{cm}^{-1}\right) \\
\end{array}$ & $\Gamma\left(\mathrm{cm}^{-1}\right)$ & $f\left[(5 p)^{4}{ }^{1} s_{0}\right]$ \\
\hline 1 & $(5 p)^{3}{ }^{4} S(6 s)^{3} s$ & -25643 & -26778 & -26814 & & 0.0124 \\
\hline 2 & ${ }^{2} \mathrm{D}(6 s){ }^{3} \mathrm{D}$ & -16542 & -18296 & $(-18782)$ & & 0.0110 \\
\hline 3 & ${ }^{4} S(5 d){ }^{5} D$ & -16144 & -17219 & $(-17621)$ & & $8.3-4$ \\
\hline 4 & ${ }^{3} \mathrm{D}$ & -12919 & -14355 & $(-14635)$ & & 0.0381 \\
\hline 5 & $(7 s)^{3} s$ & -11177 & -12089 & $(-12380)$ & & 0.0010 \\
\hline 6 & {$\left[0.529(5 s)^{1}(5 p)^{5}=0.599^{2} D(5 d)\right]^{3} P$} & -2338 & -10722 & $(-10167)$ & & 0.0622 \\
\hline 7 & ${ }^{4} S\langle 6 d\rangle{ }^{5} D$ & -8605 & -9368 & $\langle-9170\rangle$ & & 0.0024 \\
\hline 8 & ${ }^{3} \mathrm{D}$ & -6907 & -7865 & -7772 & & 0.0088 \\
\hline 9 & $(8 s)^{3} s$ & -6381 & -7253 & & & 0.0016 \\
\hline 10 & (7d) ${ }^{5} \mathrm{D}$ & -5283 & -6086 & -6030 & & $2.2-4$ \\
\hline 11 & ${ }^{2} \mathrm{D}(5 \mathrm{~s}){ }^{1} \mathrm{P}$ & -3004 & -5866 & $(-5691)$ & & 0.0016 \\
\hline 12 & ${ }^{4} S(7 d){ }^{3} D$ & -4366 & -5196 & -5253 & & 0.0018 \\
\hline 13 & $(9 s)^{3} s$ & -4120 & -4992 & & & $1.4-5$ \\
\hline 14 & ${ }^{2} D(5 d)^{3} D$ & -3484 & -4788 & -3890 & & 0.0365 \\
\hline 15 & {$\left[0.655^{2} \mathrm{P}(6 \mathrm{~s})^{3} \mathrm{p}-0.522^{2} \mathrm{D}(5 \mathrm{~d})^{3} \mathrm{D}\right.$} & -5269 & -4506 & & & 0.0223 \\
\hline 16 & ${ }^{4} \mathrm{~S}(8 \mathrm{~d}){ }^{5} \mathrm{D}$ & -3564 & -4346 & -4322 & & $4.4-4$ \\
\hline 17 & $(10 s)^{3} s$ & -2889 & -3765 & & & $1.6=5$ \\
\hline
\end{tabular}




\begin{tabular}{|c|c|c|c|c|c|c|}
\hline Level No. & Designation & $\begin{array}{l}\mathrm{K}_{\mathrm{i}} \\
\left(\mathrm{cm}^{-1}\right) \\
\end{array}$ & $\begin{array}{l}\mathrm{K}_{\mathrm{f}} \\
\left(\mathrm{cm}^{-1}\right)\end{array}$ & $\begin{array}{l}\left.\mathrm{k} \exp _{1}\right) \\
\left(\mathrm{cm}^{-1}\right) \\
\end{array}$ & $\Gamma\left(\mathrm{cm}^{-1}\right)$ & $f\left[(5 p)^{4} 1^{1} s_{0}\right]$ \\
\hline 18 & (8d) ${ }^{3} \mathrm{D}$ & -3020 & -3737 & & & 0.0133 \\
\hline 19 & (9d) ${ }^{5} \mathrm{D}$ & -2564 & -3356 & -3330 & & $9.2-5$ \\
\hline 20 & $3_{D}$ & -2212 & -2726 & -3067 & & 0.0266 \\
\hline 21 & $\left.{ }^{2} D(5 d)\right)^{3} S$ & -1602 & -2251 & & & 0.0120 \\
\hline 22 & $(7 s)^{3} \mathrm{D}$ & -223 & -1658 & & & $3.3-4$ \\
\hline 23 & ${ }^{2} P(6 s)^{1} P$ & -3604 & -1295 & & & 0.143 \\
\hline 24 & ${ }^{2} D\left[-0.565(5 d)+\underline{0.593(6 d)]^{3} p}\right.$ & 4150 & $\cdot-113$ & & & 0.0017 \\
\hline 25 & ${ }^{2} \mathrm{D}(6 d)\left(-0.6211^{3} \mathrm{D}-0.645^{1} \mathrm{P}\right)$ & 3805 & 2045 & & 322 & 0.0312 \\
\hline 26 & ${ }^{2} D(6 d)\left(-0.669^{3} D+0.5566^{1} P\right)$ & 3549 & 2655 & & 638 & 0.0053 \\
\hline 27 & ${ }^{2} \mathrm{D}(8 s)^{3} \mathrm{D}$ & 4952 & 3428 & & 87.1 & 0.0089 \\
\hline 28 & $\left.\frac{{ }^{2} \mathrm{D}[-0.705(6 \mathrm{~d})}{5}+0.300(7 \mathrm{~d})\right]^{3} \mathrm{~s}$ & 4536 & 3810 & & 82.4 & 0.0057 \\
\hline 29 & ${ }^{2} \mathrm{D}[0.490(6 \mathrm{~d})-\underline{0.553(7 \mathrm{~d})}]^{3} \mathrm{P}$ & 6939 & 4722 & & 140 & 0.0034 \\
\hline 30 & ${ }^{2} \mathrm{D}(5 \mathrm{~d}){ }^{3} \mathrm{D}$ & 6615 & 5112 & & 347 & 0.0085 \\
\hline 31 & $\quad(9 \mathrm{~s})^{3} \mathrm{D}$ & 7341 & 5796 & & 50,0 & 0.0028 \\
\hline 32 & ${ }^{2} \mathrm{D}\left[0.436(7 d)^{3} \mathrm{D}-0.435(8 \mathrm{~d})^{3} \mathrm{p}\right]$ & 8403 & 5880 & & 119 & 0.0053 \\
\hline 33 & ${ }^{2} \mathrm{D} \underline{0.450(7 \mathrm{~d})}+0.434(8 \mathrm{~d}){ }^{1} \mathrm{P}$ & 6752 & 6379 & & 14.8 & $7.2-5$ \\
\hline 34 & ${ }^{2} D(8 d)^{3} D$ & 8212 & 6717 & & 317 & 0.0066 \\
\hline
\end{tabular}


TABLE VI

(cont)

\begin{tabular}{|c|c|c|c|c|c|c|}
\hline Level No. & Designation: & $\begin{array}{l}\mathrm{K}_{\mathrm{i}} \\
\left(\mathrm{cm}^{-1}\right) \\
\end{array}$ & $\begin{array}{c}\mathrm{K}_{\mathrm{f}} \\
\left(\mathrm{cm}^{-1}\right)\end{array}$ & $\begin{array}{l}\mathrm{K}_{\mathrm{exp}} \\
\underline{\left(\mathrm{cm}^{-1}\right)} \\
\end{array}$ & $\Gamma\left(\mathrm{cm}^{-1}\right)$ & $\mathrm{f}\left[(5 p)^{4}{ }^{1} S_{0}\right.$ \\
\hline 35 & ${ }^{2} \mathrm{D}(10 \mathrm{~s})^{3} \mathrm{D}$ & 8628 & 7064 & & 66.6 & 0.0042 \\
\hline 36 & ${ }^{2} \mathrm{D}\left[0,545(10 \mathrm{~s}){ }^{3} \mathrm{D}-0.516(7 \mathrm{~d})^{3} \mathrm{~s}\right]$ & 7148 & 7097 & & 104 & $2.3-5$ \\
\hline 37 & ${ }^{2} \mathrm{D}\left[-0.373(7 \mathrm{~d})+0.583(5 \mathrm{~d})^{3} \mathrm{P}\right]$ & 9273 & 7394 & & 21.8 & $2.1-4$ \\
\hline 38 & 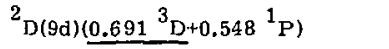 & 9149 & 7595 & & 140 & 0.0016 \\
\hline 39 & ${ }^{2} \mathrm{D}(8 \mathrm{~d})\left(-0.517^{3} \mathrm{D}+0.633^{1} \mathrm{P}\right)$ & 8293 & 8035 & & 234 & 0.0122 \\
\hline 40 & $-0.445^{2} P(5 d)^{3} P+0.555^{2} D(8 d)^{3} S$ & 7463 & 8431 & & 145 & 0.0144 \\
\hline 41 & $0.472^{2} P(5 d){ }^{1} P+0.512^{2} D(8 d)^{3} S$ & 8526 & 8660 & & 254 & 0.0425 \\
\hline 42 & ${ }^{2} \mathrm{D}(9 \mathrm{~d})\left(-0.527^{3} \mathrm{D}+\underline{\left.0.599^{1} \mathrm{P}\right)}\right.$ & 9202 & 9032 & & 4.70 & $1.4-4$ \\
\hline 43 & ${ }^{2} \mathrm{D}(9 s)^{3} \mathrm{~s}$ & 9353 & 9417 & & 250 & 0.0119 \\
\hline 44 & ${ }^{2} P(5 d)\left(0.686^{3} D-0.512{ }^{3} P\right)$ & 8269 & 10141 & & 944 & 0.0393 \\
\hline 45 & ${ }^{2} \mathrm{P}(7 \mathrm{~s}){ }^{3} \mathrm{p}$ & 11050 & 11020 & & 133 & 0.0147 \\
\hline 46 & ${ }^{2} \mathrm{P}\left[-0.422(7 \mathrm{~s}){ }^{3} \mathrm{P}+0.692(5 \dot{\mathrm{d}})^{1} \mathrm{P}\right]$ & 10323 & 11770 & & 1683 & 0.236 \\
\hline 47 & ${ }^{2} P(7 s){ }^{1} P$ & 11479 & 13662 & & 1170 & 0.0231 \\
\hline 48 & ${ }^{2} P(\varepsilon d)\left(-0.438^{3} D-0.579^{3} P\right)$ & 14652 & 15651 & & 4204 & 0.110 \\
\hline 49 & ${ }^{2} \mathrm{P}\left[-0.423(8 s)^{3} \mathrm{P}-0.579(6 d)^{3} \mathrm{D}\right]$ & 15076 & 15952 & & 9305 & $8.8-4$ \\
\hline 50 & 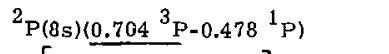 & 16225 & 16358 & & 2137 & $4.9-4$ \\
\hline 51 & ${ }^{2} \mathrm{P}[0.542(6 \mathrm{~d})-0.461(7 \mathrm{~d})]{ }^{1} \mathrm{P}$ & 18609 & 17592 & & 2391 & 0.0381 \\
\hline
\end{tabular}




\begin{tabular}{|c|c|c|c|c|c|c|}
\hline Level No. & Designation & $\begin{array}{l}\mathrm{k}_{\mathrm{i}} \\
\left(\mathrm{cm}^{-1}\right) \\
\end{array}$ & $\begin{array}{l}\mathrm{K}_{\mathrm{f}} \\
\left(\mathrm{cm}^{-1}\right)\end{array}$ & $\begin{array}{l}K_{\exp } \\
\left(\mathrm{cm}^{-1}\right) \\
\end{array}$ & $\Gamma\left(\mathrm{cm}^{-1}\right)$ & $\mathrm{f}\left[(5 p)^{4}{ }^{1} s_{0}\right]$ \\
\hline 52 & ${ }^{2} \mathrm{P}(6 \mathrm{~d})\left(0.525^{3} \mathrm{P}-\underline{0.427}{ }^{1} \mathrm{P}\right)$ & 16156 & 18253 & & 804 & 0.0809 \\
\hline 53 & ${ }^{2} \mathrm{P}\left[0.480(9 \mathrm{~s}){ }^{3} \mathrm{P}+\underline{0.500(7 d)^{3} \mathrm{D}}\right]$ & 18025 & 18449 & & 3951 & 0.0075 \\
\hline 54 & ${ }^{2} P(9 s)\left(0.632{ }^{3} p-0.450{ }^{1} P\right)$ & 18614 & 18729 & & 3343 & 0.0013 \\
\hline 55 & ${ }^{2} P(8 s)\left(-0.438^{3} P-0.661^{1} P\right)$ & 16402 & 18876 & & 563 & 0.0606 \\
\hline 56 & ${ }^{2} P(B d)\left(-0.612{ }^{3} D-0.466{ }^{1} P\right)$ & 19566 & 19708 & & 641 & 0.0120 \\
\hline 57 & ${ }^{2} P(10 s)^{3} P$ & 19901 & 19925 & & 85.0 & 0.0010 \\
\hline 58 & ${ }^{2} \mathrm{P}(9 \mathrm{~d})\left(-0.493^{3} \mathrm{D}-0.484{ }^{1} \mathrm{P}\right)$ & 20425 & 20415 & & 614 & 0.0059 \\
\hline 59 & ${ }^{2} \mathrm{P}(7 \mathrm{~d}){ }^{3} \mathrm{P}$ & 17796 & 20719 & & 2205 & 0.0030 \\
\hline 60 & ${ }^{2} \mathrm{P}[0.438(9 s)-0.406(7 \mathrm{~d})]{ }^{1} \mathrm{P}$ & & 20921 & & 1195 & 0.0567 \\
\hline 61 & ${ }^{2} P(9 s)\left(0.377^{3} P+0.594^{1} P\right)$ & 18705 & 21203 & & 46.2 & 0.0796 \\
\hline 62 & ${ }^{2} P(8 d):_{:}^{3} P$ & 19430 & 22061 & & 1292 & 0.0031 \\
\hline 63 & ${ }^{2} \mathrm{P}[-0.487(10 \mathrm{~s})+0.475(8 \mathrm{~d})]{ }^{1}{ }^{1} P$ & 19912 & 22239 & - & 183 & 0.0422 \\
\hline 64 & ${ }^{2} P(10 s)\left(0.377^{3} P+0.568^{1} P\right)$ & 19955 & 22428 & & 24.7 & 0.0552 \\
\hline 65 & $\int^{2} \mathrm{P}(9 \mathrm{~d}){ }^{3} \mathrm{P}$ & 20387 & 22951 & & 845 & $1.2-4$ \\
\hline 6 f & ${ }^{2}{ }_{P}[-0.386(8 \mathrm{~d})-0.621(9 \mathrm{~d})]^{1} \mathrm{P}$ & 20698 & 23595 & & 3489 & 0.432 \\
\hline 67 & $(5 s)^{1}(5 p)^{5}{ }_{p}^{1}$ & 40866 & 45878 & & 99919 & 1.569 \\
\hline & $(5 s)^{1}(5 p)^{5}{ }^{3} p$ & 5538 & & & & \\
\hline
\end{tabular}




\section{NEW-LASER RESEARCH AND DEVELOPMENT}

\section{OV ERVIEW}

Two new-1aser research efforts were initiated durin; this report period; the chemically pumped ioline laser and HgXe exciplex excitation by electric discharge. The chemically pumped iodine laser was recently d_scovered by personrel at the Air Force Weapons Laboratory. This laser offers exciting possibilities ats an ICF driver because it does not require a capital-intensive pulse power source to drive it, and up to $10 \%$ efficiency may be possible. Modeling studies of this laser are in progress and our opinion of it as a potential high-average power laser is very favorable at this time.

The HgXe exciplex radiates in a band centered at $265 \mathrm{~nm}$. We are studying this system because it could be used to pump an iodine laser. We will also assess its potential to be a high-power laser candidate.

An advanced oscillator system based upon a microprocessor-controlled Nd:YAG-pumped pulsed dye laser is being developed so that it can be used as the front end of new laserfusion lasers and utilized in testing and making germane laser amplifier measurements of candiclate laser systems for the wavelength region of $4000 \AA$ to $8000 \AA$ and extended range with frequency doubling and mixing. The operating requirements of the oscillator system include long-term stability, high reliatility, absolute wavelength calibration and control, tunability, hands-off operation, and variable pulse width generation in the nanosecond regime. These requirements necessitate the application of microprocessor technology to laser technology thereby resulting in a state-of-the-art system capable of satisfying all of the above operating requirements.

\section{CHEMICAELY PUM PED IODINE LASER}

Personnel at the Air Force Weapons Laboratory in $\Lambda$ lbuquerque have recently been successful in obtaining $\mathrm{cw}$ laser oscillation on the 1.3- $\mu \mathrm{m}$ atomic iodine transition by using a purely chemical technique to generate an inversion. ${ }^{33}$ The chemically pumped iodine laser system is so different from the photolytically pumped iodine laser that it must be thought of as a distinct entity. It has enough possible advantages as a laserfusion driver that its potential should be investigated thoroughly. Among the rnost important advantages of this system over others are the following. First, purely chemical generation of the active medium avoids the capital-intensive pulsed power usually associated with other pumping processes. Simple flow systems and a chemical reactor replace capacitor banks, flashlamps, elcctron beams, or other sources typically used for pulsed-laser initiation. The absence of pulsed-power requirements will greatly enhance system reliability and should lower capital cost. Second, the iodine laser using chernical generation has the potential for high efficiency. The limiting theoretical efficiency is about $10 \%$, including the cost of chemical regeneration. Third, high repetition rate is easily obtained. The chemical processes leading to a prpulation inversion can be started and stcppad quickly and frequently. If the chemically pumped iodine laser is to be developed as an effective ICF driver, it must be demonstrated that the foregoing advantages $c$ an be associated with a system that delivers short output pulses. A modeling effort directed at this task has recently been started in this laboratory. The following material briefly summarizes some information pertinent to understanding the chemically pumped iodine laser and indicates preliminary results of the modeling effort.

The chemical generation of excited atomic iocine relies on fortuitous accidents of nature which allow some interestu interactions between excited molecular oxygen and iodine. Figure 50 shows energy levels in the $\mathrm{O}_{2} / \mathrm{I}_{2} / \mathrm{I}$ system and illustrates some of the fortunate coincidences. Chemical generation of excited atomic iodine, $I^{i k}$, starts with a population of excited uxygen molecules in the $\mathrm{O}_{2}\left({ }^{1} \Delta\right)$ electronic state. The interaction of two such molecules to form $\mathrm{O}_{2}\left({ }^{3 \Sigma}\right)$ plus $\mathrm{O}_{2}\left({ }^{1} \Sigma\right)$ is energetically 
allowed and proceeds to form $\mathrm{O}_{2}\left(\frac{1}{2}\right)$ which collisionally dissociates $I_{2}$. As indicated in Fig. 50, the transfer of ener $3 y$ from $\mathrm{O}_{2}\left({ }^{1} \Delta\right)$ to $I$ to form $I^{\frac{1}{x}}$ is slightly exothermic but nearly resonant. In a flowing stream initially containing only $\mathrm{O}_{2}(1 \Delta)$, he injection of $I_{2}$ after the $\mathrm{O}_{2}\left({ }^{1} \Sigma\right)$ density has reached an appreciable value results in the dissociation of $1_{2}$ and the excitation of some of the resulting $I$ to $I^{i}$.

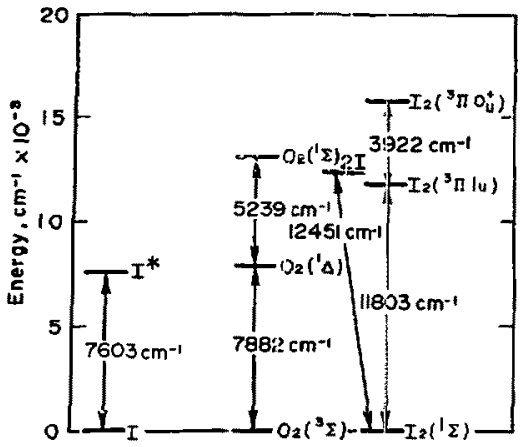

Fig. 50. Some energy levels in the $\mathrm{O}_{2} / I_{2} / \mathrm{I}$ system.

Figure 51 summarizes the most important processes involved in the generation of $\mathrm{O}_{2}\left({ }^{1} \Delta\right)$ and $\mathrm{I}^{*}$ and also inclicates the applicable chemical regeneration processes. The first line summarizes the overall chemistry involved in producing $\mathrm{C}_{2}(1 \Delta) . \mathrm{Cl}_{2}$ is bubbled through a basic solution of $90 \% \mathrm{H}_{2} \mathrm{O}_{2}$, and $\mathrm{O}_{2}\left({ }^{1} \Delta\right)$ is evolved into the gas phase. $\mathrm{O}_{2}\left({ }^{1} \Delta\right)$ is thought to be produced in $100 \%$ yield in the liquid, but only about $60 \%$ yield has so far successfully been extracted into the gas phase before deactivation. ${ }^{34}$ An $80 \%$ yield of $\mathrm{O}_{2}\left({ }^{1} \Delta\right)$ is thought to re feasible. The next several lines summarice the chemical kinetics involved in generaing $I^{*}$. The first step is energy pooling, that is the generation of $\mathrm{O}_{2}\left({ }^{\mathbf{l}} \Sigma\right)$. Next, $\mathrm{O}_{2}\left({ }^{\mathbf{l}} \Sigma\right)$ elissociates $\mathrm{I}_{2}$. The collisional transfer of energy from $\mathrm{O}_{2}\left({ }^{1} \Delta\right)$ to generate $I^{t}$ then proceeds quickly. Both the excitation reaction and its reverse are very fast so that equilibrium is established between oxygen molecules and iodine atoms even in the presence of other rapid processes:

$$
\frac{\left[\mathrm{O}_{2}\left({ }^{3} \Sigma\right)\right]\left[\left[^{*}\right]\right.}{\left[\mathrm{O}_{2}\left({ }^{3} \Delta\right)\right][I]}=K_{\text {eq }}=2.9
$$

where brackets signify concentrations. An iodine inversion exists whenever $\left[\mathrm{O}_{2}\left({ }^{1} \Delta\right)\right] /$ $\left[O_{2}\left({ }^{3} \Sigma\right)\right]>0.17$. The final reaction shown is another formation route for $\mathrm{O}_{2}(1 \Sigma)$. This reaction proceeds faster than the initial pooling reaction and the resulting $\mathrm{O}_{2}\left({ }_{5}\right)$ ensures that the dissociation of $I_{2}$ is essentially complete.

$$
\begin{aligned}
& \text { GENERATICN } \\
& \mathrm{Cl}_{2}+\mathrm{H}_{2} \mathrm{O}_{2}+\mathrm{OH}^{\prime \prime}-\mathrm{H}_{2} \mathrm{O}+\mathrm{HCl}+\mathrm{Cl}^{-}+\mathrm{O}_{2} \mathrm{l}^{\prime} \mathrm{a} \\
& \left.\left.0_{2}{ }^{\prime} \Delta\right)+0_{2}{ }^{\prime} \Delta\right)-0_{2}(\Sigma)+0_{2}
\end{aligned}
$$

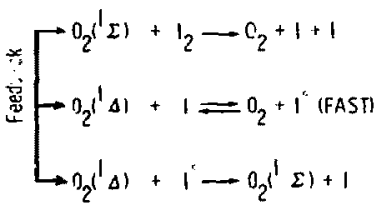

REGENERATION

$$
\begin{gathered}
\mathrm{H}_{2} \mathrm{O}+\mathrm{HCl}+\mathrm{Cl}^{-} \underset{\text { (Electrolysis) }}{-\mathrm{H}_{2}+\mathrm{Cl}_{2}+\mathrm{OH}^{-}} \\
\mathrm{H}_{2}+\mathrm{O}_{2} \longrightarrow \mathrm{H}_{2} \mathrm{O}_{2}
\end{gathered}
$$

IAnthrazuinone Autoxidation Process)

Fig. 51. Scheme for chemical generation of excited iodine atoms and commercial processes for regeneration of starting chemicals. 
Regeneration of starting materials in the chemically pumped iodine laser system involves two steps. First, the residual liquid solution from the chemical generator is subjected to electrolysis to yield $\mathrm{H}_{2}$ and $\mathrm{Cl}_{2} \cdot{ }^{35}$ Second, $\mathrm{H}_{2}$ and $\mathrm{O}_{2}$ are combined to form $\mathrm{H}_{2} \mathrm{O}_{2}$ using a reaction sequence involving the formation of an anthraquinone derivative. 36 Both steps utilize well developed, ccmmercial industrial procedures with high efficiencies. The over ill regeneration process should have greaier than $50 \%$ efficiency relative to the thermodynamic minimum energy requirement, based on the experimentally observed industrial efficiencies.

The foregoing serves as background material for understanding the chemically pumped iodine laser system. It remains to be demonstrated that this system can be used efficiently to generate short output pulses. A potential complication arises from the fact that only a small fraction of the total stored energy in the chemical system is present in $I^{*}$ at any instant. When energy is extracted as $1.3-\mu \mathrm{m}$ jodine radiation, energy stored in $\mathrm{O}_{2}(1 \Delta)$ subsequently feeds rapidly into $\mathrm{I}^{\text {th }}$ to reestablish the equilibrium indicated by Eq (11). Several sequential extractions must be performed before most of the energy initially stored in $\mathrm{O}_{2}\left({ }^{1} \Delta\right)$ is extracted as $1,3-\mu m$ iodine radiation. As partial compensation for this complication, the gain in a chemically pumped iodine laser is low enough that amplified spontaneous emission is not a problem even for large stored energies. The modeling effort has so far been dirscted toward obtaining information about, iho number of extractions required for a given eff $i-$ ciency, the physical size of a laser having a given stored energy, and the sensitivity of predicted performance to uncertain chemical rate constants. All the reactions shown in Fig. 51 plus several others have been considered and presently accepted values of rate constants have been used. 37,38

Typical starting conditions for calculations assume the presence of 10 torr $\mathrm{O}_{2}, 80 \%$ of which is $O_{2}\left({ }^{1} \Delta\right)$. After sufficient time for the generation of adequate $\mathrm{O}_{2}(\Sigma), 0.3$-torr $I_{2}$ and 100-torr Ar are added. The Ar serves two purposes. It carries $\mathrm{I}_{2}$ into the $\mathrm{O}_{2}$ stream and it pressure-broadens the iodine transition. Calculations indicate that sufficient Ar can be added for the iodine transition to be effectively homogeneously broadened without affecting the kinetics adversely. Shortly following the addition of $1_{2}$, several energy extractions are performed sequentially, separated in time by $200 \mathrm{~ns}$, a time shown in auxilliary calculations to be sufficient for approxinzate reequilibration to Eq (11). Present results indicate that the system is attractive. Extractable energy is high, about $15 \mathrm{~J} / \mathrm{L}$ for the example given here. An amplifier with an extractable energy of $10 \mathrm{~kJ}$ could have an aperture 50 $\mathrm{cm}$ in diameter and a length of $3.5 \mathrm{~m}$. Amplified spontaneous emission would not be a problem and 20 extractions would yield an overall efficiency of $6 \%$.

The calculations indicate that several reactions for which rate constants are not well known may have important bearing on overall system performance. For instance, the process

$$
\mathrm{I}^{\prime \prime}+\mathrm{O}_{2}\left({ }^{1} \Delta\right) \rightarrow \mathrm{I}+\mathrm{O}_{2}\left({ }^{1} \Sigma\right)
$$

proceeds far faster than necessary to ensure complete dissociation of $\mathrm{I}_{2}$ when the presently accepted, but uncurtain, value of its rate constant is used in the calculations. The result is a buildup of $\mathrm{O}_{2}\left({ }^{1} \Sigma\right)$, which represents a loss of stored energy because no pathway starting with $\mathrm{O}_{2}(1 \Sigma)$ and leading to $I^{* / *}$ exists. The calculations also indicate that more needs to be known about processes involving low-lying eiectronically excited states of $I_{2}$ and about several deactivation processes. Kinetic modeling is far from complete, but it is already clear that it will be important to obtain reliable experinental determinations of several rate constants as the first part of an experimental exploration of the potential utility of this system as a laser fusion driver.

\section{HgXu EXCIPLEX STUDIES}

The $\mathrm{HgXe}$ excimer band centered at $265 \mathrm{~nm}$ offers promise as an efficient ultraviolet 
pump source and possibly as an efficient ultraviolet laser, In this report, we will present the results of preliminary experiments to measure the fluorescence efficiency of $\mathrm{HgXe}\left({ }^{3} \mathrm{O}^{+} \rightarrow{ }^{1} \mathrm{O}^{+}\right)$emission at $265 \mathrm{~nm}$ in a discharge stabilized by electron-beam preionization. These results will then be qualitatively related to the predictions for fractional power transfer into the $\mathrm{Hg}$ states by a Boltzmicin transport code.

\section{Experimental}

The experin $c$ tal apparatus is shown schematically in Fig. 52. A Febetron 706 electron-beam accelerator whose output was attenuated by a factor of one hundred using wire screens was used to preionize a gas mixture containing 10 torr to 15 torr of $\mathrm{Hg}$ and 1500 torr to 3000 torr of $\mathrm{Xe}$ in a stainless-steel test cell. The attenuated electron beam was characterized by an average electron energy of $600 \mathrm{keV}$, a current density of $100 \mathrm{~A} / \mathrm{cm}^{2}$ and, a pulsewidth of $\sim 4$ ns (FWHM).

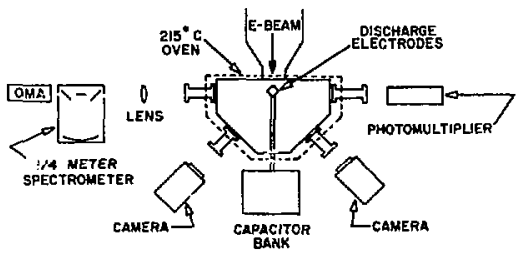

Fig. 52. Schematic diagram of experimental apparatus.

A capacitor whose value was varied from $2700 \mathrm{pF}$ to $0.01 \mu \mathrm{F}$ was charged from $1 \mathrm{kV}$ to $4 \mathrm{kV}$. It supplied energy to the $\mathrm{Hg} / \mathrm{Xe}$ mixture via a krytron switch which was triggered at a controlled delay time following the electron-beam pulse.

The discharge occurred between two stainless-steel electrodes spaced by $0.43 \mathrm{~cm}$. The actual discharge volume was determined by photographing the discharge at right angles as shown in Fig. 52. The current drawn by the discharge was limited by a 2-kilohm ballast resistor between the anode and ground.
This allowed stable discharges to be maintained for a few microseconds.

The voltage drop across the discharge was measured by two 100:1 voltage probes positioned at the cathode and anode feedthroughs into the test cell. The current flowing through the discharge was determined by measuring the voltage drop across the current-limiting resistor.

The temporal behavior and intensity of the HgXe emission was observed on a Hamamatsu R 166 photomultiplier having a CsTe photocathode. The photomultiplier plus appropriate neutral density filters were absolutely calibrated by comparing their response to a monochromatic light source to that of a photodiode which had been absolutely calibrated by the National Bureau of Standards.

Emission spectra of $\mathrm{HgXe}$ were taken by using a quarter-meter Jobin-Yvon spectrometer and a PAR OMA2 optical multichannel analyzer. The relative wavelength response of the entire system was determined by using an Optronic Model $W-40$ calibrated lowpressure $\mathrm{D}_{2}$ discharge lamp.

The Xe gas used in this experiment was obtained from Cryogenic Rare Gases at a stated purity of 99.999\% and was used without further purification. The Hg used in the experiment was triple-distilled. The Hg pressure supplied to the test cell was determined by the temperature in a temperatureregulated Hg reservoir. The temperature of the test cell was always maintained above the temperature of the $\mathrm{Hg}$ reservoir at a constant of $215^{\circ} \mathrm{C}$.

\section{Results}

The fluorescence efficiency of the $\mathrm{HgXe}$ $\left({ }^{3} \mathrm{O}^{+} \rightarrow{ }^{1} \mathrm{O}^{+}\right)$transition is defined here as the energy sinitted. .04- $\pi$ steradians by the 265-nm band divided by the energy deposited in the $\mathrm{Hg} / \mathrm{Xe}$ gas mixture by the discharge. Implicit in this definition is the assumption that the electron-beam used to preionize the discharge creates a relatively small $\mathrm{HgXe}$ $\left({ }^{3} \mathrm{O}^{+}\right)$excited state population that has radiatively decayed prior to the triggering of the discharge. This is well-illustrated in 
Fig. 53, which shows the photomultiplier signal during a discharge in 15 torr of $\mathrm{Hg}$ and 3000 torr of $\mathrm{Xe}$ with an energy input of $\sim 1.9 \mathrm{~J} / 1$. The first peak is emission from $\mathrm{HgXe}$ created by the electron-beam. The second and much larger peak arises from $\mathrm{HgXe}$ created by the discharge which is triggered some $700 \mathrm{~ns}$ after the preionizing pulse.

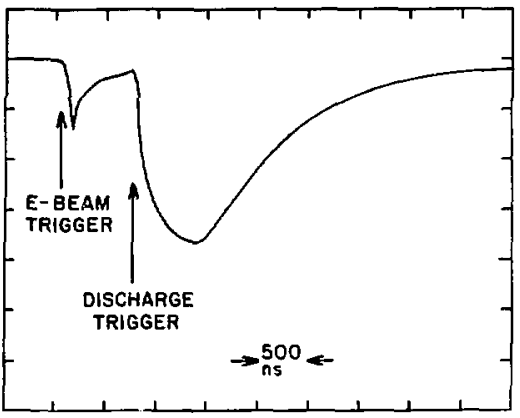

Fig. 53. Optical output with electron-beam preionized discharge excitation in 15 torr of $\mathrm{Hg}$ and 3000 torr of Xe.

The energy deposited in the $\mathrm{HgXe}$ mixture is calculated by multiplying the voltage drop across the discharge as a function of time by the current drawn by the discharge as a function of time. Figure 54 shows the voltage and current measurements during a discharge in 15 torr of $\mathrm{Hg}$ and 3000 torr of Xe with an energy input of $1.9 \mathrm{~J} / 1$.

The energy emitted into $4-\pi$ steradians by the $\mathrm{HgXe}$ emission produced by the discharge is calculated from the photomultiplier tube response by assuming the discharge is a point source. In this case the energy is given in joules by the expression

$$
E(J)=4.7 \frac{4 \pi d^{2}}{A} \frac{\int_{0}^{\infty} V d t}{(5 D \Omega) \times T \times G}
$$

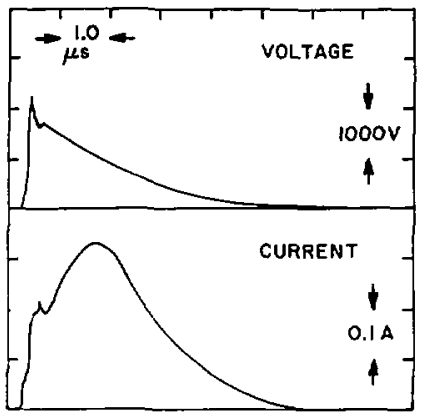

Fig. 54. Electric discharge voltage (upper) and current (lower) in 15 torr of $\mathrm{Hg}$ and 3000 torr of $\mathrm{Xe}$.

where $d$ is the distance between the discharge and the photomultiplier in $\mathrm{cm}, \mathrm{A}$ is thr area in $\mathrm{cm}^{2}$ of an aperture which defines the area of the photocathode that is illuminated, $T$ is the overall transmission of the windows between the discharge and the photomultiplier, and $G$ is the gain of the photomultiplier times its quantum efficiency taking into account any neutral density filter used during the experiment. Since $G$ is a function of wavelength it must be convoluted with the spectrum abtained from the OMA to obtain an absolute efficiency for the fluorescence emission.

The preliminary results indicate that the $\mathrm{HgXe}\left({ }^{3} \mathrm{O}^{+} \rightarrow{ }^{1} \mathrm{O}^{+}\right.$) fluorescence efficiency ranges from 6.6 to $3,3 \%$ as the power input varies from 4 to $6 \times 10^{5} \mathrm{~W} / 1$ at an $E / N$ of $5 \times 10^{-17} \mathrm{~V}-\mathrm{cm}^{2}$. At an $\mathrm{E} / \mathrm{N}$ of $\mathrm{B} \times 10^{-17}$ $\mathrm{V}-\mathrm{cm}^{2}$, the fluorescence efficiency ranges from 4.3 to $3.7 \%$ as the power input varies from 1 to $2 \times 10^{6} \mathrm{~W} / 1$. Under these conditions the electron density was $\sim 10^{13} \mathrm{~cm}^{-3}$ and the fractional ionization was $\sim 10^{-7}$. The fraction of excited states was on the order of $10^{-4}$. Efficiencies could not be determined at energy inputs above $2.0 \mathrm{~J} / 1$, because the discharge went unstable. 
A Boltzmann transport code has been used to predict the fractional power transferred to the various $\mathrm{Hg}$ states which correlate directly with HgXe states under conditions of high xenon pressure. The code predicts an orter of magnitude increase in power transferred to the $\mathrm{Hg}\left({ }^{1} \mathrm{P}_{1}\right)$ state in going from an $\mathrm{E} / \mathrm{N}$ value of $5 \times 10^{-17} \mathrm{~V}-\mathrm{cm}^{2}$ to $8 \times 10^{-17} \mathrm{~V}-\mathrm{cm}^{2}$ at a constant $\mathrm{Hg}$ pressure of 15 torr. The $\mathrm{Hg}\left({ }^{1} \mathrm{P}_{1}\right)$ state correlates with the $\mathrm{HgXe}$ $\left({ }^{1} \mathrm{O}^{+} \rightarrow 1 \mathrm{O}^{+}\right)$transition centered at $-210 \mathrm{~nm}$. Figure 55 shows the emission spectra taken with the OMA unfolded from the wavelength response of the spectrometer and detector. At an $\mathrm{E} / \mathrm{N}$ of $5 \times 10^{-17} \mathrm{~V}-\mathrm{cm}^{2}$, no $210-\mathrm{nm}$ emission is seen. At an $E / N$ of $8 \times 10^{17}$ $\mathrm{V}-\mathrm{cm}^{2}$, this band is always abserved. These results hold regardiess of whether $E / N$ is varied by changing $E$ or changing $N$.

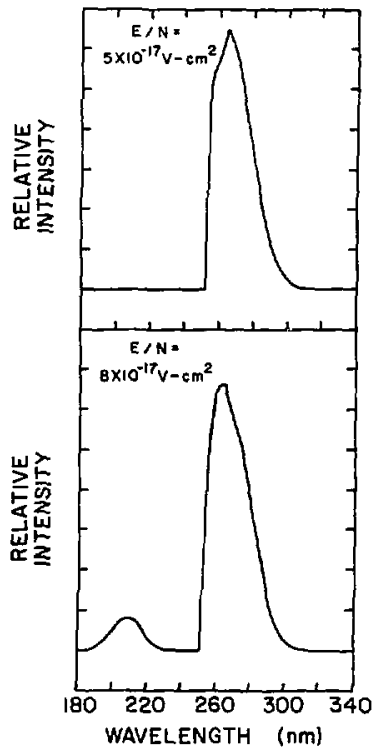

Fig. 55. HgXe discharge spectra taken at $E / N$ values of $5 \times 10^{-17}$ (upper) and $8 \times 10^{-17}$ (lower) $\mathrm{V}-\mathrm{cm}^{2}$.

\section{Summary}

Fluorescence efficiencies for the HgXe $\left({ }^{3} \mathrm{O}^{+} \rightarrow{ }^{1} \mathrm{O}^{+}\right)$emission on the order of $4 \%$ have been measured at power inputs of $\sim 10^{6}$ $W / 1$ in stable, electron-beam preionized discharge. The discharge goes unstable at power inputs greater than $2 \times 10^{6} \mathrm{~W} / 1$. Greater power inputs should be realizable by using an electron-beam sustained discharge.

\section{OSCILLATOR STUDIES}

An advanced oscillator system based upon a microprocessor-controlled Nd:YAG-pumped pulsed dye laser should meet all the nearto-mid term oscillator needs of advanced laser-fusion lasers with the exception of HF. Not only can this master oscillator concept be used as the front end of the laser fusion device, but it also can be utilized in testing and making germane laser amplifier measurements of candidate laser systems for the wavelength region of $4000 \AA$ to $8000 \AA$ and extended range with frequency doubling and mixing.

The operating requirements of such an ascil lator system include long-term stability, high reliability, absolute wavelength calibration and control, tunability, hands-off operation, and variable pulse width generation in the nanosecond regime. These requiremeni: necessitate the application of microproceisor technology to laser technology theret,y resulting in a state-of-the-art laser system capable of satisfying all of the above operating requirements.

For FY78, the goal of the Sandia oscillator research and development program is to demonstrate the basic concepts of a microprocessor controlled 5-ns pulsed dye laser system operating between $4500 \AA$ and 5000 \& These wavelengths do not represent limitations of such a system but are chosen to be in a currently interesting wavelength region for proposed laser fusion devices. By changing the dye, Nd:YAG pumping wavelength, etc., the same system could operat. any where between $4000 \AA$ and $8000 \AA$.

A block diagram of the overall system 
design is shown in Fig. 56. As can be seen there are several basic modules in the design of this kind of system. For this reporting period, three aspects of the proposed laser oscillator design are discussed.

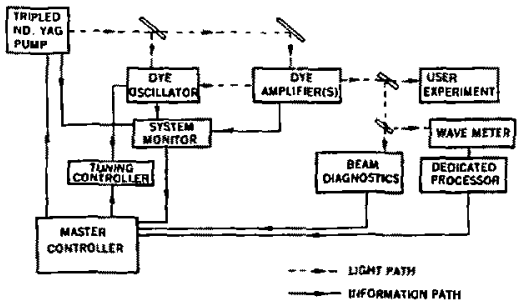

Fig. 56. Block diagram of overall system design.

\section{Nd:YAG Oscillator Pump Source}

The current configuration of the tripled$\mathrm{Nd}$ :YAG-pumped pulsed dye oscillator system is outlined in Fig. 57. The pump laser is a pulsed, Q-switched Nd:YAG unstable resonator oscillator 39 and amplifier purchased from Quanta-Ray, Inc. Air-cooling was added to the $Q$-switch device in order to prevent breakthrough throughout the operating temper ature range. The output of the Nd:YAG laser is frequency tripled to provide $7-n s 135-\mathrm{mJ}$ pulses at a wavelength of 354.7 $\mathrm{nm}$ and a repetition rate of 10 pps. This laser system is stable, reliable, has a flashlamp life of $>10^{7}$ pulses and there is no detectable alignment drift. The dye oscillator is based on an optical cavity designed by Quanta-Ray. It contains a transversely pumped nowing dye cuvette, a four-prism dispersionless beam expander, and a littrowmount grating for tuning. In order to pump coumarin and other blue-green dyes more efficiently, the cuvette and pump-beam optics have been modified to provide a gain path of $-1.5 \mathrm{~cm}$ at reduced pump beam intensity. While the prism beam expander reduces the divergence of the dye laser beam as do telescopic and grazing incidence grating methods, 40 it has far less stringent alignment requirements than the other two techniques and is, therefore, more reliable.

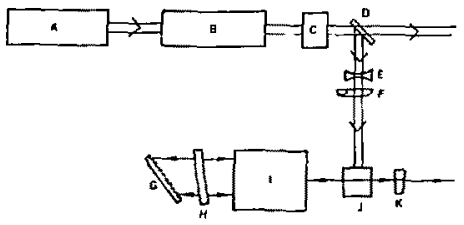

A - Nd:YAG Oscillator

B - Nd:YAG Amplifier

C - Frequency Tripler

D - Beamsplitter

E - Divurging Lens

F - Cylindrical Lens

G - Diffraction Grating

H - Intracavity Etalon

I - Prism Beam Expander

$J$ - Dye Cuvette

K - Output Coupler

Fig. 57. Nd:YAG/Dye Laser System.

Dye Performance Me.surements

In preliminary tests with Rhodamine 6. 3 dye, the dye oscillator operated with $30 \%$ efficiency and $1 \mathrm{~cm}^{-1}$ spectral linewidth at a wavelength of $590 \mathrm{~nm}$. The addition of an intracavity etalon reduced both the linewidth to $-0.1 \mathrm{~cm}^{-1}$ and the efficiency to 10 to $15 \%$.

Subsequent experiments with blue dyes showed the best coumarin dye thus far tested (coumarin 481 ) to have an efficiency of about $16 \%$, a narrew tuning range, and a short lifetime (approximately 8 hrs). However, the best dye tested (LD490) had an efficiency of $\sim 16 \%$ at a spectral linewidth of $1 \mathrm{~cm}^{-1}$. (wavelength of $480 \mathrm{~nm}$ ) a tuning range of $465 \mathrm{~nm}$ tr $505 \mathrm{~nm}$ at the half-power points (Fig. 58), and showed no detectable degradation of efficiency over $8 \mathrm{hr}$ of run time. 


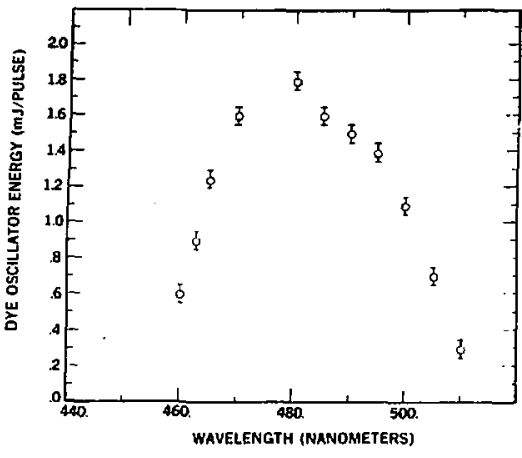

Fig. 58. Tuning range of LD490 laser dye,

\section{Microprocessor Controlled Wavemetex}

The wavemeter module designed to facilitate automatic control of wavelength for the dye laser is shown in Fig. 59. The design is based on a Fizeau-type wedge interfer ometer with a Teticon photodiode array readout, as proposed by Snyder. 41 In principle, light beams reflected from the two surfaces of the wedge create a ginusoidal interference pattern on the photodiode array. The intensity values from the photodiodes are digitized, stored, and processed on a microcomputer to yield the frequency and phase of the sinusoidal pattern. This information, combined with the calibrated properties of the wedge, yields a value for the wavelength of the light

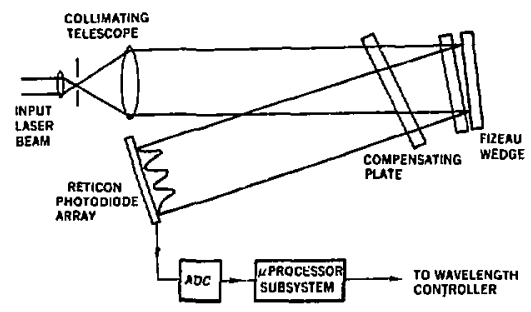

Fig. 59. Wavemeter. incident on the wedge. A mathematical analysis and extensive computer simulation have revealed several difficulties overlooked by Snyder, and methods have been developed to overcome these problems.

1. The angle of incidence of the light on the wedge which minimizes effects of angular deviation is not zero degrees (normal incidencel, as is the case for a parallel-plate interferometer, but is a finite angle which depends upon the distance from the wedge to the detestor. The resultant dispersion from the finite thickness of the front plate in the interferometer must be compensated for by the introduction of a similar plate in the reflected beam path.

2. Spatial modulation of the fringe pattern, Jue to the combination of the spatial profile of the incident beam and slow gain variation along the length of the detector array, changes the apparent locations of the intensity extreme and must be accounted for in the processing software.

3. Curvature of wedge surfaces leads to nonlinearity of fringe spacing, which must be corrected for in the analysis.

Fast, efficient software routines have been developed for the Z-80 microprocessor to process the fringe pattern, incorporating items 2 and 3 above. Citrrently, the Reticon data can be read and processed approximately four times per second. Software has been written to utilize a hardware arithmetic processor to improve this speed.

Experiments were performed with an etalon having a $0.5-\mathrm{mm}$ separation and a 16 arcsecond angle between wedge surfaces, $\lambda / 20$ surface flatness, and $3 / 4$ in. clear aperture. Collimation was provided by a SpectraPhysics 200-mm collimating lens and a $10-\mu \mathrm{m}$ pinhole. Angle of incidence was $\sim 4$ degrees, with the Reticon array $30 \mathrm{~cm}$ from the wedge. The light source was a single wavelength, from a cw HeNe laser, so no compensating plate was used. The Reticon array was a 1024 element unit with high sensitivity diodes $17 \mathrm{mil}$ wide separated by $1 \mathrm{mil}$. Digitization of intensity 
information was performed with an eight-bit $A / D$ converter with $5.5-\mu s$ settling time and $\pm 1 / 2$ LSP accuracy. The data yielded fringe location and fringe period to an accuracy within a factor of $\mathbf{2}$ of that necessary to achieve the desired wavelength measurement accuracy of $0.01 \mathrm{~cm}^{-1}\left(5 \times 10^{-7}\right.$ at $500 \mathrm{~nm}$ wavelength). Uncorrectable intensity variations caused by dust ox. the wedge surfaces contributed partly to the errors, and it was determined that a clean wedge with a spacing of $0.25 \mathrm{~mm}$ and an angle of 25 arc-secands would provide the required accuracy. 


\section{REFERENCES}

1. Laser Development for Laser Fusion Applications Research Progress Report October 1977-March 1978, SAND78-0811, Sandia Laboratories, Albuquerque, NM, June 1978.

2. Reference 1, p. 20.

3. M. E. Riley and M. A. Gusinow, Appl. Opt. 16, 2753 (1977).

4. Reference 1, p. 12.

5. Laser Development for Laser Fusion Applications Research Progress Report January-September 1977, SAND77-1517, Sandia Laboratories, Albuoquerque, NM, February 1978.

6. Reference 5, p. 16 .

7. J. A, Halbleib, Jr., and W. H. VanDevender, SAND74-0030, Sandia Laboratories, Albuquerque, NM, March 1975.

8. Reference 5, p. 17.

9. M. A. 1.. guay, G. A. Fisk, J. M. Hoffman, J. B. Moreno, R. E. Palmer, M. E. Riley, and R. P. Sandoval, SAND76-0094, Sandia Laboratories, Albuquerque, NM, March 1976.

10. R. P. Sandoval, J. Appl. Phys. (Sept. 1978).

11. Reference 1, p. 16.

12. Reference 1, pp. 27-30.

13. Reference 1, pp. 50-55.

14. Reference 1, p. 42 .

15. G. A. Fisk, The Effects of Chemical Kinetics and Starting Material Regeneration on the Efficiency of an lodine Laser Amplifier, SAND77 0880, Sandia Laboratories, Albuquerque, New Mexico, May 1977.

16. G. A. Fisk, "Multiple Photon Induced Chemistry in Mixtures of $C_{2} F_{6}$ with $\mathrm{H}_{2}$ or $\mathrm{C}_{6} \mathrm{H}_{14}$ " "Chem. Phys. Lett., in press.

17. O. P. Judd, App1. Phys. Lett. 22, 95 (1973). 
18. S. J. Kast and C. Cason, J. Appl. Phys. 44, 1631 (1973).

19. R. Eujen and R. J. Lagow, Inorg. Chem. 14, 3128 (1975).

20. The Atomic Iodine Laser, SAND78-1071, Sandia Laboratorieg, Albuquerque, New Mexico, June 1978.

21. Reference 1, pp. 33-35.

22. M. A. Gusinow, Sandia Laboratorieg, private communication.

23. J. F. Shaw, R. Maynard, and P. Lovoi, Additive Enhancement of Short Pulse Flashlamps, R-ILC-75-13/F, ILC Technology, Inc., Sunnyvale, CA, April 1977.

24. Reference 5, PP. 70-71.

25. M. A. Gusinov, IEEE J. Quantum Electron. QE-11, 929 (1975).

26. F. M. Matsumga and K. Watanabe, J. Chem. Phys, 46, 4457 (1967).

27. T. G. Slanger and G. Black, J. Chem. Phys. 64, 3763 (1976).

28. G. Black, R. L. Sharpless, and T. G. Slanger, J. Chem. Phys. 63, 4551 (1975).

29. C. E. Moore, "Atomic Energy Levels, " Natl, Bur. Stand, Circ. No. 467 U. S. GPO, Washington, DC (1949).

30. G. Tondello, Astrophys. Journal 172, 771 (1972).

31. D. Bartelt, Zeit. Phys. BB, 522 (1934).

32. M. J. Conneely, K. Smith, and L. Lipsky, I. Phys. B3, 493 (1970).

33. W. E. McDermott, N. R. Pchelkin, D. J. Benard, and R. R. Bousels, Appl. Phys. Lett. $\underline{32}, 469$ (1978).

34. D. J. Benard and N. R. Pchelkin, Rev. Sci. Instrum. 49 , 794 (1978).

35. C. A. Hampel, ed., The Encyclopedia of Electrochemistry, Reinhold Publishing Corporation, New York (1964).

36. A. F. Trotman-Dickenson, ed., Comprehensive Inorganic Chemistry, Pergamon Press, Elmsiord, NY(1973).

37. R. F. Heidner, III, J. G. Coffer, and C. E. Gardner, $\mathrm{O}_{2}(\bar{\lambda})-\mathrm{I}$ Atom Energy-Transfer Studies: cw Inversion on 1.315- $\mu \mathrm{m}$ I-Atom Transition, Report SAMSO-TR-77-215, Aerospace Corporation, El Segundo, CA, December 1977.

38. Private communication, R. R. Bousek, Air Force Weapons Laboratory, Kirtland Air Force Base, Albuquerque, NM. 
39. R. L. Herbst, H. Komine, and R. L. Byer, Opt. Commun, 21, 5 (1977).

40. I. Shoshan and U. P. Oppenheim, Opt. Commun, 25, 375 (1978).

41. J. J. Snyder, Laser Wavemeter for Pulsed or cw Lasers, presented at the Conference on Laserf and Electro-Optics Systems, San Diego, CA, February 1978. 


\section{PUBLICATIONS}

MULTILEVEL PARAXIAL MAXWELL-BLOCH EQUATION DESCRIPTION OF SHORT PULSE AMPLIFICA TION IN THE A TOMIC IODINE LASER, M. E. Riley (4211), T, D. Padrick/ R. E. Palmer (4212), IEEE Journal of Quantum Electronics (accepted).

LASER BEAM CHARACTERISTICS OF PHOENIX, AN HF OSCILLATOR-AMPLIFIER SYSTEM, F. L. Patterson/G. N. Hays/R. A. Gerber/F. K. "uby (4212), Journal of Applied Physics (accepted).

ENERGY EXTRACTION FROM A LARGE VOLUME HF AMPLIFIER, J, M. Hoffman/ E. L. Patterson/R. A. Gerber (4212), Journal of Applied Physics (accepted).

PULSED A COUSTO-OPTICAL MODULATOR DRIVER, E. D. Jones/F. R. Franklin (4214), R. E. Palmer/T, D. Padrick (4212), Rev. Sci. Insirum. 49, 1355 (1978).

RAMAN SPECTRUM AND CROSS SECTIONS OF n-C3F 7 I: IMPLICATIONS FOR A LARGESCALE ATOMIC IODINE LASER, J. C. Cummings/D. P. Aeschliman (4216), and R. E. Palmer (4212), Optics Communications (accepted).

MULTIPLE PHOTON INDUCED CHEMISTRY IN MIXTURES OF $\mathrm{C}_{2} \mathrm{~F}_{6}$ WITH $\mathrm{H}_{2} \mathrm{OR}_{6} \mathrm{C}_{14}$, G. A. Fisk (4212), Chemical Physics Letters, 60, 11 (1978).

DIFF RACTION-LIMITED A TOMIC IODINE PHOTODISSOCIA TION LASER, R. E. Palmer/ T. D. Padrick (4212), and M. A. Palmer (4234), Optical and Quantum Electronics (accepted). 


\section{PRESENTATIONS}

BEAM QUALITY MEASUREMENTS OF SANDIA'S HF OSCILLATOR-AMPLIFIER CHAIN, E. L. Patterson/G. N. Hays/J. M. Hoffman/R. A. Gerber/G. C. Tisone/F. K. Truby (4212), and R. P. Sandoval (4214), 10th Int'l Quantum Electronics Conf., IEEE/OSA, Atlanta, GA, May 29-June 1, 1978.

ENERGY EXTRACTION FROII AN ELECTRON-BEAM-INITIATED HF AMPLIFIER, E. L. Patterson/G. N. Hays/G. C. Tisone/J. M. Hoffman and J. B. Moreno (4212), 10th Int'1 Quantum Electronics Conf., Atlanta, GA, May 29-June 1, 1978.

BROADENING OF THE CF 3 I ABSORFTION BAND NEAR $270 \mathrm{~nm}$ BY VIBRATIONAL EXCITA TION OF $Y$ WITH CO2 LASER IRRADIATION, T. D. Padrick/A. K. Hays (4212), and M. A. Palmer (4234), Pacific Conference on Chemistry and Spectroscopy, Society for Applied Spectros copy and A.merican Chemical Society, San Francisco, CA, 9/27-29/78. 